\title{
INFRASTRUCTURE ASSET DIAGNOSTICS: \\ ENABLING SMARTER ASSET MANAGEMENT DECISIONS WITHIN THE ELECTRICITY DISTRIBUTION INDUSTRY.
}

BY

RICHARD VERNON BRYSON.

\begin{abstract}
A thesis
submitted to the Victoria University of Wellington in fulfilment of the requirements for the degree of Master of Innovation and Commercialisation
\end{abstract}

Victoria University of Wellington 


\begin{abstract}
This thesis examines the opportunities for better asset management within the electricity distribution industry. The project partner, a supplier of distribution products, observed their customers are often purchasing incorrect equipment for maintenance operations. This observation led the project partner to believe a lack of accurate asset knowledge exists within these electricity distribution businesses (EDBs). Coupled with the information that much of the installed asset base of these EDBs is approaching end of life, it was proposed to investigate the suspected lack of asset condition and type knowledge with the intention of developing the Infrastructure Asset Diagnostic Tool (IADT). A literature review was conducted to determine the current state of asset diagnostics within the electricity distribution industry.

The principles of lean start-up business development have been used to isolate the most needed technology within the New Zealand marketplace through interviews with industry personnel. These interviews helped identify a possible Minimum Viable Product (MVP) for the IADT, and also indicated that providing the IADT as a professional service would be the most appropriate model for the MVP variant.

Condition and type knowledge of wooden poles, conductors and line hardware was found to be the most lacking. It was recommended to focus product development on the assessment of these assets. The project partner has contracted two smart tool suppliers for the analysis of poles and conductor clearances. These products were then integrated to enable accurate assessments of wooden poles. An additional product identified as an aside during the interviews, was for a simple pole designing application which could be used in the field. An existing product from one of the smart tool suppliers contracted can fulfil this requirement.

Possible benefits from IADT use were calculated for a sample EDB. These calculations indicated accurate condition assessment of wooden poles could lead to a saving of up to $\$ 5.4$ million per year. This saving would equate to a possible reduction in time for securing pole integrity on this network from 30.8 years to just 5.9 years through more effective use of available funding. This reduction would lead to enhanced network reliability and improved public safety in a much shorter time frame than present, therefore this study recommends implementing the MVP form of the IADT at an initial EDB.
\end{abstract}




\section{Acknowledgements}

I would firstly like to thank my project partner, PLP Electropar for allowing me to explore the viability of one of their commercial products prior to formal release, especially the Managing Director, Mr Brett Hewitt, and also Mr Dave Devonport for his invaluable insight into the electrical distribution industry, and assistance with the interview process. I would also like to thank the staff of Powerco and Counties Power for their invaluable contributions. Thanks also go to Reliable Lines for their extremely informative review of the technology involved, and the capacity available therein.

Dr Nick Long of Robinson Research Institute at Victoria University has been extremely helpful in providing guidance throughout this exercise, helping me to refocus on the task at hand at crucial times throughout the year. Thanks also to my class mates in this first iteration of the Master of Innovation and Commercialisation programme. Their input and encouragement has given me strength throughout the programme. I would like to thank Victoria University of Wellington, especially Jenny Douché for establishing this course, and for her continuous encouragement and enthusiasm throughout. This has been a strong motivation for me to produce a quality product.

I must thank my wife and daughter, Mia and Shekinah, for their understanding and support during this program. It has been a long year and they have certainly noticed that I have not been able to spend the time with them that they had previously become accustomed to. Finally, I thank the Lord, for without Him none of this would be possible.

Richard Bryson.

October 2016 


\section{Table of Contents}

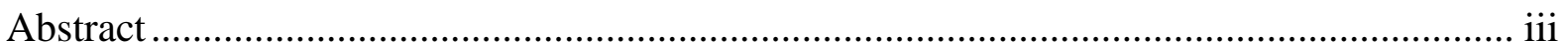

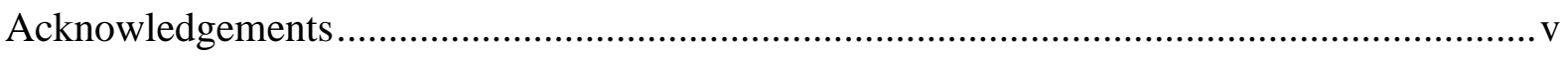

List of Illustrations ....................................................................................................

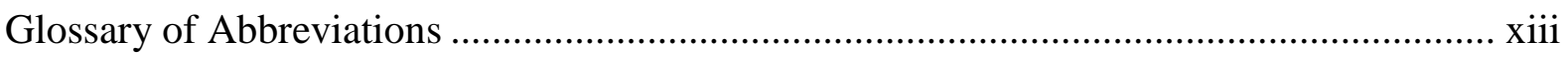

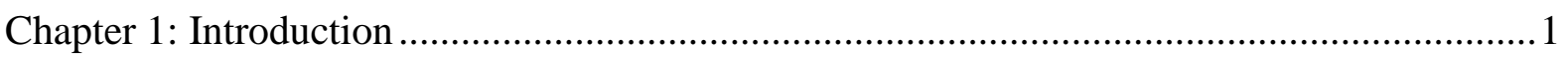

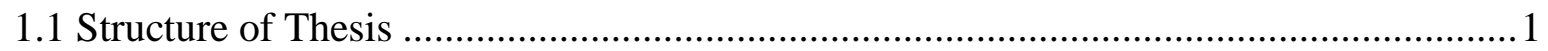

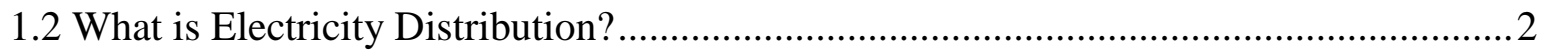

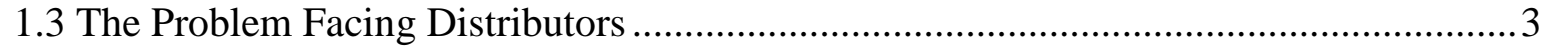

1.4 Introducing the Project Partner, Electropar.....................................................................

1.5 Current Situation within the Electrical Distribution Industry .....................................5

1.6 Available Technologies from Around the World ...................................................6

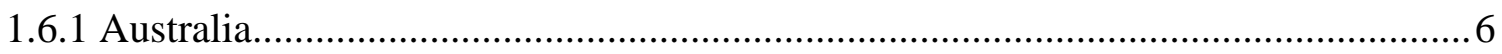

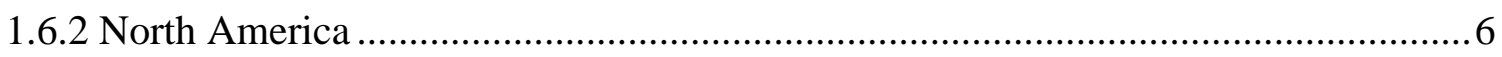

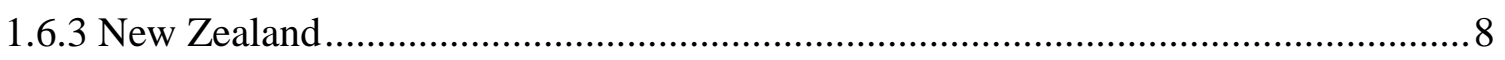

1.7 Issues with Standards and Asset Assessment........................................................

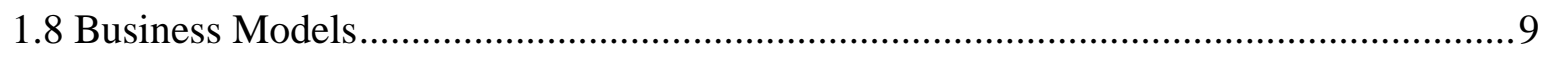

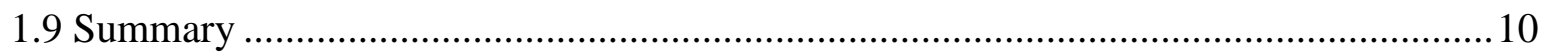

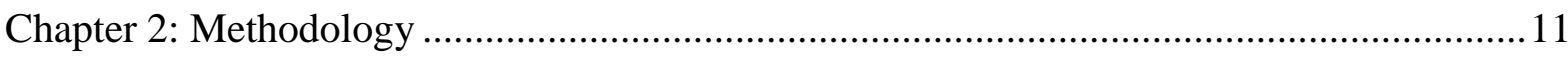

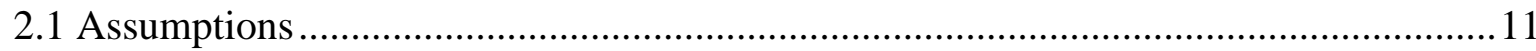

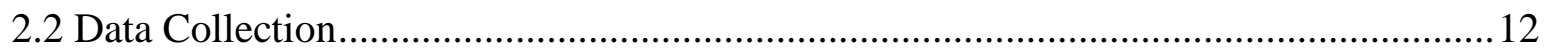

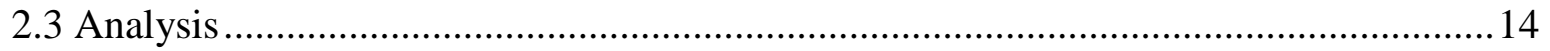

2.4 Business Model Design Process and Financial Viability .......................................... 16

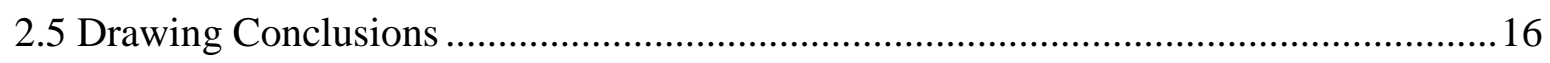

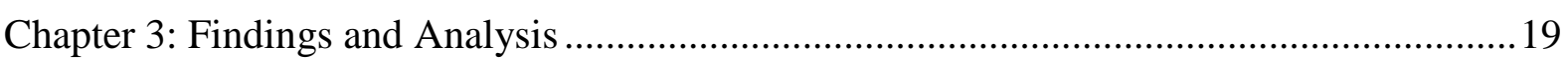

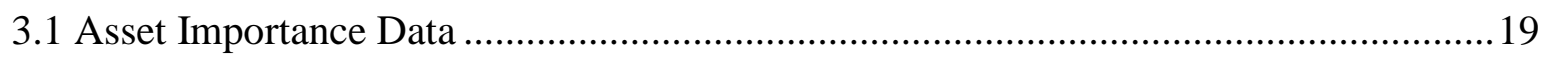

3.1.1 Asset importance ratings as collected and in weighted form ..............................20 
3.1.2 Data by asset classes

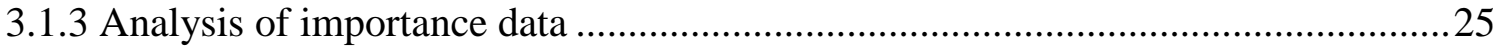

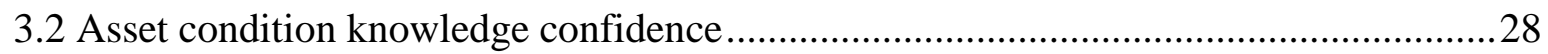

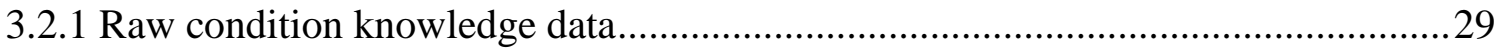

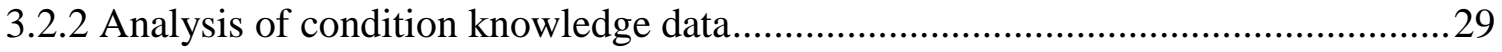

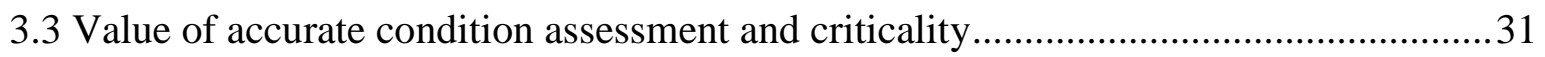

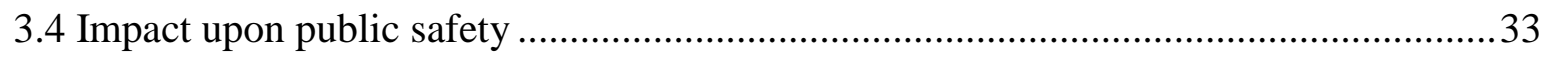

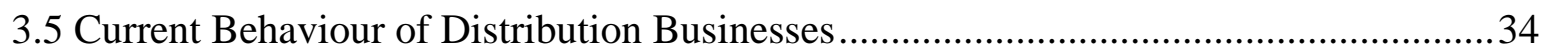

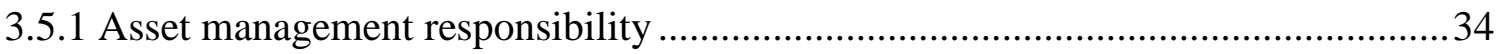

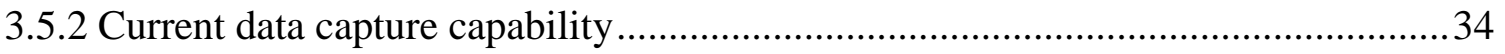

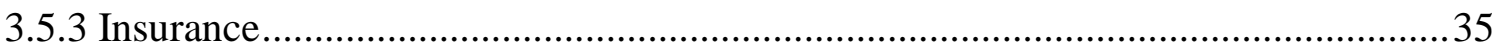

3.5.4 Pressure to comply with the Commerce Commission ........................................... 35

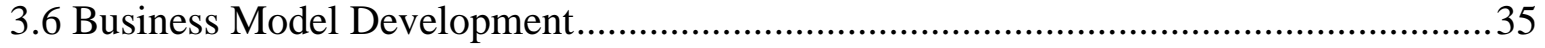

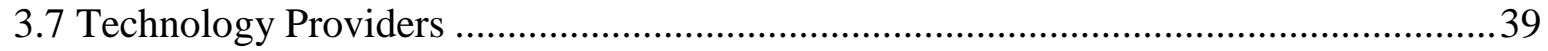

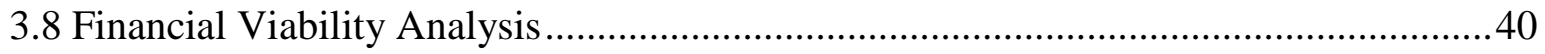

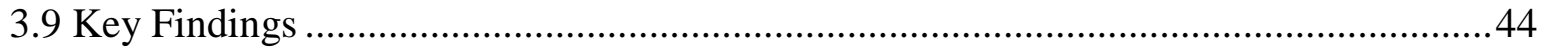

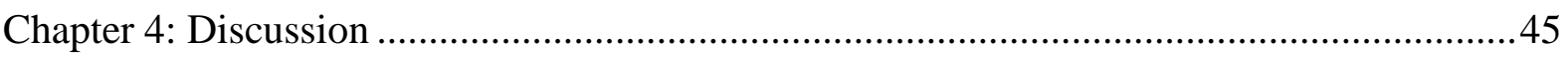

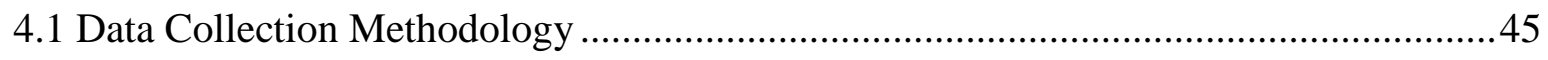

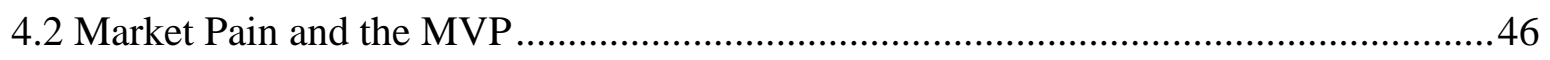

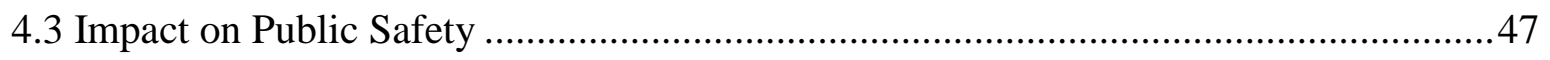

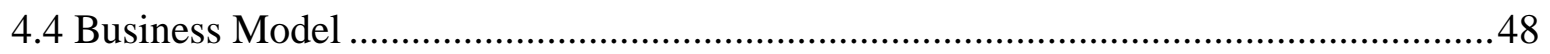

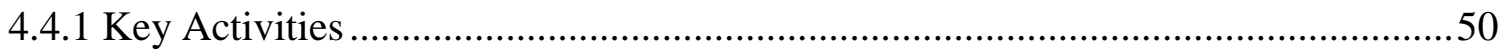

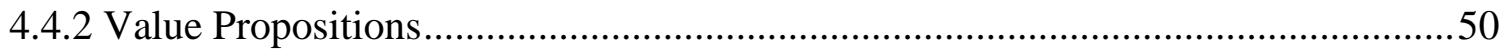

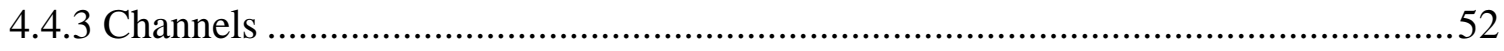

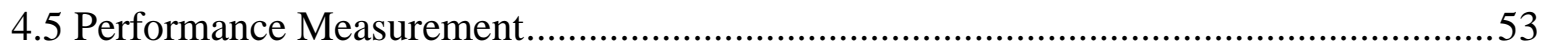

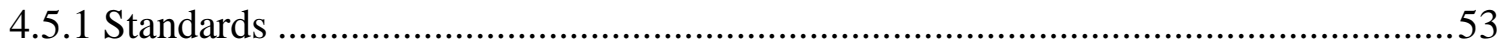

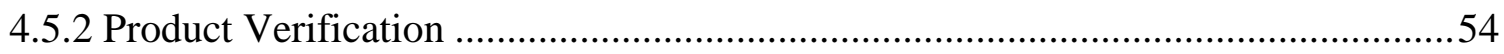


Chapter 5: Recommendations - The Business Case

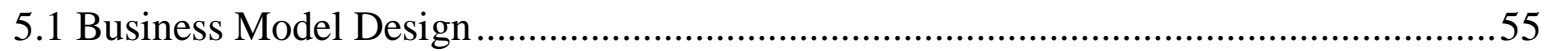

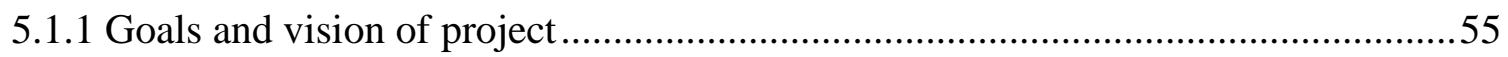

5.1.2 Assessment of opportunities and constraints to development ...............................56

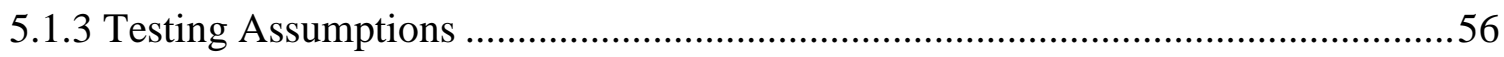

5.1.4 Evidence based recommendations on most appropriate business model ................57

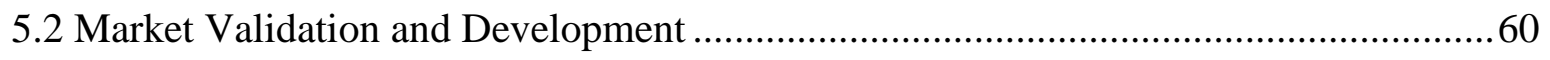

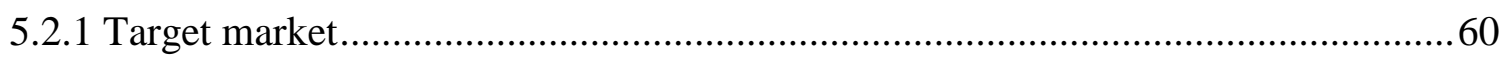

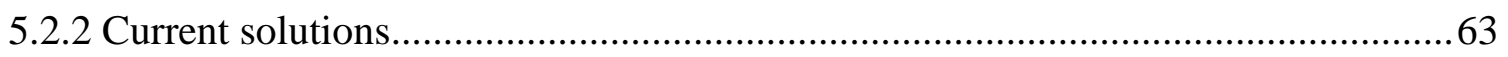

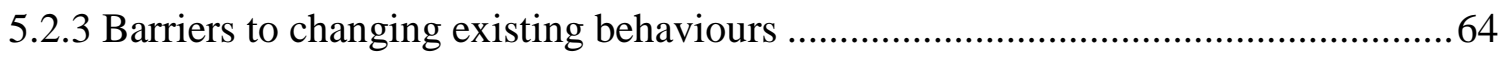

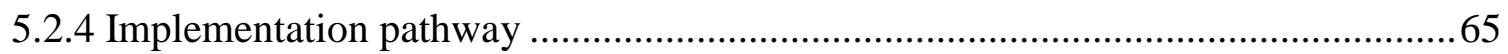

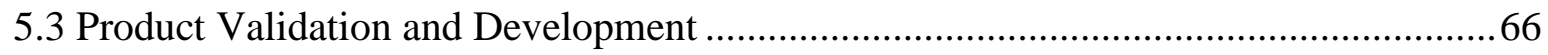

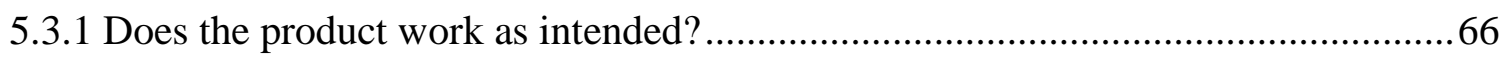

5.3.2 Process for development, testing and the regulatory environment........................66

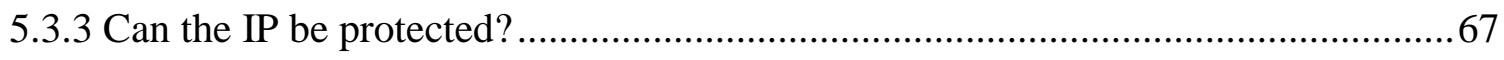

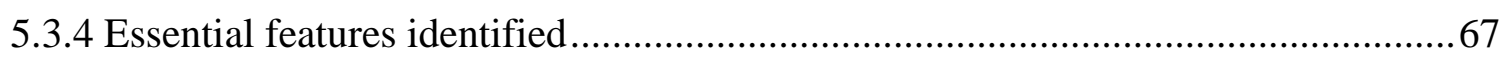

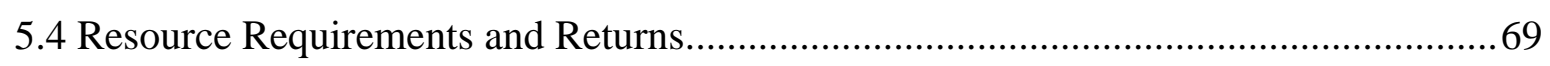

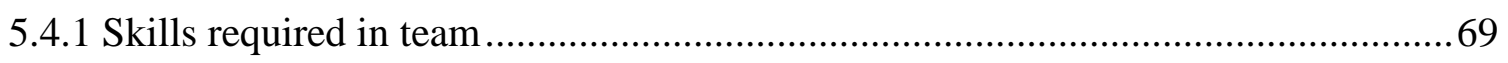

5.4.2 Development and manufacturing process and required equipment....................... 70

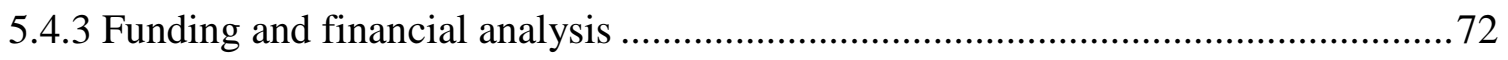

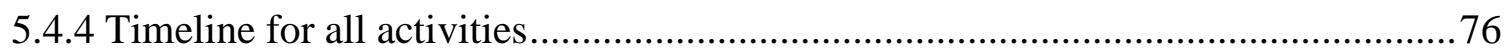

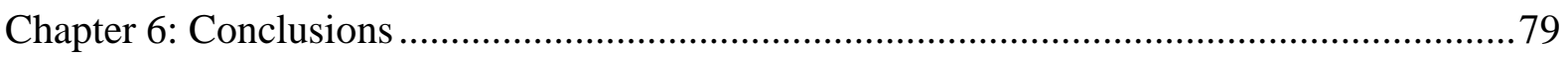

Appendix A - Example Interview Questionnaire .......................................................... 83

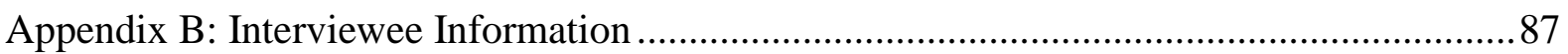

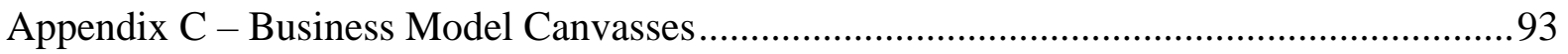

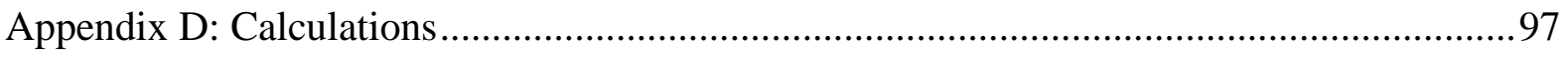

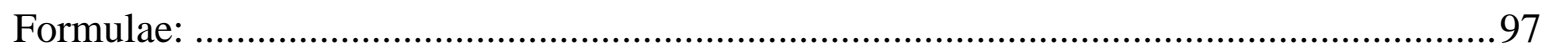




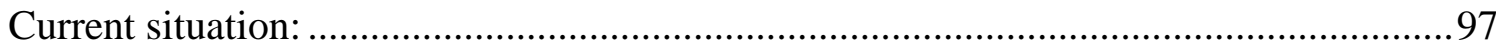

Using the IADT for accurate pole condition assessment: ...........................................98

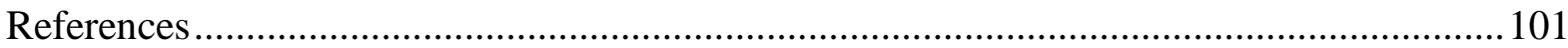




\section{List of Illustrations}

Figure 2.1. The MVP cycle .................................................... 13

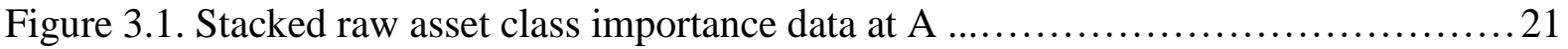

Figure 3.2. Stacked raw asset class importance data at B .............................. 22

Figure 3.3. Highest priority assets at A, weighted values, stacked bar chart .................23

Figure 3.4. Highest priority assets at B, weighted values, stacked bar chart ................. 24

Figure 3.5. Consolidated highest priority assets at A, stacked bar chart ....................25

Figure 3.6. Consolidated highest priority assets at B, stacked bar chart ....................26

Figure 3.7. Combined asset class importance rating, raw values .........................2 27

Figure 3.8. Combined asset class importance rating, weighted values ....................28

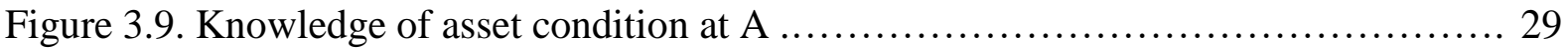

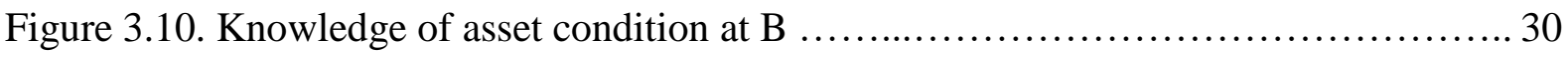

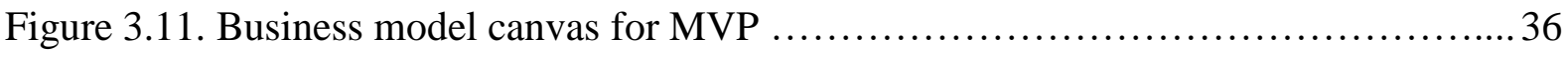

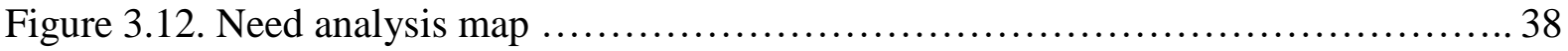

Figure 3.13. Value of wooden pole assessments .....................................42

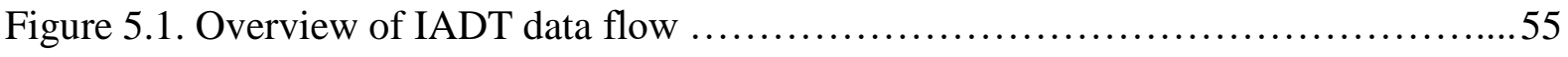

Figure 5.2. Business model canvas for MVP ........................................ 58

Figure 5.3. Combined asset class importance rating for EDBs A \& B, raw values .......... 61

Figure 5.4. Knowledge of asset condition at A ...................................... 62

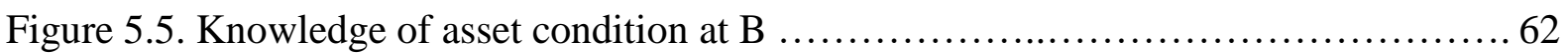

Figure 5.6. Value of wooden pole assessments ................................... 74

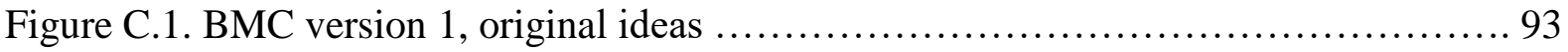

Figure C.2. BMC version 4, IADT for research proposal ...............................94

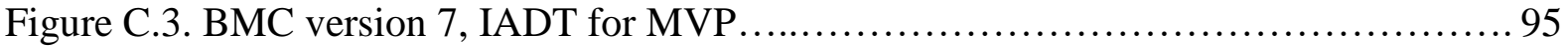




\section{Glossary of Abbreviations}

AC Alternating Current

AMP Asset Management Plan

BMC Business Model Canvas

CAPEX Capital Expenditure

CRR Current Rate of Replacement

DC Direct Current

DGA Dissolved Gas Analysis

EDB Electricity Distribution Business

EEA Electricity Engineers Association

FIM Feeder Investment Model

GNSS Global Navigation Satellite System

GXP Grid Exit Point

HVDC High Voltage Direct Current

IADT Infrastructure Asset Diagnostic Tool

IAM Institute of Asset Management

IEC International Electrotechnical Commission

IER Institute for Energy Research

LiDAR Light Detection and Ranging

LV Low Voltage

MBIE Ministry of Business, Innovation and Employment

MVP Minimum Viable Product

OPEX Operating Expenditure

SAIDI System Average Interruption Duration Index 
SAIFI System Average Interruption Frequency Index

TRR Target Rate of Replacement 


\section{Chapter 1: Introduction}

This report presents an investigation into the viability of a software and hardware system for analysing electrical distribution infrastructure assets which has been conducted as part of the Master of Innovation and Commercialisation programme at Victoria University of Wellington, New Zealand. This research has been done in conjunction with Electropar PLP New Zealand (Electropar) who have been working on developing the tool in question. The project is focussed on the commercial viability of this tool, in particular, discovering the most important features to include for its initial release to industry.

\subsection{Structure of Thesis}

This first chapter presents an overall background to the industry including a brief history, leading to the identification of the problem targeted by this study. Different technologies from around the world that have been applied to this problem are reviewed, identifying a space for the proposed solution.

Chapters 2, 3 and 4 form a logical sequence similar to a traditional thesis. Chapter 2 guides the reader through the methodology of this study, with the findings and analysis from the interview data presented in Chapter 3. The discussion of this information is found in Chapter 4 after which the report digresses from a traditional thesis as required by this Master's.

Chapter 5 presents a business case for the proposed product, designed as a standalone document. As such, the information from the preceding chapters is drawn upon to build the substance of this case, resulting in some repetition of information. This chapter also contains recommendations for the product which are by nature repeated within the conclusions of the subsequent chapter.

Chapter 6 concludes this study with a summary of the key findings, recommendations for further development of the product and finally a brief note regarding ongoing involvement of the researcher relative to the product. Some information from the business case is repeated here as this chapter should be able to be comprehended if one were to skip the business case of chapter 5 .

Although this structure appears unconventional, the report is delivered in this way to ensure the reader applies sufficient value to the business case of chapter 5, which may be neglected if this were relegated to an appendix. 


\subsection{What is Electricity Distribution?}

The electrical energy industry in most developed nations comprises four discreet components, generation, transmission, distribution and retailing (Powerco, 2016). Electricity generation occurs through the process of taking energy in one form and converting it to electrical energy. Over half of New Zealand's generation capacity comes from hydroelectric schemes distributed throughout both the North and South Islands (Transpower, 2017a), such as the 848MW Upper Waitaki scheme in the MacKenzie Basin (Energy NZ, 2013). These hydroelectric power stations use the potential energy stored in a mass of water at altitude, converting this into kinetic energy by flowing the water through the plant turbines which in turn rotate the generators, thereby releasing the energy in an electrical form for transmission.

The electrical energy is fed into the transmission grid and transmitted at high voltage over large distances to grid exit points (GXPs) at which point the distribution businesses take over (Powerco, 2016). In New Zealand, the electricity is transmitted as either alternating current (AC) at up to $220 \mathrm{kV}$ overland, or as direct current (DC) over the HVDC link between Benmore in the South Island and Haywards in the North Island (Transpower, 2017b). The HVDC link has been required due to the large hydro reserves available in the South Island while the largest consumer market has been in Auckland in the north of the North Island (World Nuclear Association, 2014). In New Zealand the company that manages this grid is Transpower and it is operated as a regulated monopoly overseen by the Commerce Commission (MBIE, 2016).

Electricity distribution refers to the final major physical part of the electricity network prior to the customer and has been in use in the developed world for over 130 years (IER, 2014). Initially used to replace gas lighting, networks were developed in the late $19^{\text {th }}$ century in major cities such as New York and London (IER, 2014), with the first use in New Zealand being in 1888 delivering power to Reefton (Powernet, 2014). Distribution businesses have responsibility for delivering electricity from the GXPs to the consumers (Powerco, 2016). These businesses operate a network of substations and power lines at a variety of subtransmission voltages which within New Zealand are typically $66 \mathrm{kV}$ or $33 \mathrm{kV}$, with distribution voltages of $22 \mathrm{kV}$ and $11 \mathrm{kV}$ depending on region and application (Powerco, 2016). The final distribution voltage to the consumers is at $400 \mathrm{~V}$ over a three phase network, with most consumer outlets being single phase at 230V (Powerco, 2016). In New Zealand distribution businesses are regulated monopolies to prevent duplication of networks around the country, which are overseen by the Commerce Commission (MBIE, 2016) 
The last component of this industry is the retailers. They purchase electricity from generators, and on sell it to the end users. The amount of electricity used is logged at the consumer property by an electricity meter. These retail companies operate in a competitive environment and are overseen by the Electricity Authority within New Zealand (Electricity Authority, 2016).

\subsection{The Problem Facing Distributors}

Having been spurred on through governmental investment during both the First and Second World Wars, the subsequent handover to feed electricity for civilian use greatly accelerated the use of electricity during the rapid economic expansion of the post war periods within developed societies (IEC, 2014). Traditional engineering methods during this time have led to a large volume of very long-lived assets within the electrical distribution industry, such as power poles, transformers and switches (Brown, 2004). These methods have in turn resulted in electrical distribution infrastructures throughout the world with large numbers of very old assets (Di Matteo, 2015; IEC, 2014). These assets survive under routine maintenance regimes until they reach end of life, at which point a supply outage often results. This mode of operation, known as the run to failure model (IEC, 2014), has been the traditional method of operation for this industry (IEC, 2014). Avoiding such outages has become the main focus for many electrical distribution businesses across the developed world (Di Matteo, 2015; IEC, 2014; Otal and Hjartarson, 2010).

The focus of this study is on improving the asset management capability of the distribution businesses. The generation, transmission and retailing sectors of this industry are not investigated.

Within New Zealand, much of the current infrastructure was installed 30 to 60 years ago by government agencies. By the late 1980's this centralised development had essentially ended (with the notable exception of the Clyde Dam, commissioned in 1992, (Te Ara, 2010), and the process of privatisation was established for not only the distribution businesses, but also the retailers and generators. As these latter two were deemed competitive markets, multiple companies rose to deliver these services within a given region. It was decided by government agencies that distribution and transmission would remain as regulated monopolies in order to limit the overall environmental and cost impact of these activities (MBIE, 2015). As such, controls were implemented by government to ensure that these would theoretically be managed in the best interests of consumers. These new Electricity Distribution Businesses (EDBs) have since been expected to maintain their networks under strict regulation enforced by the 
Commerce Commission. With many network components theoretically requiring replacement at the same time, in combination with the aforementioned Commerce Commission regulation, EDBs are facing a significant problem of how to provide the expected level of service within the allowed expenditure framework. Replacements on the scale required with aged based assessment would need very large capital expenditure (CAPEX) by the EDBs, which for many of the distributors would exceed that which is permitted under the Commerce Commission's regulations. As such a method to reduce this potentially massive expenditure needs to be found.

It is worth noting that within this industry there exist wider issues in regard to the structure of the industry and the regulation there of. These wider issues are not the focus of this study. This study will focus on the specific issue of assessing the need and value of a tool to optimise the available capital and operational expenditures (OPEX) for the EDBs, with the primary objective of enabling smarter asset management to take place along with the added benefit of enhanced public safety.

\subsection{Introducing the Project Partner, Electropar}

Electropar is a division of Preformed Line Products (PLP), a US based manufacturer of transmission line components such as isolators, clamps, cables and other associated electrical distribution equipment. Their main customers within New Zealand are the twenty-nine EDBs where they provide equipment for the repair and maintenance of electrical distribution infrastructure assets. They were formed after the acquisition of Electropar Limited by PLP in 2013 (Electropar PLP, 2016).

Electropar has collated what they believe to be significant empirical evidence showing that the current maintenance and replacement regimes of New Zealand's power distribution companies has often lead to equipment in serviceable condition being prematurely replaced, whilst at the same time, other equipment is failing in service resulting in supply interruptions (B. Hewitt, personal communication, December 17, 2015). Based upon their own data, Electropar set out to find a solution to this problem.

Electropar has proposed the Infrastructure Asset Diagnostic Tool (IADT) as a possible solution to the problem at hand. This tool comprises a collection of measurement technologies integrated with analytical algorithms which calculate for example, the remaining longitudinal and lateral strength as a percentage of original strength for multiple types of wooden power poles, and conductor elongation from the reduction in clearance from the ground, thereby 
highlighting potential sites for asset failure. This would enable a smarter maintenance and replacement schedule to be developed, opening up the opportunity to optimise these activities for current assets in service.

The underlying business objectives for Electropar are to add a high added value revenue stream to their business, and to potentially draw on the information generated from the IADT to optimise their offshore manufacturing activities, leveraging their global manufacturing footprint for cost competitiveness (B. Hewett, personal communication, February 4, 2016).

\subsection{Current Situation within the Electrical Distribution Industry}

In order to pre-empt possible failures, power distributors have already begun collecting infrastructure asset condition data, for example the state of degradation of a power pole, utilising third party contractors, each with particular expertise in their field (B. Hewitt, personal communication, February 4, 2016). These data allow the distributors to predict more accurately the remaining life of the discreet assets. However, it does not allow them to take into account how these discreet assets interrelate with one another. This lack of correlation leads to forecasting inaccuracies in regard to the remaining life of these infrastructure assets due to different assets impacting to different degrees on the total system (B. Hewitt, personal communication, February 4, 2016).

Over time Electropar have observed that within New Zealand, EDBs do not necessarily have comprehensive knowledge of their infrastructure assets. An example of this is when scheduled maintenance of assets has not been carried out, not because it wasn't required, but because the asset that they believed to be at a given site was in fact not there (B. Hewitt, personal communication, February 4, 2016). This kind of discrepancy is usually due to the asset having been replaced during a previous maintenance cycle or prior failure, without proper logging of the prior activity (B. Hewitt, personal communications, December 17, 2015). In such cases, maintenance equipment would have already been purchased on the incorrect information, leading to the site requiring a return visit with the correct maintenance equipment and in some cases a different service team. The net result of this lack of accurate infrastructure information is a potentially significant increase in the cost of maintenance through double handling of materials and additional labour costs. Delays associated with these maintenance issues may lead to non-supply of electricity by the distributor in cases where the system has gone offline. This gives rise to the potential to increase the company's insurance costs against such failures, be they self-insured or otherwise. 
In addition to the apparent lack of accurate asset type information is the inherent lack of accurate condition information surrounding those assets. Electropar have noted that this frequently leads to power supply disruption when assets have failed, seemingly prematurely, forcing the EDBs to behave in a reactionary manner with regard to their maintenance activities (B. Hewitt, personal communication, February 4, 2016). This reactionary behaviour by the EDBs limits their ability to provide the level of service expected not only by consumers, but also by government. New Zealand government regulations require electricity distribution companies to have comprehensive Asset Management Plans (AMPs) to ensure the reliable supply of electricity to the country, with target levels for the System Average Interruption Duration Index (SAIDI) measured in minutes, and the System Average Interruption Frequency Index (SAIFI) or number of interruptions per year (Powerco, 2015).

\subsection{Available Technologies from Around the World}

In the last ten years or so, much focus has been given to developing a better way of more effectively managing these aging assets. A variety of approaches have been applied within the industry with varying results. The idea of some form of condition monitoring is central to most of these ideas.

\subsubsection{Australia}

Asset condition indexing as described by Di Matteo (2015) is a process whereby a given asset is assigned a number based upon its current condition combined with the risk it poses on the network (its criticality), with the highest numbers typically indicating an asset posing a lower risk to SAIDI. Di Matteo (2015) recommends a simple scale from 0 to 100 to provide sufficient granularity to the data. Information about assets can then be pooled to determine an overall rating for a particular substation for example. This information is stored within a dedicated asset management data retrieval system which can determine how likely the target asset pool is to result in an outage, which in turn can be used to assign asset maintenance tasks. This system has also been adopted in the formulation of ISO 55001 (Di Matteo, 2015).

\subsubsection{North America}

In New York, a team from Columbia University, in conjunction with Consolidated Edison Company, constructed a computer model of the distribution feeders (the line from the distribution transformer to a group of customers) within New York City which used an artificial intelligence algorithm to rank feeder susceptibility to failure (Gross et al, 2006). This was done 
to test the accuracy with which feeder failures could be predicted utilising machine learning. In this case, during July 2005 this self-adapting model was approaching 0.8 out of a possible 1.0 performance rating (Gross et al, 2006). A 1.0 in this system means that all feeder failures were at the top of their susceptibility ranking determined by the machine learning algorithms, whereas a 0.0 would indicate that they were ranked as least susceptible. A performance rating of 0.5 indicates that the prediction is no better than random for this engine. If this technology could be applied to develop a forecast-based maintenance regime, rather than a traditional timebased system, then potential feeder failures could be pre-empted thereby reducing the risk of a supply outage occurring (Gross et al, 2006). Consolidated Edison believed the results were good enough to be useful and have subsequently incorporated the tool into their maintenance regimes. It is worth noting however that a considerable amount of work was required in this case to translate Consolidated Edison's human centric data into computer centric data and the end result was only able to be used as a bespoke tool for this company (Gross et al, 2006).

In New Hampshire, Unitil have been utilising predictive analytics in conjunction with radio frequency (RF) monitoring of the overhead lines, using the tools of Exacter Corporation, to successfully prevent outages occurring (Letourneau, 2015). The basic principle here is that the RF emissions change as the lines age due to electrical and physical fatigue. When the lines are in good condition they emit a particular electromagnetic signature, but as they wear and age this signature changes (Letourneau, 2015). If the conductor is left to progress to the stage where excessive physical heating is occurring, this would lead to annealing of the conductor which results in a reduction of strength from its cold drawn state. Such reductions could lead to premature failure of the conductors in service. By monitoring the RF emissions from the conductors and comparing these to the corresponding asset condition information within Exacter's database, areas of concern are highlighted for further investigation (Letourneau, 2015). The level of progression towards failure for the highlighted asset can then be assessed, with the information gathered being collated and further analysed by a predictive engine to determine the most likely sites of failure. These sites are then indicated by the system for maintenance inspection. In Unitil's case, the target reduction in SAIDI of 10\% was exceeded after the application of Exacter's technology (Exacter Corporation, 2016). Exacter's extensive asset condition RF emission database is where this tool gets its accuracy (Letourneau, 2015). This tool is being investigated for integration with Electropar's IADT.

In Canada, Toronto Hydro have developed what they call a Feeder Investment Model (FIM) which draws upon four primary factors, those being calculation of asset failure probability, 
estimation of asset failure impacts, risk evaluations and determination of optimal asset intervention timing (Otal, Hjartarson, 2010). Here there were two recognised approaches to determining the remaining asset life, an age based assessment calculated from the historic performance of a particular asset class, that is the survival rate, and a condition based approach. The latter was proven by Otal and Hjartarson (2010) to be the more accurate method as it allows for assets of similar ages to exist in different states of degradation, however this was still not good enough until a criticality measure was also applied. For example, a transformer with a low health rating feeding a billboard as compared to a slightly healthier transformer feeding a hospital which could be deemed more important and therefore higher on the replacement schedule. The FIM overlays this with the life cycle cost of the current and replacement assets to find the points of lowest cost where the risk curves for the two assets intersect thereby minimising the risk of failure and hence reducing the potential to incur additional cost to a customer. This method is similar to the asset health indexing discussed by Di Matteo (2015) as it utilises both asset criticality and asset condition to drive the assessment.

\subsubsection{New Zealand}

An issue facing New Zealand distributors is the degradation of wooden power poles. It has been found that there can be as many as 150 types of wooden pole used within a single network in New Zealand (Pattie \& Silk, 2016). These can be notoriously difficult to assess the condition of due to the traditional testing methods still in use, typically a subjective assessment from an inspector with a hammer (Pattie \& Silk, 2016). The ability to more accurately assess the condition of such poles could lead to a far more efficient replacement schedule, with as much as a ten-fold improvement being achievable with the various tools investigated by Pattie and Silk (2016). During their investigation they found that no particular tool gave consistently accurate results and hence determined that a measure of subjective input from an experienced inspector was likely to be required with any given assessment.

Another technology in use within New Zealand is mobile 3D laser scanning which uses a LiDAR sensor in combination with the Global Navigation Satellite System (GNSS) and inertial guidance for position (B. Hewitt, Personal Communication, May 25, 2016). A digital camera is used to provide true colour for the point cloud generated by the laser reflections in this system which is used to build representation of the environment at speeds of up to $100 \mathrm{~km} / \mathrm{h}$ (Point Geodata, 2016a). From these scans the position and clearances around power lines can be derived along with pole and cross arm attachment information (Point Geodata, 2016b). Point 
Geodata are engaged by EDBs to perform this task around the country. This information could be valuable for the proposed asset management tool if it could be leveraged in some useful way, for example to provide loading information.

\subsection{Issues with Standards and Asset Assessment}

One of the issues surrounding the industry globally is the overall lack of consistent standards in regard to how performance is measured and what should trigger asset maintenance or replacement (IEC, 2014). Although some measures such as SAIDI and SAIFI sound like they should be consistent, the way that these values are calculated vary greatly throughout the different regions, and even between distribution companies within the same region in some instances (IEC, 2014). Equally, when assessing the condition of a particular asset within a network, there is no consistency in how this is done resulting in a situation where, for example, ten different networks are currently providing ten different assessments for identical condition assets. Also occurring is the case where different inspectors give different assessments for the same assets within a network (IEC, 2014). This leads to a situation where it is not possible to accurately compare the performance of a given network against any other network globally, leading to uncertainty around how good a particular network is actually operating. This issue is well recognised within the industry and steps are currently underway to address this (IEC, 2014). Amongst the steps to address the lack of standards within the electrical distribution industry is the recent compilation of a new global standard, ISO 55001 (IAM, n.d.). which is now gaining traction internationally, and within New Zealand the International Infrastructure Management Manual (EEA Asset Management Forum, June 2016).

\subsection{Business Models}

The proposed Infrastructure Asset Diagnostic Tool (IADT) provides information to the distribution businesses to enable more accurate condition assessments to be made, allowing critically degraded assets to be identified along with those with many years of life remaining. This would enable the EDBs to spend their available funds in the most effective manner to ensure the ongoing supply of electricity.

There are a number of business models which could be used for this project, and in this study these were tracked using the Business Model Canvas (BMC) of Strategyzer.com (n.d.). The BMC is used to identify where different components such as stakeholders and channels fall within the overall business as the project progresses, and helps to clarify the overall business 
situation on a single page. The key BMCs developed during this study are included in Appendix A. Three different business models have been identified as being appropriate for the IADT as follows:

i. Providing an engineering service on an as required basis with a team from Electropar.

ii. Licensing the IADT with training to a third party specialist for subcontracting to distribution businesses.

iii. Licensing the IADT to the distribution businesses with training for the assessment team.

\subsection{Summary}

On the surface it would appear that there are significant challenges facing the electrical distribution industry globally, with significant disparate technologies existing which could help to alleviate these challenges. If all or some of these technologies could be pulled together and analysed collectively, the potential exists to create an asset failure forecasting engine generating more efficient maintenance schedules and mitigating the risk of costly outages.

The main objective of this study is to determine firstly, the existence of a genuine industry need for the proposed IADT, and secondly to identify through the process of market discovery what a Minimum Viable Product (MVP), as described by Adams (2010), meeting that need might look like. This is to be done through the processes of market discovery and development described initially by Blank (2007) and subsequently by Adams (2010) and Ries (2011). This report guides the reader through the method used to gather data, including techniques for assessing and reassessing subjective data, the findings and analysis of this data and discussion thereof. This is followed by a business case for the IADT as proposed by Electropar, outlining the recommendations from the study, including a financial analysis. The key outtakes from the study are presented in the conclusion, where the future of the project is also outlined. 


\section{Chapter 2: Methodology}

The methodology for this study falls into three distinct areas, the method of data collection, the process used for analysis and the iterative activity after the identification of a possible MVP. Prior market validation has been done through a set of questions (included in Appendix A) which were taken to the marketplace and posed to potential customers, in this case from the electricity distribution industry. The target market for the proposed IADT is specifically the 29 EDBs charged with the stewardship of the infrastructure assets delivering electricity to our industries, businesses and homes.

For this study, EDBs were selected that would give a good cross section of the infrastructure asset framework in use within New Zealand, based upon the industry knowledge of Electropar staff. The initial plan had been to interview staff from three or four different EDBs (as recommended by Blank (2007) and Ries (2011) for large corporate products), however, due to partner availability and the commercial sensitivity of this and other projects, it was only possible to interview staff from two EDBs. From the EDB Information Disclosures (2016), these two EDBs represent approximately $18 \%$ of the New Zealand customer connections (360,000 ICPs) and 32\% of New Zealand's overhead distribution and sub-transmission lines $(38,700 \mathrm{~km})$. Combined, these two EDBs also have a very broad range of installed equipment (D. Devonport, personal communication, June 30, 2016). Within each EDB, candidates from a variety of roles were interviewed including engineering managers, asset managers, line managers, financial managers and engineering analysts. A total of 14 people were interviewed for this report.

\subsection{Assumptions}

Buying behaviour of EDBs observed by Electropar over the last few years has indicated that a lack of precision around installed asset knowledge may exist. The assumption drawn from this observed behaviour is that current processes within the industry are inadequate, or not fit for purpose. This has led to the hypothesis that a tool to improve this situation could have significant value for the EDBs.

It was thought that the most likely customers for the IADT would be the EDBs. In addition to the EDBs, the government regulator (the Commerce Commission) might have an interest if the tool could be guaranteed to deliver regulatory requirements to customers. They may view it as an essential component of an EDB's asset management plan for example. 
Additionally, it has been assumed that the IADT would be either a new product being used in a new market, or a niche product re-segmenting a current market as described by Blank (2007), which is to be determined during the study. It is also worth noting that at the time of the interviews, the interviewer had yet to see the proposed IADT, and hence had little real knowledge of the actual product. Although not intentional, this lack of information had the benefit of removing an amount of interviewer bias from the questions. An absence of bias is important when assessing a market place as the interviewees are not guided directly or indirectly to a particular outcome, thus making a given assessment more believable.

Another key assumption relating to the structure of the business model is that Electropar would be developing the software for the IADT themselves, with input from relevant industry service providers. This thinking was therefore prevalent within the researcher's mind during questioning sessions and as such incidental commentary could have been thus influenced.

Competition for the tool is thought to come from internal processes and spreadsheets where makeshift solutions to the perceived problem have been developed. Other competition is assumed to include a variety of different approaches to asset management, especially those which utilise condition assessment as primary drivers, and other tools in the marketplace.

A clearer picture as to whether or not these assumptions are valid was derived from the data collected through the interview process.

\subsection{Data Collection}

The main customer data required is whether or not there is sufficient need within the market place for the proposed product, described by Adams (2010, pA43) as the "market pain". The primary focus of the "Customer Discovery Process" (Blank, 2007, pA33) is to isolate this pain in order to home in on an MVP, that is, the smallest product that will address this pain. This then becomes the initial target of the product development team. An alternative way of stating this comes from Reis (2011, pA38) where he says "We must learn what customers really want, not what they say they want (or what we think they want)", which really refers to the measure part of the diagram in figure 2.1 adapted from Ries (2011) where one complete cycle of buildmeasure-learn is enabled by an MVP. 


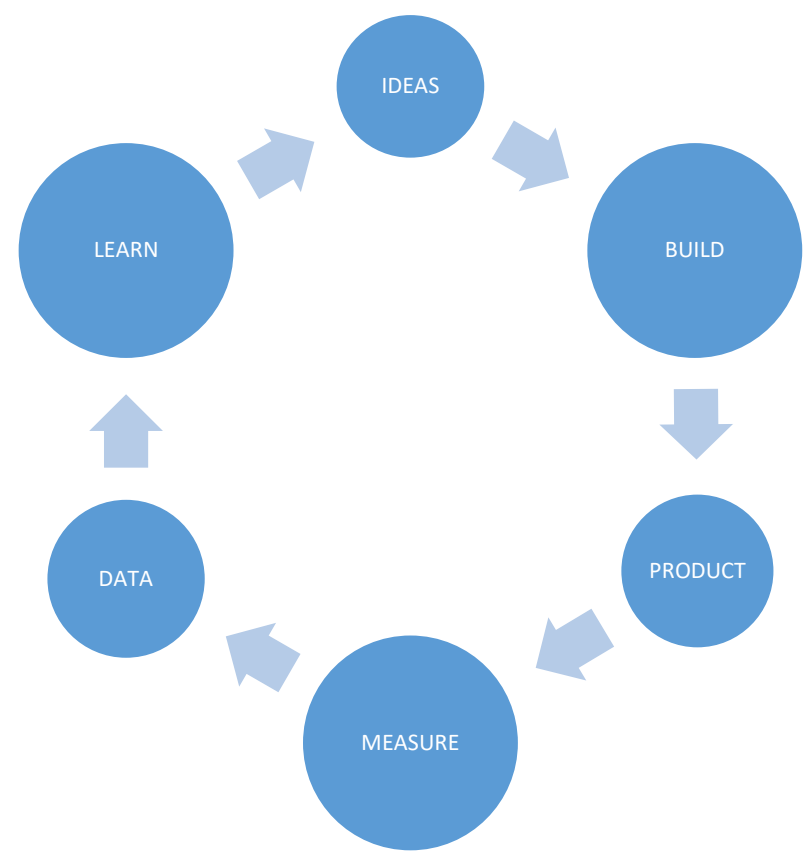

Figure 2.1. The MVP cycle, adapted from Ries (2011).

Understanding the value that the MVP can bring to the customer is critical to achieving buyin. To determine this MVP, questions were formulated (Appendix A is representative of these), in conjunction with Electropar to ensure industry relevance, which would draw out where the main issues are within the industry from the EDB employees' perspectives, that is the end users of the proposed product. These questions were designed in such a manner as to not lead the interview participants towards a particular problem, but rather to let them describe what actual problems they were experiencing. The reasoning behind this logic is that if a target customer is simply asked if they thought the proposed product was a good idea, they are likely to agree, however this would not guarantee that they would be willing to part with money for it, nor would it ensure that the product would be commercially beneficial.

A more effective approach, and the one followed here, is to probe for the underlying needs of the customer's business without referring to the proposed solution. Interview participants were encouraged to speak freely and express their opinions, and it was made explicitly clear that there were no right or wrong answers. The questionnaire was essentially the same for all interviews with only minor changes relating to the specific business being interviewed. This consistency of questions was to ensure that responses from participants were being drawn from a consistent framework or train of thought. The target length for these interviews was 50 minutes and these were conducted face to face at both EDBs, with three interviews being conducted via video conferencing from one of the EDB sites. For most of these interviews, 
Dave Devonport of Electropar was present and provided additional industry specific input as required. The audio of each interview was also recorded for later reference if required. The information provided to the candidates can be found in Appendix B. The Victoria University of Wellington Ethics Committee approval number for this study is 22989.

In order to ensure good engagement from the EDBs, Electropar were able to leverage their established business relationships, providing the direct means to arrange interviews with a variety of engineering, senior managerial and financial staff within the targeted EDBs. Due to this, the EDBs selected were those which were friendly towards Electropar in general. This relationship could potentially have introduced bias into the interview answers, however great care was taken by the researcher and by Electropar to ensure that the outcome of this study would in no way be detrimental to the participant's businesses. In one case, legal clearance for the interviews had to be obtained, with a very clear framework agreed for the use of the data.

Another subtle approach used for general data collection was to engage in conversations with people within the industry. Attending the Asset Management Forum held by the Electricity Engineers Association (EEA) in June 2016 was a good opportunity, and the information derived here was of a general nature that was relevant to the industry. This forum also gave an opportunity to gauge industry feel for the proposed IADT at a high level.

Along a similar line, a conversation was held with Reliable Lines, the main technology provider to Electropar for this project. This conversation was conducted on site at Electropar, with Dave Devonport of Electropar present. As this was not able to occur until after the interviews with the distributors, the information obtained couldn't be incorporated into those events. However, these conversations did provide a good source of material for a second round of interactions with an EDB if required. They were also invaluable in helping the writer to gain a clear understanding of the capability of the proposed IADT.

\subsection{Analysis}

The nature of the questions yielded a lot of qualitative and some quantitative data. This necessitated an approach which sought out similar problems from the different interviewees in an effort to isolate possible MVP features.

Due to the qualitative nature of the data, a variety of techniques had to be applied to derive useful information. Where data could be represented numerically, this has been tabulated and graphed, not only in its raw form, but also in contracted and expanded forms derived from 
assumptions about the data. This was done to test the validity of the results, the idea being that if an overall consistency could be found even after such manipulations, this would, in the opinion of the researcher, give a strong indication of market sentiment. Stacked bar charts are used to highlight the most commonly indicated areas of concern from the interview responses. These allowed very clear similarities between the needs of the two EDBs to be seen, and therefore highlighted potential MVP features. From these highlighted features, the question of why these were considered important was also investigated, with the subsequent need map providing a more in depth insight from these qualitative data. In this type of diagram, the number of arrows in and out of a particular item reflects that item's overall importance, with the maximum number of arrows being the most important component. The process followed to build this map is by asking why a particular aspect is important or relevant repeatedly, working from the feature on the right to the money (either a reduced cost or increased revenue) on the left, and finding the interrelationships between the various aspects identified. The identified impacts are shifted left or right until the diagram flows cleanly without looping back on itself, at least as much as possible.

In order to clarify possible results, data were also categorised into asset classes, eliminating the variety of descriptions for essentially identical assets (from a physical diagnostic perspective), and then graphed similarly to the raw data. Where a component could form a part of multiple classes, it has been assumed to be divided evenly between these classes.

The interview summaries were substantially reviewed, with the audio recordings being used to provide enhanced richness to the data as required. For each interview, overriding themes and issues were sought out so as to give weight to the value of the proposed solution. These themes could then be used to guide the determination of the MVP. This approach also allowed gaps to be highlighted which would allow for a second set of more directed questions to be formulated if necessary, keeping the essential iterative path open as espoused by Blank (2007) and Ries (2011). The last question asked was directly to ensure this door was kept open.

Where answers were more qualitative in nature, these were compared with the responses of others within their business, and also compared to responses from the other business in this study. Where inconsistencies were found between participants within a business, reasons for the difference of opinion were sought out. Likewise, where a significant difference is found between the two different businesses, reasons for these are postulated. Equally if there was a 
strong correlation between these businesses in regard to a particular issue, this is also highlighted.

\subsection{Business Model Design Process and Financial Viability}

The BMC of Strategyzer.com (n.d.) has been used to develop the business model for the IADT. This lays out different aspects of the business on a single sheet, with relationships between these not explicitly stated. This is instead inferred through the headings and where different stakeholders fall onto the map. During the course of the project, the BMC was updated to reflect the current environment perceived for the business. This updating occurs as new information comes to light with the BMC altering to reflect the newly apparent places for the stakeholders. This process can then be used to help guide the business on how it should be dealing with the various stakeholders. The BMCs used in this project have been included in Appendix C.

With reliability taking the place of pure profitability within the electrical distribution industry (Newton, 2002), the financial analysis was therefore conducted with this focus in mind. Avenues to redirect funds currently available for maintenance and replacement work were sought out from the data gathered during both the interviews and background company investigations. The purpose here was to locate possible significant gains in network reliability with the goal of reducing SAIDI minutes for the distributors. The monetary values have been calculated at constant rate, that is with no allowance for inflation due to the primary focus being the redirection of funds to additional possible works, a measure independent of magnitude.

\subsection{Drawing Conclusions}

When drawing conclusions from the data analysis, the primary focus was on isolating a possible MVP for the IADT. In the case of multiple possible MVPs, these are highlighted and assessed against each other with the intent of determining which is the most valuable to the customer. The reasoning behind this comes back to wanting to deliver the highest quality product possible as an MVP, in other words the one which targets the customer pain most effectively. Any conclusions as to the nature of possible products have been reviewed and cut down to their most basic forms, and reassessed for fitness.

Other information to be derived from the data are conclusions about the nature of each EDB studied, that is how each of the participants view their roles in regard to asset management. It was desired to discover what impact, if any, the different structures of the two EDBs 
interviewed could have upon acceptance and utilisation of the IADT, although it is recognised that the sample size could be a limiting factor in reaching a decisive conclusion on this point. Additionally, questions which are designed to gauge the EDB's appetite for using external contractors were included for completeness.

Questions were also asked to elicit required payback periods and the perceived value of a particular level of accuracy for the tool. The conclusions from these types of questions achieved two objectives, firstly, they give a measure of how well a company thinks it is doing at the current time, and secondly, they give an indication of how well the tool needs to perform to be deemed acceptable. The researcher has drawn upon his own experience working with predictive analysis tools when considering these values.

Gaps within the EDB's collective knowledge around asset condition were also sought out, in addition to direct requests for desirable features, although not phrased in that way. This information is used to add value to the case in favour of the IADT, for example, the most commonly requested items could be considered as candidates for inclusion in the MVP.

The conclusions drawn collectively from the above analysis are intended to be used to drive possible iterations of the IADT until an optimal solution for this is found (Note however that this optimal solution is not necessarily the MVP). The intention after the initial round for MVP development is to return to the customers once they have trialled the product and seek out possible refinements. These could be based on the initial question set, or could be completely different questions depending on how well the product fits the perceived need and what issues arise. It is also conceivable that questions will arise which were not initially considered, and which are not necessarily related to the product features. This further iteration represents the next stage of this project if development is to continue. 


\section{Chapter 3: Findings and Analysis}

To determine the most suitable MVP for the IADT, fourteen interviews were conducted with participants from two discreet EDBs, one large and one small, which combined are strongly representative of the New Zealand marketplace. Also consulted were representatives from within the project partner, Electropar, and from Reliable Lines, the primary technology provider to Electropar for the IADT project.

The data collected has been collated into a number of tables and charts in order to find significant patterns into which the proposed IADT might fit. These have been categorised alternatively as impacting upon network reliability and on public or staff safety. Data has also been drawn into specific areas in such a manner that more meaningful interpretations could be extracted. These are followed with an explanation of how different assets classes have been grouped and the reasoning behind these groupings.

It is important to note that much of the information gleaned from the interview process has been of a qualitative nature, therefore when analysing this, the interpretation of these data is that of the researcher. The value of accurate asset condition assessments, an asset's potential to endanger the public, and an asset's impact on overall network reliability were also considered.

A need assessment was conducted to develop an idea of the reasons behind the perceived needs as spoken by the interview participants, to find the real reasons behind the needs. This analysis was a very valuable tool for helping the researcher to understand the real issues within the EDBs, and to reassure him that the proposed product would be of value.

\subsection{Asset Importance Data}

The data presented in this section represent a numerical interpretation of qualitative data gathered from the interviews. These data have been numericised, tabulated and charted to determine which particular assets are of the most importance to the EDBs interviewed, with each EDB being assigned a name, A and B. Each participant from an EDB was assigned a signature (e.g. A1 associated with A) at random to help protect the identity of those participants who so desired this. The responses of the participants from the two EDBs questioned are first considered separately and then collectively. 
When assessing the importance of a particular asset class, a mention of such an asset by an interview participant is indicated by a 1 in tables 3.1 and 3.2, with totals shown in the final column. These data are then weighted in an attempt by the researcher to determine a clear hierarchy for each asset class. Weightings were applied by giving each response a number from one to four, with the highest number being assigned to the asset class that the interviewee deemed most important. Four was the highest number in this ranking system as it corresponded with the maximum number of asset classes that a single participant noted during the interviews. When an interviewee mentioned less than 4 asset classes, the most important was still assigned 4 and the series ended at the lowest number, 2, 3 or 4 in the case of only one asset class. It should be noted that one limitation of this weighting system is it assumes that each participant's opinion is equally valid for a particular class of asset, with no consideration given to their roles in the organisation. It is recognised by the researcher that this homogenisation of roles could skew the results, however the weighting system is included as an attempt to partially compensate for the small number of interviews which were able to be conducted in this study.

\subsubsection{Asset importance ratings as collected and in weighted form}

The data derived from that given by the participants from the two EDBs questioned are presented in tables 3.1 and 3.2. Here a mention of an asset class is represented by a 1 as noted

Table 3.1.

Raw Asset Class Importance Data at A.

Participant

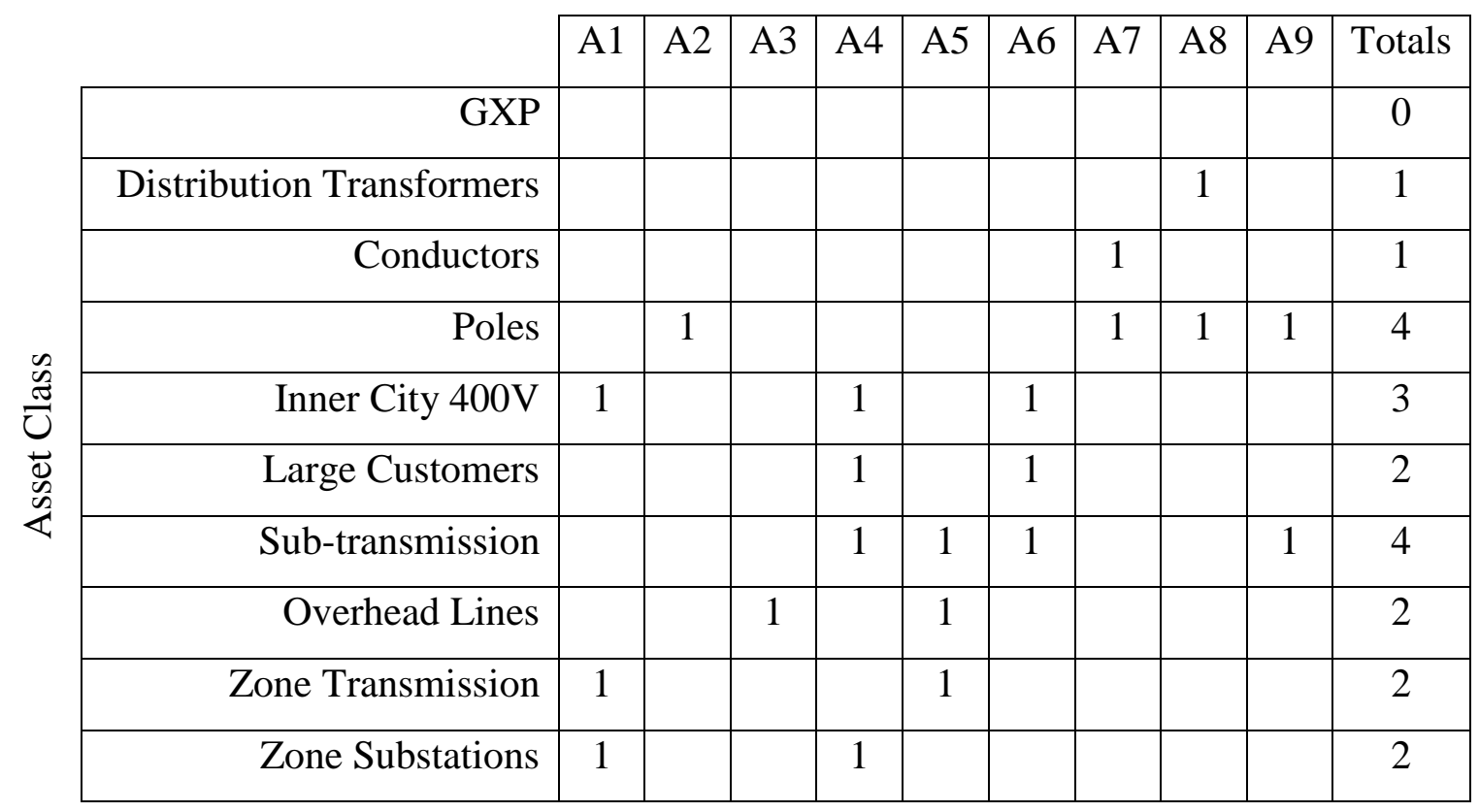




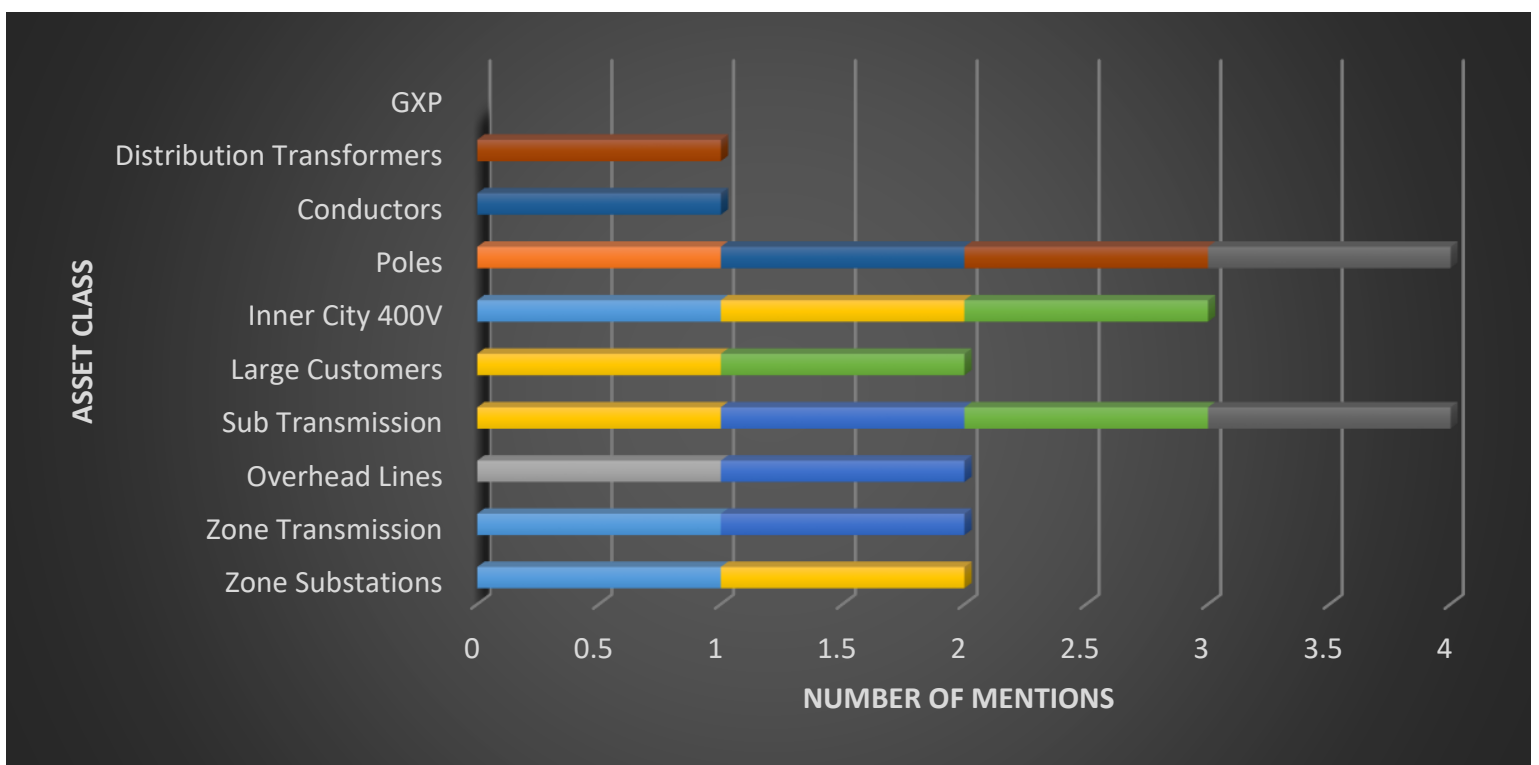

Figure 3.1. Stacked raw asset class importance data at A.

previously. In an attempt to visualise the relative importance of each asset class, these tables are followed by corresponding stacked bar charts, Figures 3.1 and 3.2 respectively. From the plots of Figures 3.1 and 3.2 the initially apparent areas of most concern are poles and subtransmission for A and overhead lines for B. These asset classes represent the first areas of potential focus for an MVP variant of the IADT.

Table 3.2.

Raw Asset Class Importance Data at B.

\begin{tabular}{|c|c|c|c|c|c|c|}
\hline & \multicolumn{6}{|c|}{ Participant } \\
\hline & B1 & $\mathrm{B} 2$ & B3 & B4 & B5 & Totals \\
\hline GXP & & & 1 & & & 1 \\
\hline Distribution Transformers & & & & & & 0 \\
\hline Conductors & & & & & & 0 \\
\hline Poles & 1 & & & 1 & & 2 \\
\hline Inner City 400V & & & & & & 0 \\
\hline Large Customers & & & & & & 0 \\
\hline Sub-transmission & & & 1 & & 1 & 2 \\
\hline Overhead Lines & 1 & 1 & & 1 & 1 & 4 \\
\hline Zone Transmission & & & 1 & & 1 & 2 \\
\hline Zone Substations & & & 1 & 1 & & 2 \\
\hline
\end{tabular}




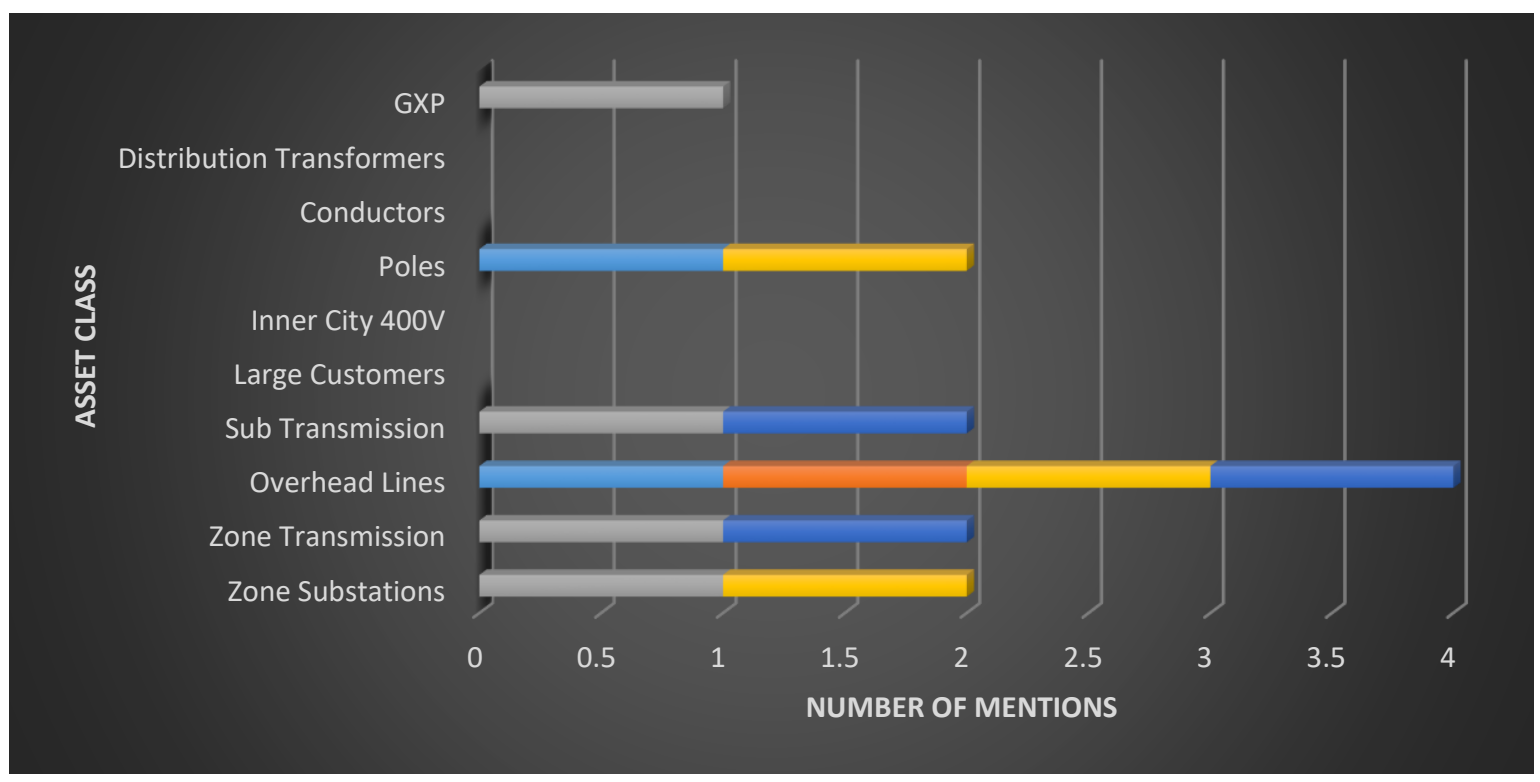

Figure 3.2. Stacked raw asset class importance data at B.

In order to generate stronger distinctions between asset classes, the weighted data derived from the aforementioned process is presented in tables 3.3 and 3.4 and figures 3.3 and 3.4 respectively, with totals again shown at the right of the tables.

Table 3.3.

Weighted Asset Class Importance Data at A.

\begin{tabular}{|r|r|c|c|c|c|c|c|c|c|c|}
\multicolumn{1}{c|}{} & A1 & A2 & A3 & A4 & A5 & A6 & A7 & A8 & A9 & Totals \\
\hline GXP & & & & & & & & & & \\
\hline Distribution Transformers & & & & & & & & 4 & & 4 \\
\hline Conductors & & & & & & & 3 & & & 3 \\
\hline Poles & & 4 & & & & & 4 & 3 & 3 & 14 \\
\hline Inner City 400V & 2 & & & 1 & & 2 & & & & 5 \\
\hline Large Customers & & & & 3 & & 3 & & & & 6 \\
\hline Sub-transmission & & & & 4 & 4 & 4 & & & 4 & 16 \\
\hline Overhead Lines & & & 4 & & 2 & & & & & 6 \\
\hline Zone Transmission & 3 & & & & 3 & & & & & 6 \\
\hline Zone Substations & 4 & & & 2 & & & & & & 6 \\
\hline
\end{tabular}

In this weighted data it can be seen that for business $A$, the strongest importance ratings are closely split between poles and sub-transmission assets, and for B the strongest importance rating is for overhead lines, reiterating these as areas of particular interest for this investigation to isolate a possible MVP. 


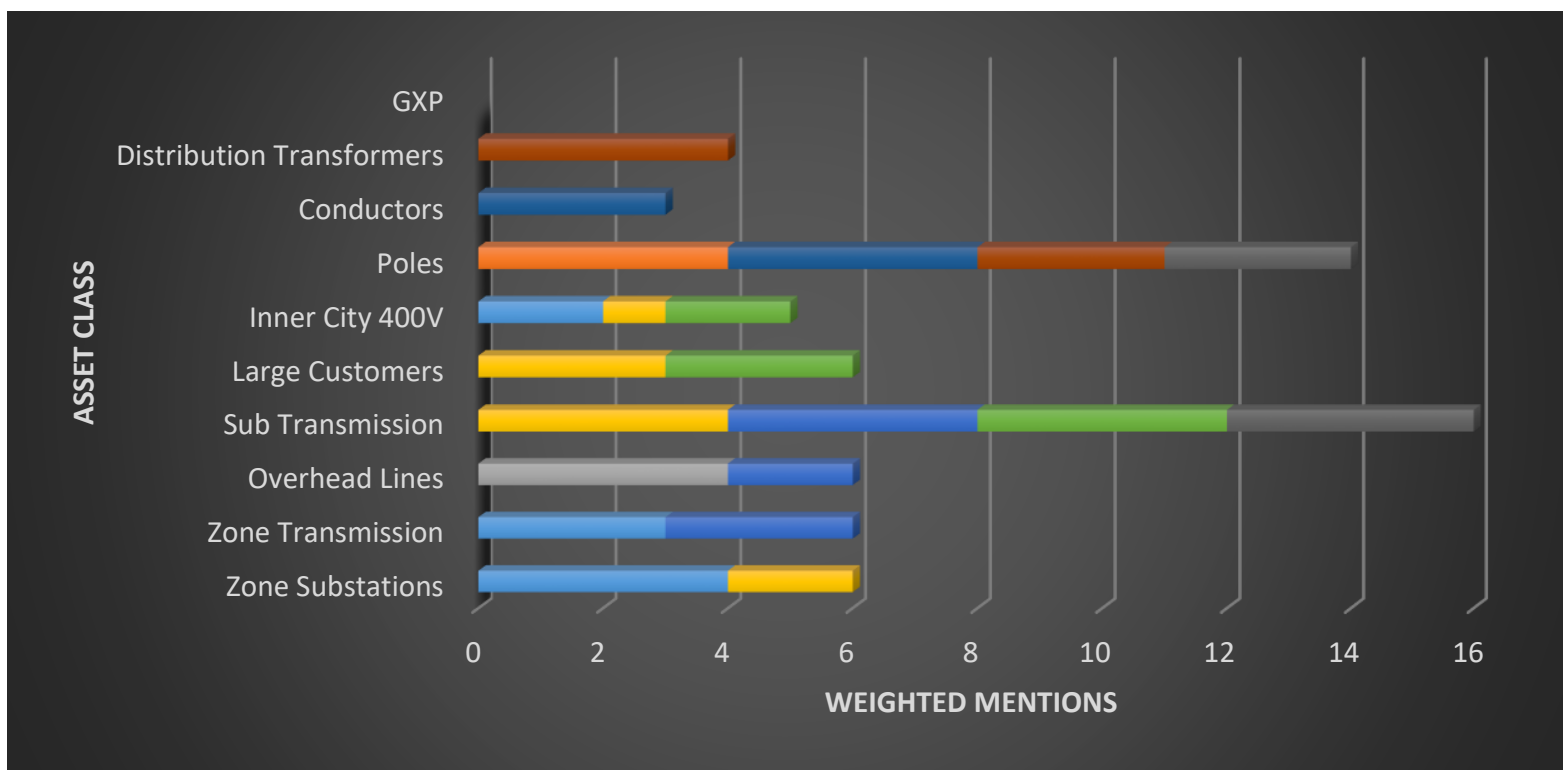

Figure 3.3. Highest priority assets at A, weighted values, stacked bar chart.

Table 3.4.

Weighted Asset Class Importance Data at B.

Participant

\begin{tabular}{|r|c|c|c|c|c|c|}
\cline { 2 - 7 } \multicolumn{1}{c|}{} & B1 & B2 & B3 & B4 & B5 & Totals \\
\hline GXP & & & 4 & & & 4 \\
\hline Distribution Transformers & & & & & & \\
\hline Conductors & & & & & & \\
\hline Poles & 3 & & & 2 & & 5 \\
\hline Inner City 400V & & & & & & \\
\hline Large Customers & & & & & & \\
\hline Sub-transmission & & & 3 & & 3 & 6 \\
\hline Overhead Lines & 4 & 4 & & 3 & 4 & 15 \\
\hline Zone Transmission & & & 2 & & 2 & 4 \\
\hline Zone Substations & & & 1 & 4 & & 5 \\
\hline
\end{tabular}

\subsubsection{Data by asset classes}

For the second pass at this data, the assets are grouped into classes. For example, subtransmission is split between conductors (overhead lines) and poles as this segment of the network consists of these smaller elements. Zone transmission which supplies the inner city $400 \mathrm{~V}$ network via distribution transformers is also split in this way. The 400V network immediately prior to consumers is also included in this grouping due to participants indicating that the main concern here is when this is provided through overhead lines suspended from poles. 


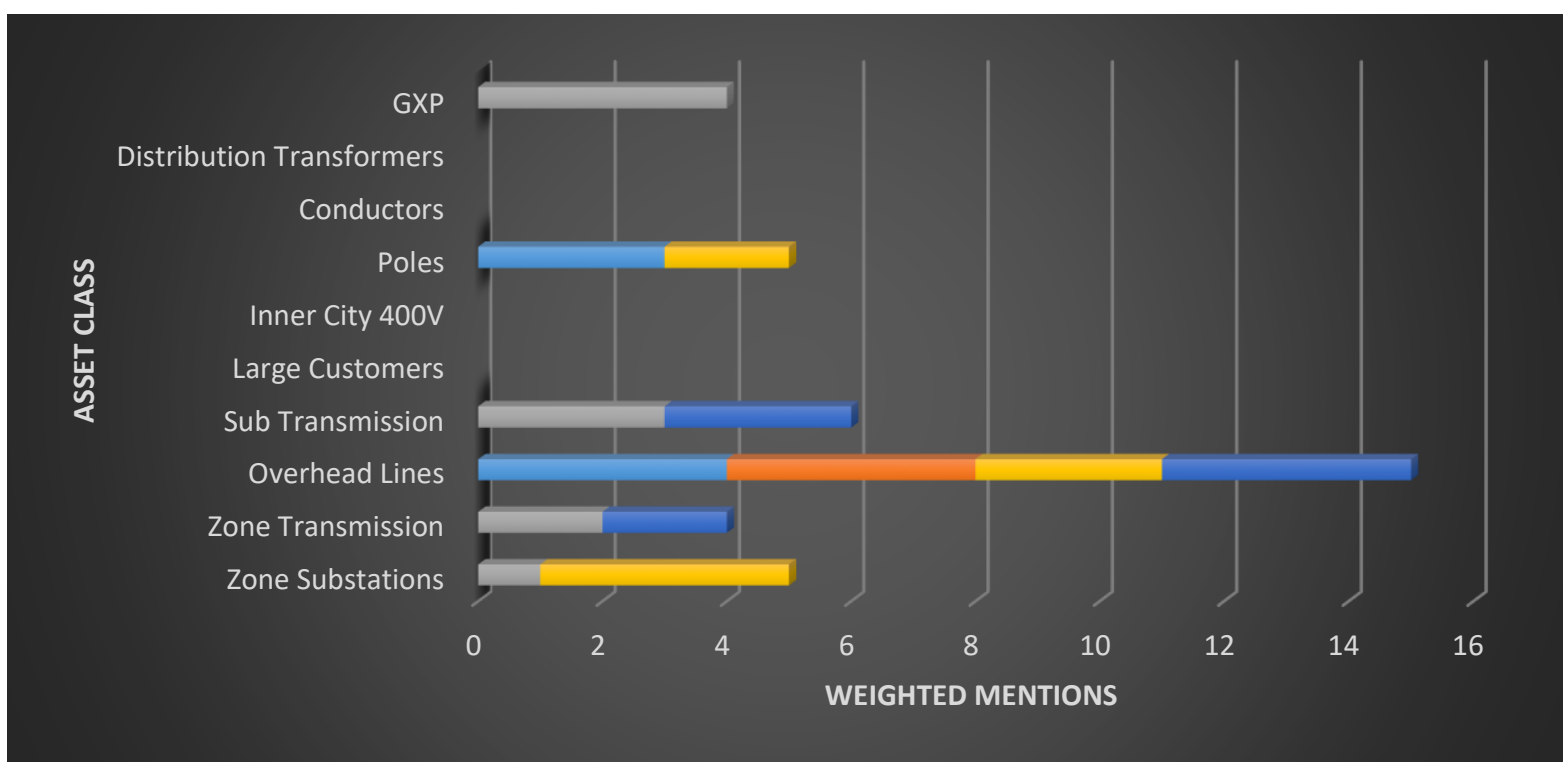

Figure 3.4. Highest priority assets at B, weighted values, stacked bar chart.

Although this may appear to be simplistic, it is designed to exaggerate the areas of concern to discover if the raw data and reclassified data produce essentially the same results. Distribution transformers are left separate as the concern for these comes from their public accessibility when ground mounted (it should be noted here that these also form part of the $400 \mathrm{~V}$ network). The result of this manipulation is tabulated below in Tables 3.5 and 3.6, and displayed graphically in Figures 3.5 and 3.6. The weighting system as used in the first example has been retained in this case for consistency. Additional iterations of this concept were also tried without the weighting however these resulted in similar distributions among the asset classes and were therefore deemed unnecessary for inclusion here, providing no further insights.

Table 3.5.

Consolidated Highest Priority Assets at A.

\begin{tabular}{|c|c|c|c|c|c|c|c|c|c|c|c|}
\hline & \multicolumn{10}{|c|}{ Participant } \\
\hline & & A1 & A2 & A3 & A4 & A5 & A6 & A7 & A8 & A9 & Totals \\
\hline \multirow{6}{*}{ 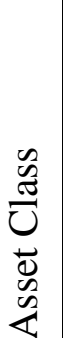 } & GXP & & & & & & & & & & 0 \\
\hline & Distribution Transformers & & & & & & & & 4 & & 4 \\
\hline & Poles & 3 & 4 & & 3 & 3 & 4 & 4 & 3 & 4 & 28 \\
\hline & Large Customers & & & & 4 & & 4 & & & & 8 \\
\hline & Overhead Lines & 3 & & 4 & 3 & 4 & 4 & 3 & & 3 & 24 \\
\hline & Zone Substations & 4 & & & 1 & & & & & & 5 \\
\hline
\end{tabular}




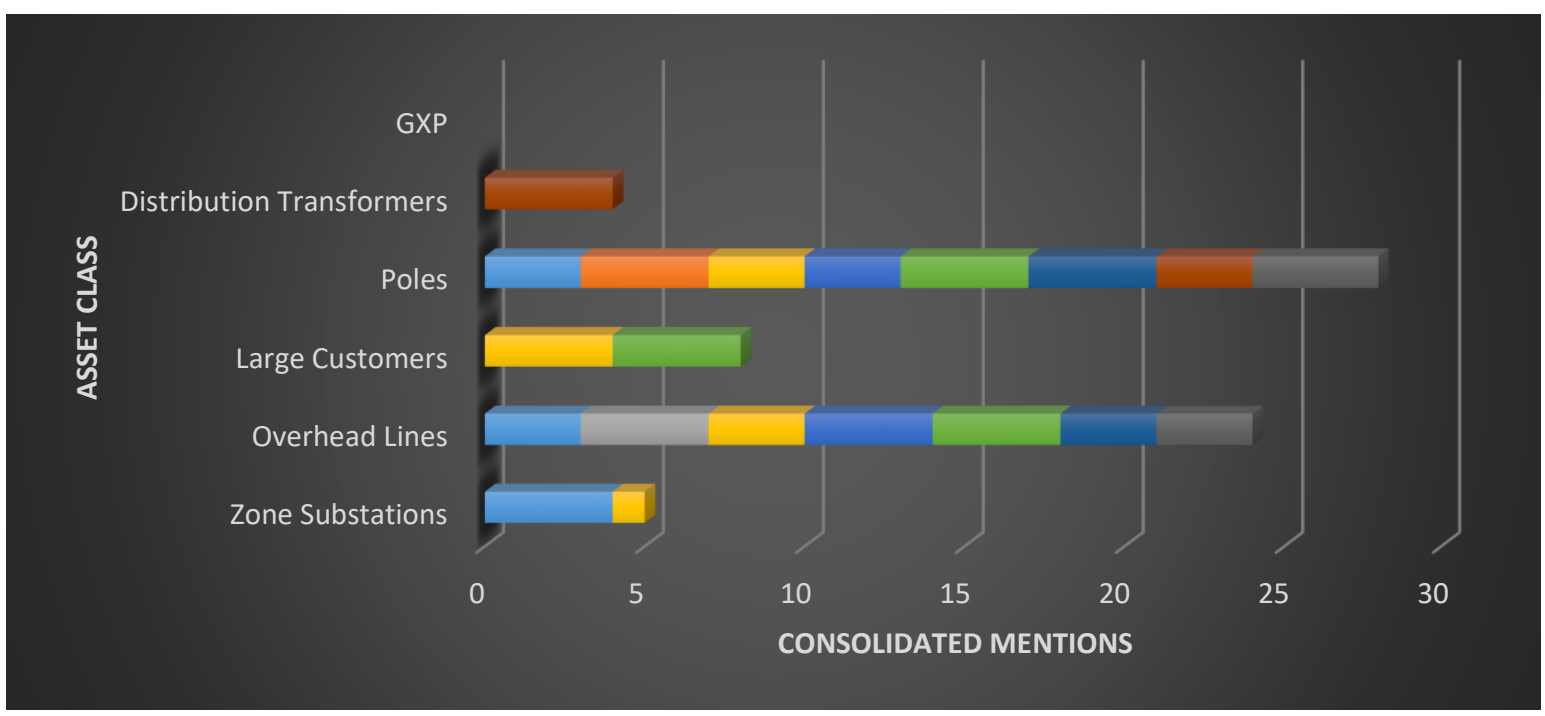

Figure 3.5. Consolidated highest priority assets at A, stacked bar chart.

\subsubsection{Analysis of importance data}

From the amplified charts it is clear that the area of sub-transmission appears to be of greatest concern at A followed closely by poles. If we then consider collectively the components that make up the sub-transmission system, that is conductors (also called overhead lines in clarification), line hardware and fittings and poles, this area of concern becomes even stronger. From the data it can be inferred that the primary focus of A was in poles associated with subtransmission, thereby making a tool capable of analysing these of interest for the MVP. The reasons given for the concern with poles were the high number of aged wooden poles remaining on A's network with many in remote areas, with A6 stating, "I use the GIS data to age profile, just to check that a row of poles tested as poor are actually $40,50,60,70$ years old."

Participants from B however show a stronger focus on the overhead line class. As mentioned above, this is also a significant component of the sub-transmission system. The main concern expressed here came from where these assets are highly visible to the public, with B2 stating in relation to condition "Personally again would be our overhead assets, purely because of the quantity, visibility and impact ... we tend to have the overhead asset [which are] the older type of asset ...". Participants from B considered the condition of underground cables of less importance at this time due to the relative age of these assets, and also the lack of public visibility of these. B4 stated "most of the cables on the network have gone in in recent times" indicating that these cables were typically much newer than the overhead assets, hence were considered more reliable. As such, these were monitored through their impact on SAIDI, implying that they only attract focus from the business when a fault occurs. 
Table 3.6.

Consolidated Highest Priority Assets at B.

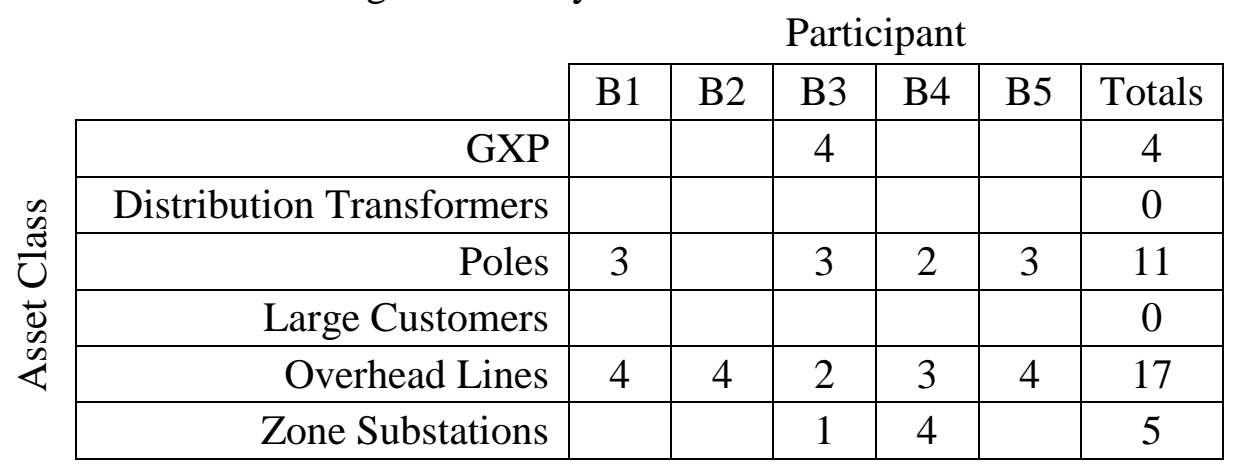

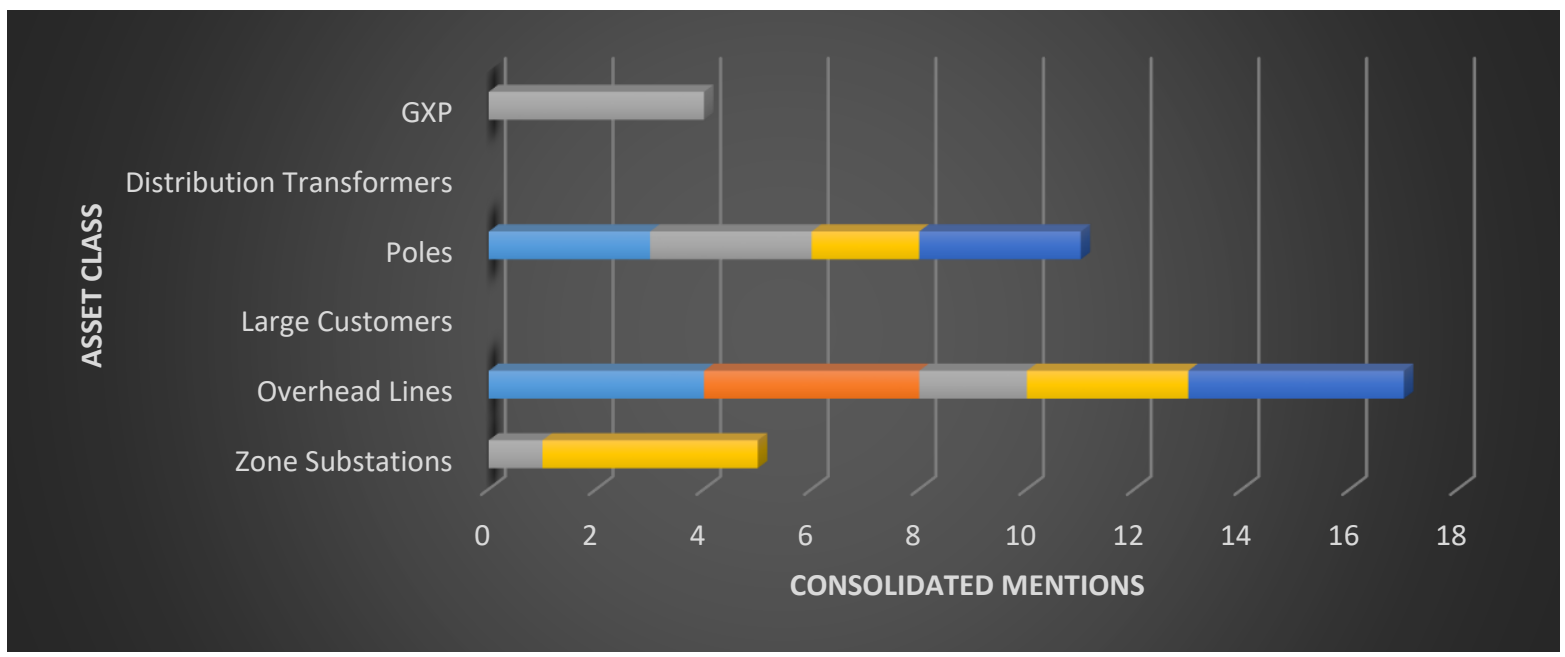

Figure 3.6. Consolidated highest priority assets at B, stacked bar chart.

From this analysis it becomes very clear that a tool focussing on improving the situation around overhead lines and poles has potential to be quite valuable. Participants from both EDBs expressed a strong concern in both of these areas, with A closely split between poles and overhead assets, and B leaning towards the overhead lines specifically. This focus from the interview participants indicates that the MVP for the IADT might be best to target the areas of overhead line integrity and pole integrity. Six participants mentioned that the overhead assets are traditionally very challenging to assess with A9 stating "We record it from the ground, and all you can see is if it's rusting, so we know nothing." Pole integrity was of particular concern to A, primarily due to their having 40,000 wooden poles which they were in the process of replacing, currently at a rate of 1300 poles per year. This pole replacement project was mentioned by six participants during the course of the discussions at this EDB, however concern was expressed as to whether or not this process was correct, with A6 stating "I believe 
we're replacing a lot more assets than we should be, they're not at end of life..." indicating potential for an accurate assessment tool to have significant value. Concern was also expressed around the ability of those tasked with inspections, and the quality of the data, with A1 stating “..., we would like inspections done by a dedicated group of people so that you have that consistency" and from A3 “..., you go and find out that some poles that are rated poor, the designers rate as okay, and vice versa happens."

The data from A and B were combined both in raw form and in the asset class form to highlight the areas of most concern, and this is displayed in the charts of figures 3.7 and 3.8 respectively.

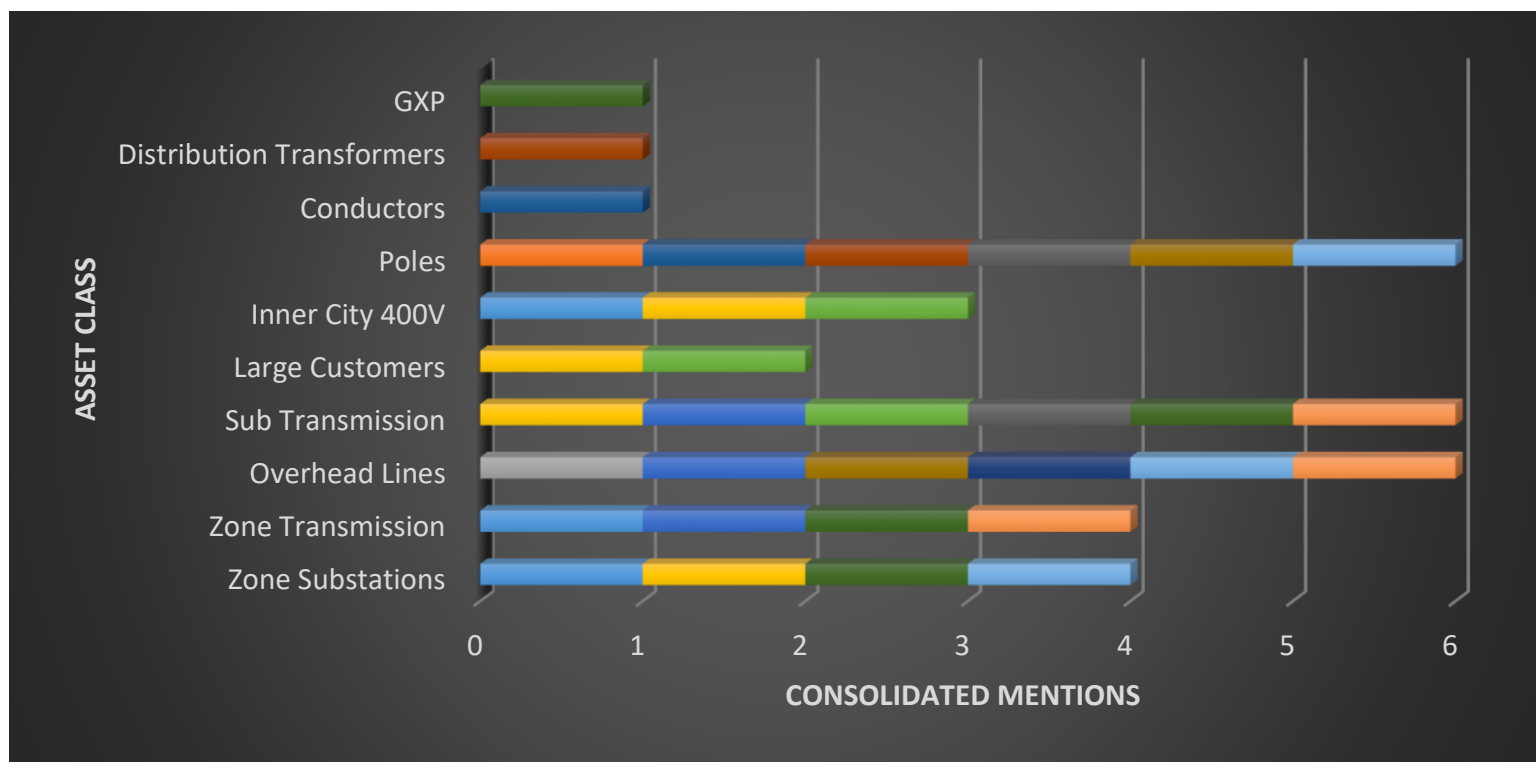

Figure 3.7. Combined asset class importance rating, raw values.

It can be seen from the combined plot that the previous hypotheses in regard to components worth targeting for the MVP is intensified towards sub-transmission, overhead lines and poles. This is borne out in both the weighted and raw analyses. It has been previously noted that subtransmission is made up primarily of poles and overhead lines, and as such these two asset classes appear to be the best candidates for the initial IADT to be focussed on. It is worth noting that this focus would also deliver analysis capability for zone transmission, which is also highly ranked, as this too consists of these two major asset classes.

In addition to the above assets, Zone substations were mentioned frequently as being of high importance within the network. This importance comes from these substations being high value assets, and critical for feeding the consumer network with power. Due to this well recognised high importance, coupled with the relative ease at which these can be accessed, thirteen participants indicated that these assets are generally well attended to by the EDBs. 


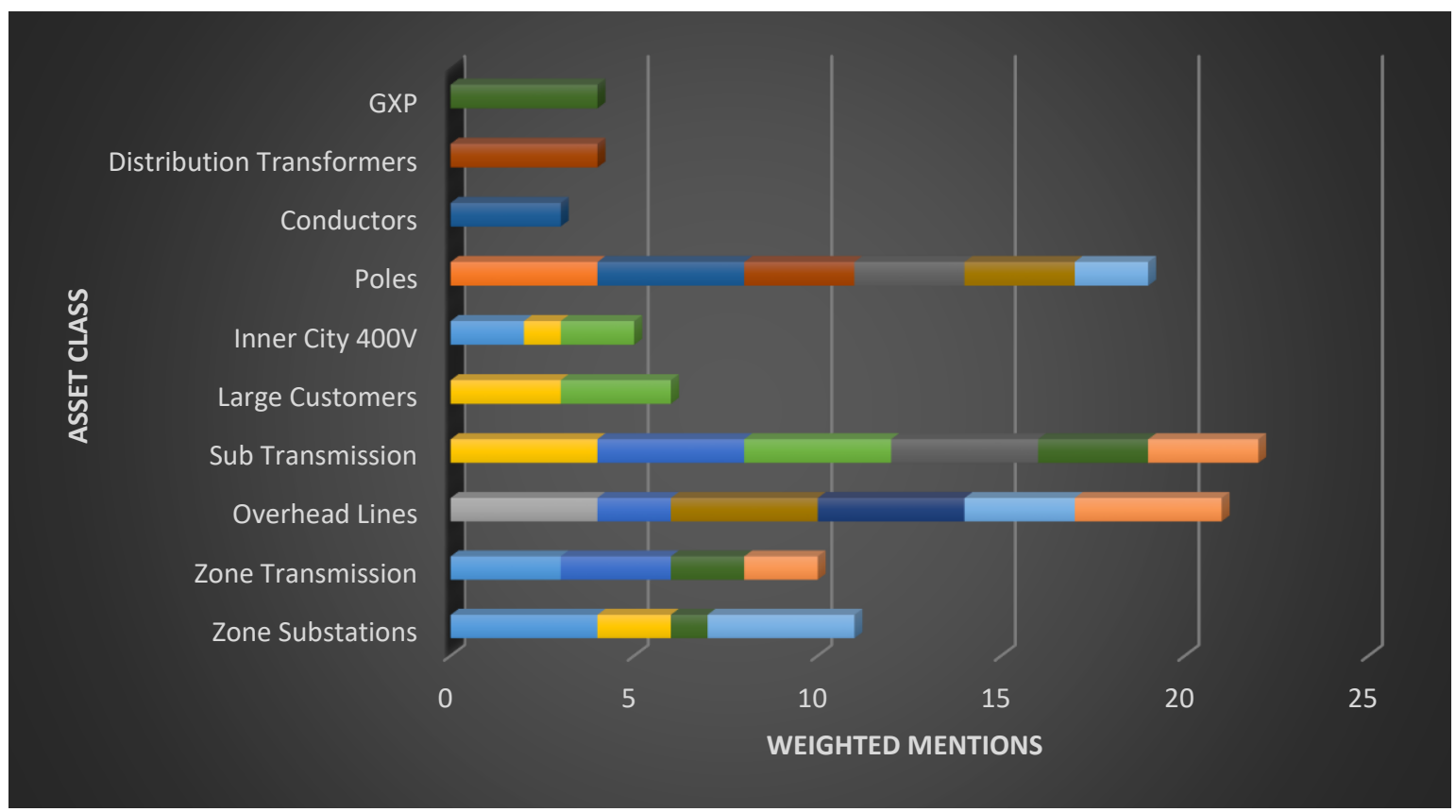

Figure 3.8. Combined asset class importance rating, weighted values.

\subsection{Asset condition knowledge confidence}

The next area plotted was the qualitative view of the knowledge of the condition of the infrastructure assets within the networks as held by the participants. The participants were asked to rate from 1 to 5 each asset class within their network as shown in table 3.7.

Table 3.7.

Condition Knowledge Ranking System.

\begin{tabular}{|l|l|}
\hline 1 & Not recorded \\
\hline 2 & Recorded but unsure of accuracy \\
\hline 3 & Recorded \& accurate (as best known) \\
\hline 4 & Highly confident in terms of all data relating to the asset \\
\hline 5 & Data resides in the appropriate repository and is $100 \%$ accurate for all attributes \\
\hline
\end{tabular}

From this ranking system it can be seen that a score of less than 3 has potential to result in issues during maintenance or replacement of these assets. Note also that not all interviewees gave a rating for every asset class. This was due to them not wishing to comment on this status as it was outside of their area of influence. 


\subsubsection{Raw condition knowledge data}

The collected data are presented in raw form below in tables 3.8 and 3.9 and figures 3.9 and 3.10 for each distributor respectively. Where multiple responses were given for a single asset class being used in different applications, a mean value has been used in this analysis.

Table 3.8.

Knowledge of Asset Condition at A

\begin{tabular}{|c|c|c|c|c|c|c|c|c|c|c|c|c|}
\hline & \multicolumn{11}{|c|}{ Participant } \\
\hline & & A1 & A2 & A3 & A4 & A5 & A6 & A7 & A8 & A9 & Totals & Min. \\
\hline \multirow{9}{*}{ 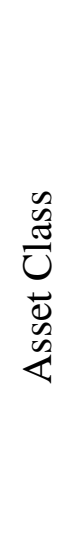 } & Substations: & 3.5 & 4 & 3.5 & 4 & 5 & 4 & 3 & 4 & 4 & 35 & 27 \\
\hline & Cross-arms: & 3.5 & 2.5 & 2.3 & 3 & 2 & 2.5 & 2.5 & 3 & 1 & 22.3 & 27 \\
\hline & Poles: & 3.5 & 2.5 & 2.5 & 2 & 4 & 2 & 2.5 & 2 & 2 & 23 & 27 \\
\hline & $\begin{array}{r}\text { Line Hardware \& } \\
\text { Fittings: }\end{array}$ & 3.5 & 2.5 & 2 & 1 & 3 & 1 & 1.5 & 1.5 & 1 & 17 & 27 \\
\hline & Switch Gear: & 3.5 & $\mathrm{n} / \mathrm{a}$ & 3 & 2 & 4 & 2.5 & 3 & 4 & 3.5 & 25.5 & 24 \\
\hline & Insulators: & 3.5 & 2.5 & 2 & 1 & 3 & 0.5 & 2 & 2 & 1 & 15.5 & 27 \\
\hline & Transformers: & 3.5 & 4 & 2.5 & 3 & 3 & 3 & 2.5 & 4 & 3.8 & 29.3 & 27 \\
\hline & Cables: & 3.5 & $\mathrm{n} / \mathrm{a}$ & 3 & 3 & 1 & 2.5 & 1.5 & 4 & $\mathrm{n} / \mathrm{a}$ & 18.5 & 21 \\
\hline & Conductors: & 3.5 & $\mathrm{n} / \mathrm{a}$ & 2 & 3 & 2 & 1 & 1 & 4 & 1 & 17.5 & 24 \\
\hline
\end{tabular}

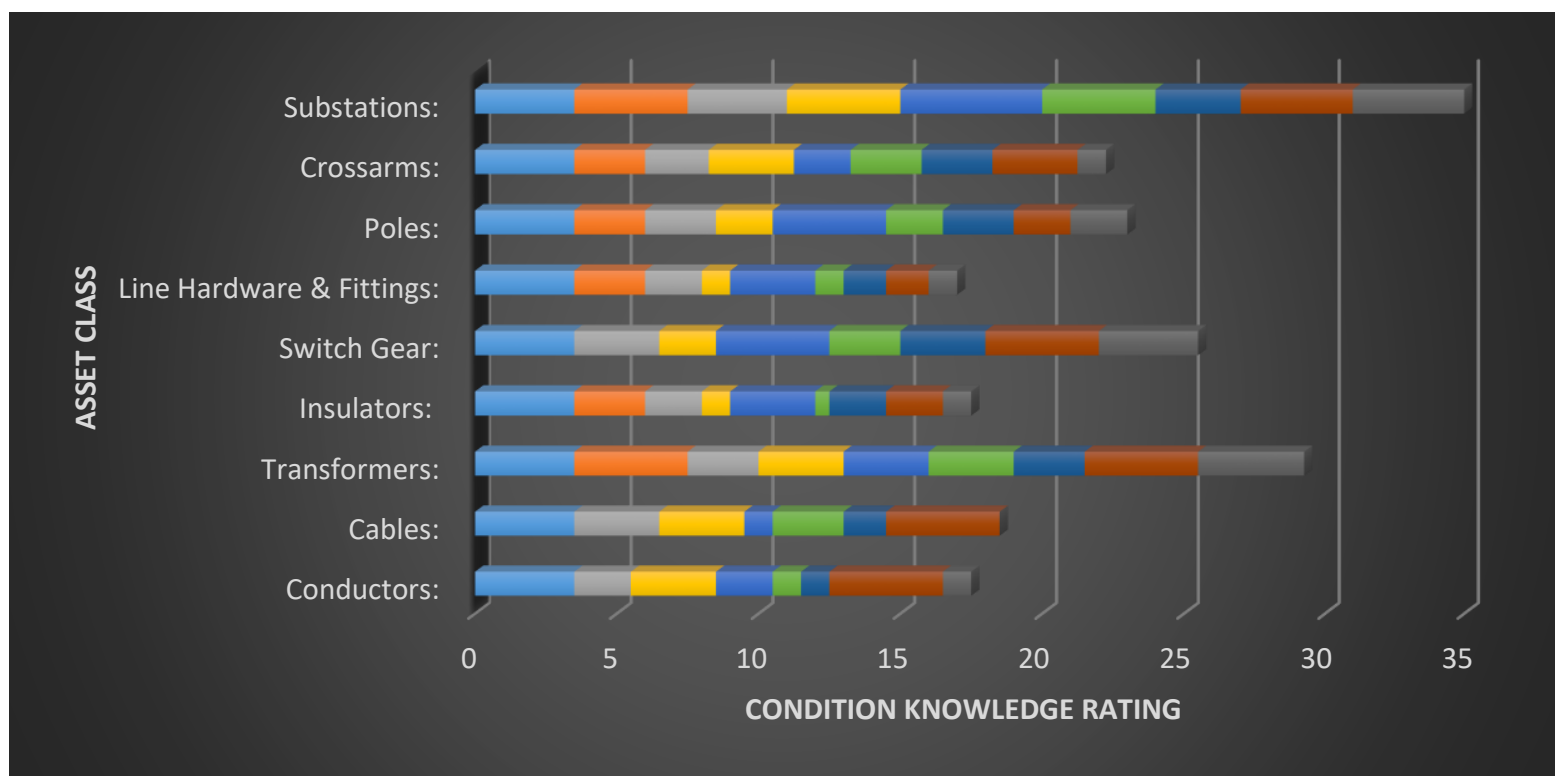

Figure 3.9. Knowledge of asset condition at A.

\subsubsection{Analysis of condition knowledge data}

From figure 3.9 for $\mathrm{A}$, the confidence in condition knowledge can be seen to be highest for substations, switch gear and transformers whereas the lowest confidence in condition exists for line hardware and fittings, insulators and conductors and cables. This reflects the value density 
and traditional accessibility of these types of asset. Table 3.9 gives the same assessment but for B. It is interesting to note that the general theme is similar, albeit with smaller deviation. It can be seen that an overall slightly higher confidence existed for cables within this organisation. Participants here have attributed this to relying upon the age of these and their impact on SAIDI to assess them. These cables are typically much newer than their overhead counterparts with B4 stating “... they're relatively new assets."

Table 3.9

Knowledge of Asset Condition at B.

\begin{tabular}{|r|c|c|c|c|c|c|c|}
\multicolumn{1}{c|}{} & \multicolumn{10}{c|}{ Participant } \\
\cline { 2 - 10 } \multicolumn{1}{c|}{} & B1 & B2 & B3 & B4 & B5 & Totals & Min. \\
\hline Substations: & n/a & 3 & 4 & 4 & 4 & 15 & 12 \\
\hline Cross-arms: & 2 & 3 & 3.5 & 3 & 3 & 14.5 & 15 \\
\hline Poles: & 3 & 3 & 3.5 & 3 & 3 & 15.5 & 15 \\
\hline Switch Gear: & 2 & 3 & 2.5 & 3 & 4 & 14.5 & 15 \\
\hline Insulators: & 1 & 3 & 3 & 2.5 & 3 & 12.5 & 15 \\
\hline Transformers: & 4 & 2 & 2 & 3 & 3 & 14 & 15 \\
\hline Cables: & 2.5 & 3 & 1 & 4 & 3 & 15.5 & 15 \\
\hline Cine Hardware \& Fittings: & 1 & 2.5 & 3 & 2.5 & 3 & 12 & 15 \\
\hline \multirow{2}{*}{$\underset{\sim}{4}$} & 3.5 & 3 & 1.5 & 2 & 3 & 13 & 15 \\
\hline
\end{tabular}

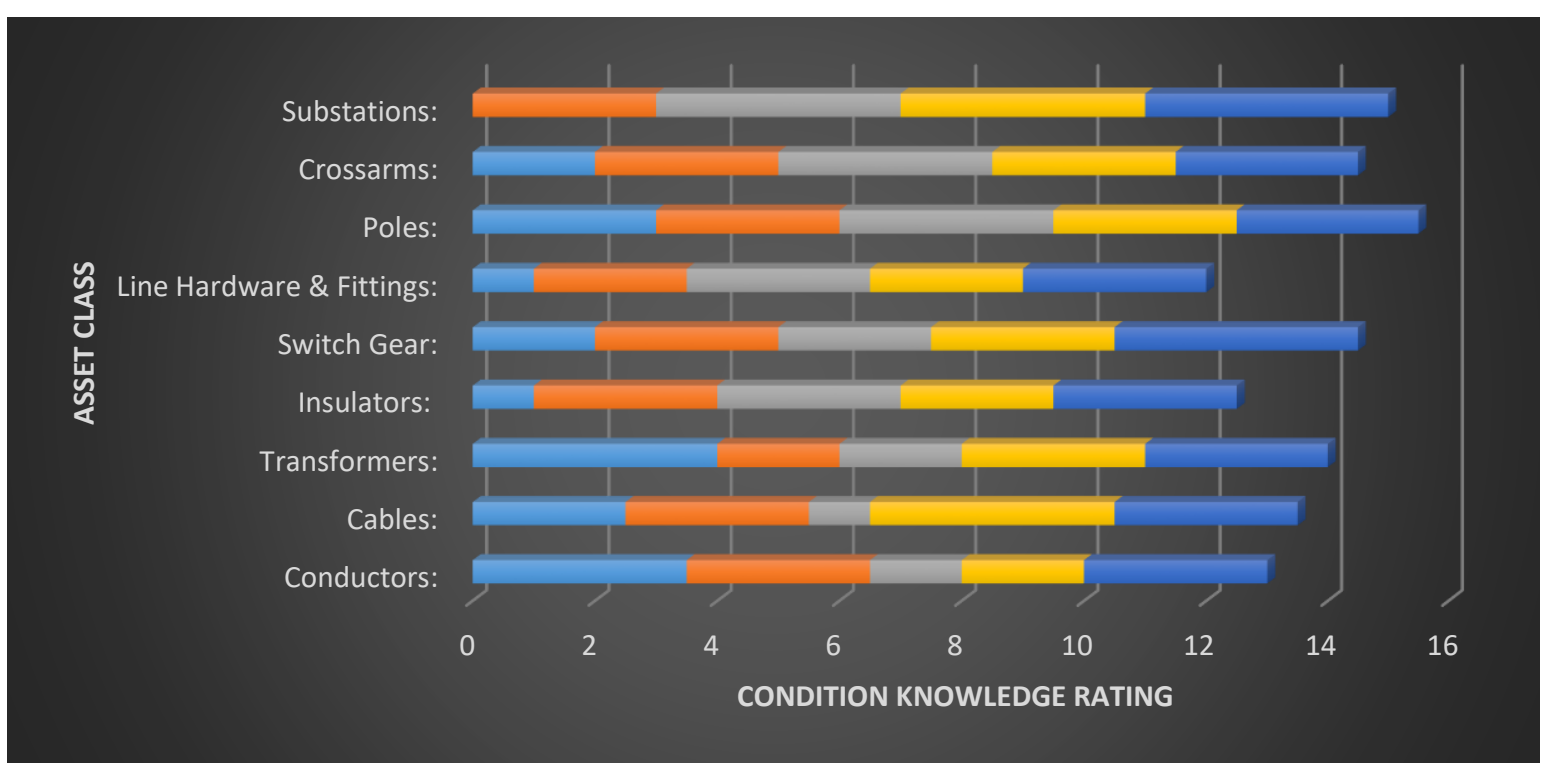

Figure 3.10. Knowledge of asset condition at B.

Four participants have attributed the lack of knowledge surrounding conductor condition to the lack of a traditional way in which to monitor this parameter, and have indicated that poor 
accessibility also plays a role. These issues were also stated to plague insulator and fitting hardware leading to a similarly low condition knowledge confidence. A suitable technology for measuring the condition of these asset classes could add significant value to the proposed IADT, and could therefore be considered for the MVP.

It can also be seen that the knowledge of the condition of the poles on each network is moderate, which is not to say that they do not need closer scrutiny. In the case of wooden poles, the technology typically used to assess their condition was somewhat archaic, that is hitting them with a big hammer, listening to the response and observing visual behaviour, with A1 referring to this as the "hammer test" and "ear meter." A9 stated "The thing with poles is, we've done R\&D on pole breaking for, I don't know how many years. Are we using it in the field? I don't think so." It should also be noted that the knowledge of pole location, which was said to be very good by all participants, may have influenced the condition value reported in cases where the participant rolled the value together. When looking at the raw figures, any rating below 3 should give rise to concern around the condition of that asset, and options to resolve this lack of confidence would be worthy of investigation.

A8 and A9 explicitly stated that condition data from transformers is being collected, specifically through dissolved gas analysis (DGA) testing, and has been for a number of years. Whilst vast amounts of data have been collected, this has not necessary been utilised in the best possible manner and as such little real value has been derived from it. If this data could be utilised to form a picture of a network of transformers, it is conceivable that it could also be used to predict potential failures when a given set of parameters occurs, and this thought has been reiterated by other participants. This represents an unexploited opportunity within the industry locally, and therefore has potential to add value to the IADT.

\subsection{Value of accurate condition assessment and criticality}

Another aspect to consider is the criticality of a given asset, that is how much impact the failure of said asset has on the network. Data of this nature has already been assigned by at least three EDBs within New Zealand (A4, A9, interviews, 2016) and this could provide an excellent source of information for a predictive engine to utilise. If an effective tool for infrastructure asset diagnostics is to be developed, the criticality should also form part of the overall assessment. Poles in remote areas feeding small facilities for example would have less value than poles feeding a high value region such as a town centre. The cost of replacing each pole however would be similar, at least so far as materials and direct labour costs are concerned, 
although it should be noted that poor accessibility can significantly increase the cost of the total operation (MLL, AMP 2016). Criticality was also used in both the FIM at Toronto Hydro, by Bentley Systems with their asset health indexing, and forms a part of the ISO 55001 standard (Di Matteo, 2015), indicating that this component of asset assessment is considered good practice by the wider industry.

Replacing a pole has been costed at an average of approximately $\$ 4,500$ each (A6, interviews, 2016), hence when considering a total network of 266,000 poles, as is the case for A, these can be considered collectively as a substantial asset. A would like to assess 40,000 wooden poles, however their current approach is to simply take whole feeders and replace every pole, ensuring that no unsafe poles are left standing. During the interviews it has been stated that on average, using this method, 40 of 100 poles need not be replaced (A6, interviews, 2016). At the current replacement rate of 1,300 poles per year for A's blitz programme, that error rate equates to $\$ 2.34$ million wasted per year on unnecessary replacements. It should be noted here also that the target rate of replacement for this business was 3,000 poles per year which would increase potential savings proportionally. This waste is a very strong indicator that the if IADT could incorporate an accurate pole testing facility it could add immediate value to A, making pole testing a very good candidate for inclusion in the MVP.

In the 2016 EEA presentation from Pattie and Silk a vendor sample of 199 poles were assessed using both traditional methods and the particular vendor's tool, an ultrasonic testing device. The traditional methods indicated forty-nine of these would require replacement whereas using this particular tool, only four poles were flagged for replacement. This result indicates that through the use of appropriate technologies, the poles requiring replacement could theoretically be reduced to about $10 \%$ of the level that would be required under traditional methods. However, a number of different diagnostic tools were compared in the study of Pattie and Silk (2016) with varying results from each. Pattie and Silk (2016) concluded that in order to achieve the desired accuracy and safety, multiple currently available diagnostic products would be required. They also concluded that due to the variability in the results from the different tools tested, skilled technicians would still be required to subjectively assess the poles. If a single tool could be made which could deliver consistently accurate pole assessments, it would be able to replace the currently available competitor tools. This reiterates the desirability of this feature for the IADT and would provide a strong point of difference from the current competition. 
In relation to overhead line hardware, multiple respondents have indicated that this has been traditionally challenging to accurately assess, not only for conductors, but also for insulators and joints, in fact some even stated that this assessment was impossible to achieve. Reasons given for this position were the combination of poor accessibility and lack of suitable technology for assessing the condition, or current state of degradation. This has subsequently led to this hardware being replaced either after failure or during other maintenance only if significant defects had been noticed during a nearby inspection. This approach has a particularly undesirable impact on the network due to its effect on SAIDI and SAIFI. This is a strong indication that providing an assessment capability here would be a valuable addition to the IADT and should be considered as a potential feature for the MVP. This study has discovered that tools for monitoring certain parameters these asset classes do exist and hence can be considered for assessment for the IADT. Being able to cater for this previously untapped market could add significant value to the IADT, allowing a reduction in unplanned SAIDI minutes, currently costed at $\$ 72,000 / \mathrm{min}$ (A7, interviews, 2016).

\subsection{Impact upon public safety}

Mention needs also to be made of the public safety aspects of this project. Six participants commented on this aspect in relation to assets which exist either in close proximity to the public, or where a failure would endanger the public. There was a prevailing feeling that overhead lines and the poles supporting them needed to be very robust as failure of these could seriously endanger the public. An example of the proximity concern comes on the $400 \mathrm{~V}$ network with the ground mounted transformers, which are deemed to be a potential public safety issue. Because these can be easily accessed by the public, any fault which enlivens their cases could be deadly. Fortunately, this risk has been well identified historically, and measures to mitigate this risk are well established across the EDBs. This makes these assets of less interest for the IADT at this early stage.

While concern for these transformers is limited to their proximity to the public, the overhead lines and poles are of greater concern due to the lack of accurate knowledge of the types in service and the condition of these. These latter two issues did not apply to the transformers as they are generally well serviced. This status is reflected within the high condition confidence index for these derived from the interview data, with many participants stating that they were happy with these. In contrast to the transformers, the inadequate knowledge surrounding the condition of both poles and overhead conductors is of considerable concern as when these fail 
there is not only an immediate impact on SAIDI and SAIFI, but also an extreme danger to the public. There was a strong desire to be able to assess these highly visible assets more effectively prevailing throughout the interviews. The types of poles and conductors in use at A was a large unknown due to the inherited nature of their network, with fragmented prior information. Improving data around this issue was stated to be of great value for assessing the validity of maintenance activities.

Also gleaned from the interviews was an overall strong sense of responsibility for ensuring public and staff safety around the distribution assets and as such any improvement in the confidence in asset integrity would be desirable. Measures relating to network reliability were also mentioned by six participants. Issues raised of importance to this study were that insufficiently experienced staff were currently being used for infrastructure assessment operations, particularly where this work was subcontracted to third parties. This was seen to be an increased risk to SAIDI as well as a potential risk to the public.

\subsection{Current Behaviour of Distribution Businesses}

A number of questions (included in Appendix A) were posed to determine the attitude to asset management within the company, how much data they tracked and whether or not this was considered good enough for their purposes.

\subsubsection{Asset management responsibility}

The prevailing attitude within A was that responsibility for asset management fell directly with the asset management group (A2, A4, A7, A8, A9, interviews, 2016). Four participants stated that this was the responsibility of everyone in the company as it defines the company purpose, with A6 stating that "everyone held stewardship" over the network assets.

For B the overall impression given to the researcher was that everyone within the company has responsibility for effective management of the assets, with all five B participants stating something to this effect. They did however have dedicated teams for particular asset classes to ensure that each asset class was sufficiently well looked after. The prevailing attitude was still that the responsibility was everyone's.

\subsubsection{Current data capture capability}

It was good to discover that both organisations had well developed procedures for conducting inspections, with template driven data capture devices. These essentially directed inspectors to 
fill in a form with only a few fields for comments. It was stated by nine participants across both EDBs that the freeform fields were limited because of the inability to extract meaningful statistics from such comments, hence reducing the value of such. This limitation of subjective inputs from asset inspectors implies that the maintenance planning is heavily data driven, a hypothesis confirmed by A6 (interviews, 2016) when talking about asset maintenance planning, and A2 (interviews, 2016) referring to the same planning. All nine participants at A indicated that they felt their data capture tools were a bit limited and consistently expressed an interest in finding something better, and similarly, all five participants from B also expressed an interest in having a more comprehensive data collection tool as they felt their current solution was also limited.

\subsubsection{Insurance}

Distributors may carry insurance on large assets such as zone substations and indoor distribution substations, where the cost of a major failure could be in excess of $\$ 10$ million (A4, interviews, 2016). For lesser impact assets (or collections of assets) they often choose to self-insure (A2, A4, A5, B4 interviews, 2016), that is simply carry the risk of failures and pay for the consequences of these. Information as to the level of this cost was unavailable or not recorded as such. There are also cases where a distributor might negotiate to opt out of liability for power grid failure with a particular consumer, usually a larger entity (B4, interviews, 2016).

\subsubsection{Pressure to comply with the Commerce Commission}

Spending controls imposed by the Commerce Commission limit the amount of money which these regulated monopolies can pass on to the customers, hence limiting how much they can invest in network infrastructure in a given year. A9 (interviews, 2016) stated within the context of allowable spend based upon Commerce Commission regulations "Any efficiency improvement is a good thing ... because we haven't got enough money, we haven't got enough OPEX."

\subsection{Business Model Development}

The proposed business model for the IADT has been laid out by the researcher on a Strategyzer.com BMC since the early days of the study. At the time of writing, this had progressed through seven iterations during the research, of which the three main stages are 


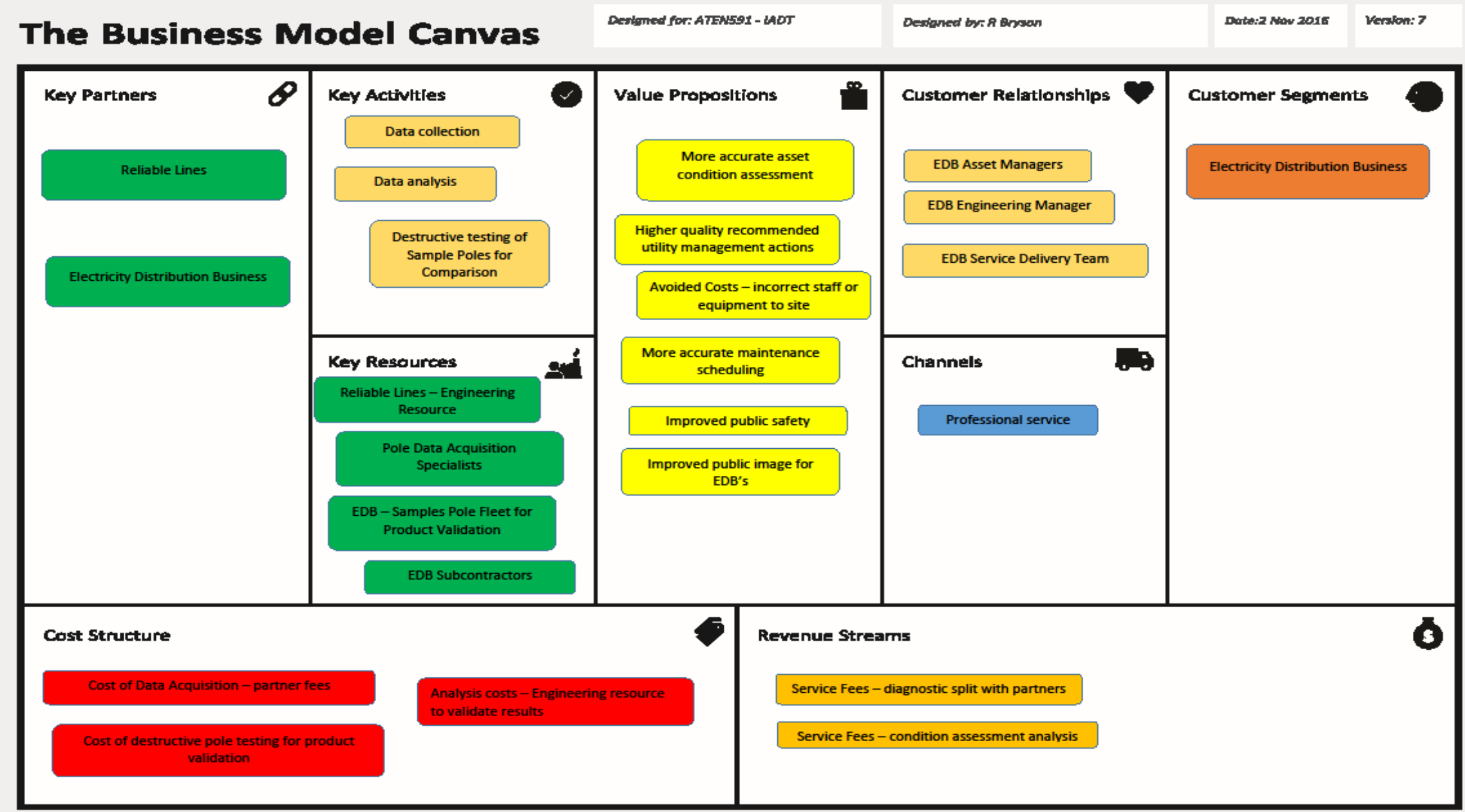

() (1) (1) $1=$

Figure 3.11. Business model canvas for MVP. 
included in Appendix $\mathrm{C}$ illustrating the development of the BMC. The original research proposal for the study included the forth iteration of this model which has had only minor changes since. The current version seven for the MVP is included in figure 3.11 as well. The main differences to be noted in the current version of the BMC when compared to previous ones is that it contains fewer stakeholders and clearer value propositions. This simplification of the business model reflects the nature of the MVP targeting a very specific issue in the marketplace rather than trying to encompass the entirety of this. Although seven is a relatively low number of iterations when compared to some other new enterprises (Blank \& Dorf, 2012), however, this is most likely due to a very clearly defined target market derived by Electropar from actual sales within the industry, information which was explained to the researcher prior to commencement of the project.

It is worth noting that the MVP canvas also has a reduced number of channels when compared to earlier BMCs. This reduction is desirable at this early stage to improve control over the product and its deployment, allowing focus to fall on maximising the initial benefits rather than fighting fires on multiple fronts. Limiting the channels will tend to reduce the overall impact of the product on the complete business system as the MVP is a highly focussed variant, designed to generate value for the end user quickly.

Looking further at the MVP canvas, we can see that the initial customer is used as a resource for product validation and as such is also included within both the partner and resource fields. This multiplicity of roles is due entirely to the customer owning the target assets of the IADT, in this case, the wooden poles. Also attached to the customer are their subcontractors. These are shown as they may be used in the removal of the poles after testing by the IADT and hence liaison with them may be required. Although this operation is strictly not part of the normal IADT business process, it is included as it is very important to have genuine validation of the tool, especially in an environment populated by competitor products delivering inconsistent results (Pattie \& Silk, 2016).

The value propositions at the centre of the MVP canvas should draw strong interest, and particularly the bottom one, an improved public image for the customer. This value proposition was added after a need analysis diagram was derived from the features of the tool. This diagram is included in figure 3.12, in which the brand image of the company can be seen to have the most arrows in and out, in this case eight. 


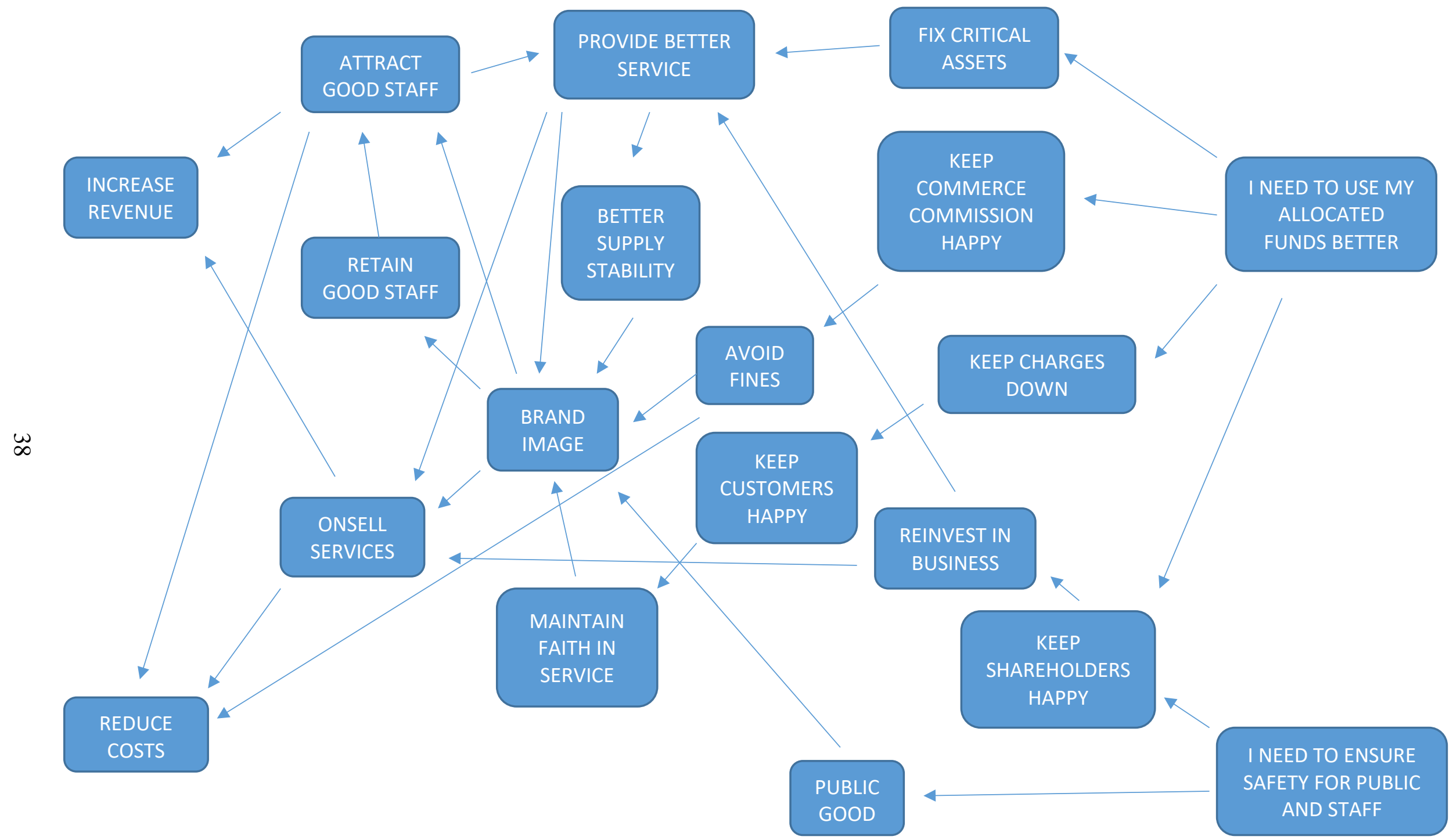

Figure 3.12. Need analysis map. 


\subsection{Technology Providers}

It is worth adding here the findings from direct communication between the researcher and Reliable Lines, the primary technology provider to Electropar for the IADT. The researcher had assumed at the outset that this tool was something yet to be developed by Electropar, and to a certain extent it is. Electropar provide the glue, bonding a number of third party technology providers together to enable the development of a comprehensive toolset for asset assessment, with Electropar providing the direct conduit to the EDBs. However, Reliable Lines have already developed and successfully tested a stand-alone tool which is capable of accurately determining the remaining strength of a given wooden (or concrete) pole based upon the pole's initial strength and installed environment. The process for this analysis is quite simple, but must be done correctly and as such they use a specific contractor for this task which aligns with a particular business model. The residual strength of the pole is determined by firstly installing the piezoelectric sensors that measure the pole integrity into the pole surface, ensuring that the outer sap layer is penetrated (necessary for some Australian hardwoods). The sensors are then tapped sequentially with a small mallet causing a response to occur in the other attached sensors. The data from these sensors is sent to Reliable Lines' Pole Tester software and a series of algorithms embedded within this software calculate the effective cross section of the pole. The system is driven by dropdown menus where the technicians select the type of wood that the pole is made from and enter the other parameters as prompted. This information is then combined with the measured data to calculate the residual pole strength as a percentage of original strength.

To complement this tool, Reliable Lines have also designed a Pole Designer application which takes the installation conditions for a given pole, then calculates the most optimal pole to use in the particular location. These tools can be used together to provide asset replacement strategies for poles, including concrete poles where the piezoelectric sensors are not utilised with instead the required input data coming from physical inspection. On top of this, the LiDAR information from Point Geodata has been added into the total analysis engine. This

information allows the loading on poles on a given feeder for example, to be calculated and in combination with the Pole Designer application, the total load on the pole can be determined. The job done by this particular tool is a very close match for a tool that was requested as an aside during the 2016 interview with A1, who stated "I'd like an application made to simplify overhead line design", followed by: 
Really we need an app that doesn't need proper designer input. In other words, what I'm thinking of, you've got a cell phone, it's got a location facility on it. You roll up to a pole and you put in what the spans are either side of it, you put in what the conductive material is, it's already worked out your location so it's known the windage parameters and all those things to apply. You give it an indication what you think the tension is in the wire, what angle is on that pole, and it will spit out the answer of what size pole you need there.

The result of these calculations is that from driving down a street and scanning the power lines, coupled with the assessment of the poles making full use of the Pole Tester and Pole Designer applications, the entire feeder can be assessed for conductor sag and remaining pole strength. Conductor sag, as the name suggests is determined from the current clearance between an overhead powerline and the ground. The clearance around foliage can also be determined and areas of concern flagged. These data sources have already been fully integrated by Reliable Lines to produce an effective assessment tool. Work is currently underway to find a suitable partner to provide an electromagnetic monitoring solution for the overhead line condition such as that provided by Exacter Corporation in the USA, which would then allow early warning of potential issues in conductors, line fittings and insulators. Once this technology is incorporated into the tool, the capacity will be available to scan an entire feeder and produce an accurate asset replacement or maintenance strategy, meeting a need identified by both A1 and A6 for F3 feeders (urban distribution lines) and the 400V network low voltage (LV) network coming from those feeders.

The described toolset sounds like a very close approximation to the IADT as proposed by Electropar at the outset of this study and as such appears to be an excellent collection of integrated tools to take to market. During the meetings with Reliable Lines and Electropar, the researcher was able to determine that they have already signed a contract to this effect. This does however mean that the assumption at the beginning in regard to the functional status of the IADT was incorrect, or at least by the time the researcher was able to speak to the relevant parties, the potential hurdle of whether the tool could be made to work has already been substantially overcome.

\subsection{Financial Viability Analysis}

To determine the financial viability or otherwise of the infrastructure asset diagnostic tool, information around costs and needs were gathered. These costs included amongst others, the 
actual cost of pole assessment with Pole Tester, what is currently being done, replacement cost for a pole and the number of poles in need of replacement per year to meet SAIDI requirements. Items of interest which arose were the current process being used to ensure pole integrity for adequate service delivery and safety to both staff and the public, the associated costs of this, and the other options which have already been explored by the distributors.

A distributor with a pressing need in the area of wooden pole replacement has been chosen as the example for this analysis. The information for this distributor which was determined from the interviews and from corporate publications is laid out in table 3.10. From these data additional values have been calculated based on assumptions of the researcher. These include the high cost pole assessment rate, assumed to be time dependent, and the available cash pool for pole replacement activities. It should also be noted here that the poles at this distributor are required to be assessed using the current techniques once every five years.

Table 3.10.

Provided Data around Wooden Pole Replacement and Assessment.

\begin{tabular}{|l|l|}
\hline Poles needing testing & 40,000 \\
\hline Current replacement error rate & $40 \%$ \\
\hline Replacement cost & $\$ 4,500$ \\
\hline Current replacement rate & $1,300 \mathrm{pa}$ \\
\hline Target replacement rate & $3,000 \mathrm{pa}$ \\
\hline Current OPEX & $\$ 29,268,000$ \\
\hline Pole assessment cost low & $\$ 50$ \\
\hline Pole assessment cost high & $\$ 100$ \\
\hline Pole assessment rate low cost & 30 poles/day \\
\hline Days available per year for assessments & 249 \\
\hline
\end{tabular}

The spreadsheet of figure 3.13 was built using the collated data with calculations for replacement costs, percentage of operating expenditure (OPEX), potential savings from assessment and additional pole replacement capacity due to potential savings per annum. The total cost per annum for pole assessment activities was assumed to be constant with the rate of pole assessment being the varying factor. This resulted in an average rate of pole 


\begin{tabular}{|c|c|c|c|c|c|c|}
\hline No. Wooden Poles on Network & 40,000 & & Pole Replacement Cost & $\$ 4,500$ & Current OPEX & $\$ 29,268,000$ \\
\hline Current replacement error rate & $40 \%$ & & Assessment Cost Low & $\$ 50$ & Calculated OPEX at Target level & $\$ 36,918,000$ \\
\hline \multirow[t]{2}{*}{ Days available for assessment pa } & 249 & & Assessment Cost High & $\$ 100$ & & \\
\hline & No. Poles Replaced (pa) & Cost of Replacements & $\%$ OPEX & $\begin{array}{l}\text { Potential Savings from Accurate } \\
\text { Assessment }\end{array}$ & $\begin{array}{l}\text { Extra pole replacement from } \\
\text { available funds }\end{array}$ & \\
\hline Current & 1,300 & $\$ 5,850,000$ & $20.0 \%$ & $\$ 2,340,000$ & 437 & 401 \\
\hline Target & 3,000 & $\$ 13,500,000$ & $36.6 \%$ & $\$ 5,400,000$ & 1,117 & 1,081 \\
\hline \multirow[t]{3}{*}{ Pole assessment per day } & 30 & & & & & \\
\hline & 15 & & & & & \\
\hline & Pole assessments pa & Cost pa & & & Increased assessment rate cost & \\
\hline Easy Access (e.g. roadside) & 7,470 & $\$ 373,500$ & & & $\$ 533,333.33$ & \\
\hline Difficult (e.g. over hilly farmland) & 3,735 & $\$ 373,500$ & & $\begin{array}{l}\text { Increase in testing capacity } \\
\text { required }\end{array}$ & & \\
\hline & & Time to assess (years) & 7.1 & $143 \%$ & & \\
\hline & & & poles pa & 1 st 7 years & Thereafter extra pa & $\begin{array}{l}\text { including } 5 \text { yearly } \\
\text { assessment cycle }\end{array}$ \\
\hline Time to replace all poles current rate & 30.8 & with assessment pa & 1,737 & 12,402 & 520 & 1,701 \\
\hline \multirow[t]{2}{*}{ target rate } & 13.3 & & 4,117 & 29,394 & 1,200 & 4,081 \\
\hline & & with pole test halt & & after 7 years & after 7 years & \\
\hline Time to replace faulty poles current & 13.8 & 13.4 & 1,820 & 11,598 & 6.4 & \\
\hline target & 5.8 & & 4,200 & $-5,394$ & -1.3 & \\
\hline \multicolumn{7}{|l|}{ Including 5 yearly assessment cycle } \\
\hline Time to replace faulty poles current & 14.1 & & & & & \\
\hline target & 5.9 & & & & & \\
\hline
\end{tabular}

\footnotetext{
Figure 3.13. Value of wooden pole assessments
} 
assessment being derived from the data. Calculations embedded within the spreadsheet are included in Appendix D.

The first information to be calculated was cost of pole replacement using the current methodology, both for the current rate of replacement (CRR) and for the target rate of replacement (TRR). The percentage of OPEX that this cost represents was also calculated to give the researcher a sense of the relative importance of this operation. For the CRR, an annual cost of $\$ 5.85$ million is being spent on pole replacement, representing about $20 \%$ of the current relevant OPEX which is a significant amount. When factoring in the current replacement error rate of $40 \%$, the potential saving from this operation was determined to be $\$ 2.34$ million. This waste was then represented as a number of additional poles which could be replaced in the year, the relevant number being 437, factoring in the cost of accurate assessment. Assuming that the pole replacement fund of $\$ 5.85$ million is fully available for this activity, with accurate pole assessment, the rate of replacement could be increased by 437 poles per year. Similarly, for the target rate of replacement, the total expenditure would be $\$ 13.5$ million, the potential saving would be $\$ 5.4$ million and the resulting additional poles per year would be 1,117 . For the target case the OPEX was assumed to increase in direct proportion to the number of poles assessed, that is, currently the pole replacement programme is not using all of its allocated expenditure.

From the calculations it was found that with the current method of assessment, it would take 30.8 years to ensure that all of these wooden poles were safe at the current rate. If the target rate is met this could be reduced to 13.3 years. In comparison with using the IADT for pole assessment, and replacing only those poles which are truly defective, these times can be reduced to 13.8 and 5.8 years respectively, a substantial decrease in both cases. The total time required to assess all of the poles on the network was also calculated using the average of the two given pole assessment rates, and this time was found to be 7.1 years. As this distributor requires its poles to be tested once every 5 years, this indicates an increase in assessment capacity of $143 \%$ would be needed, pushing the cost of assessments to $\$ 533,333$ pa. The funding for this increase in assessment capacity has been drawn from the OPEX budget for pole replacement, leading to a reduction in the pole replacement rate from 1,737 to $1,701 \mathrm{pa}$ and from 4,117 to 4,081 pa respectively for the CRR and TRR, with the respective adjustment in values for the time to replacement of the pole fleet of 14.1 and 5.9 years. 
From this analysis it can be inferred that an opportunity exists to reduce SAIDI in a much shorter time frame than the status quo through proper use of the proposed IADT. This reduction in SAIDI which will result from the lower risk of failure associated with having accurate pole condition knowledge, combined with identifying and replacing the defective poles much more quickly. The potential to eliminate failure of poles more quickly would also result in an improvement to public safety. The optimised asset replacement programme could be used in marketing the safety of the network to customers, thereby improving the image of the distributor, which is one of the underlying goals of the businesses discovered during this study.

\subsection{Key Findings}

The key findings to come out of this study were as follows:

- Both EDBs in this study indicated poor knowledge of the condition of their conductors, line hardware, insulators and poles, all of which could potentially negatively impact upon network performance and public safety in the event of failure.

- There is a strong willingness within the EDBs to improve their current data collection and analysis capability.

- This improvement must to be done accurately to improve efficiency.

- There was a specific requirement for the proposed MVP of the IADT, that being the ability to design a pole installation.

- Accurate wooden pole assessment using the IADT has the ability to reduce the time required to replace potentially dangerous poles by more than $80 \%$ in the example studied.

- Conductor and line hardware assessment should be included in the next iteration of the IADT. 


\section{Chapter 4: Discussion}

In this chapter the findings from the interviews will be discussed, specifically to answer questions regarding the viability of the proposed IADT. The method of data collection used is reviewed with a focus on effective identification of possible MVPs through market pain analysis. Possible improvements to public safety through IADT use are also discussed, primarily due to the highlighting of this aspect from the interview participants.

Consideration is then given to the possible business models for the IADT, and variations to these required for effective implementation of the MVP variant. From these models, the key activities required for successful trialling of the product are identified, and the identified value propositions are reviewed. The chapter concludes with an assessment of how best to measure product performance in the electricity distribution industry.

\subsection{Data Collection Methodology}

The first part of this discussion will consider the methods followed in order to extract the market information necessary for development of a potential MVP. It was envisioned at the outset that the data gathered would be mostly qualitative in nature and as such some way of representing this would be required. The tactic employed to quantify some of this opinion was to have the interviewees rank different aspects of their business, firstly the importance of particular assets on their network, and secondly, their confidence in their knowledge of the condition of the assets on their network. These questions resulted in data which was able to be presented in graphical manner, clearly indicating areas of concern from the businesses. Participants were also encouraged to speak candidly about other aspects of the business, and were continually reassured of the confidentiality of their responses. This approach was helpful in eliciting more valuable qualitative information about the businesses.

The approach adopted during the study resulted not only in a good spread of opinion, but also in a very clear indication of where the participants deemed their weakest points to be in regard to asset management, leading to a strong focus of what features a potential MVP of the IADT should have. At the outset of this study, the initial proposal for the tool was to bring together a collection of data gathering technologies and derive from these more accurate, condition and environmentally based asset management capabilities. From the methodology adopted for data collection, a clear indication as to what these tools should be capable of was found. 


\subsection{Market Pain and the MVP}

The first item to be targeted by this study was the market pain being experienced by the EDBs, this being where they felt the strongest need for improvement within their businesses existed. Two dominant asset classes became apparent as being of most concern from the data, these being the poles supporting the overhead lines, and the overhead lines themselves as indicated in figures 3.5 and 3.6. This information indicates that the main features which should be considered for the MVP would be technology to assess pole condition in situ, and technology to assess overhead lines in situ. On elaboration, the specific concern from A was for their 40,000 wooden poles which were currently in line to be replaced en masse (A6, interviews, 2016). A1, A6 and A9 indicated that a tool which could accurately assess remaining pole strength would be very valuable.

Also featuring in the data were zone substations and the GXP. Although these items were deemed of significant importance, the historic treatment of these assets has resulted in very high confidence in the maintenance regimes surrounding them. This historic focus has made these distribution components not a specific pain point within the businesses. As such they are not good candidates to include in the MVP due to the limited additional benefit that could be derived over what the businesses already have. Large customers were mentioned in responses to these questions but as these are not actual infrastructure assets, they fall outside of the scope of the proposed IADT. It has however been stated by A6 that the infrastructure feeding large customers is generally well monitored and maintained as these customers have specific focus from the EDBs which serve them.

Another pain point from the data comes from the asset condition confidence as seen in tables 3.8 and 3.9. The lowest confidence here was in the condition of the line hardware and fittings and insulators for both EDBs, followed closely by conductors and cables. The pain being experienced was stated to come from the inability to accurately assess the condition of these asset classes due to an historic lack of available technology coupled with poor accessibility. These limitations indicate that technologies capable of assessing these assets would be good candidates for inclusion in an MVP. It should be noted here that there existed less real concern for the underground cables for two reasons, firstly these are typically newer than the conductors, and secondly, because upon failure, they do not endanger the public in the same manner as overhead hardware (B2, interviews, 2016). This detail leads to the conclusion that a 
tool which could analyse the overhead hardware alone could add significant value to the MVP with a tool for analysing cables in situ as a possibility for later addition to the IADT.

It is important to add that for both networks the participants indicated a very high degree in confidence in regard to the knowledge of the condition of their substations. As substations have historically been well recognised as extremely important, thus have subsequently had generally good accessibility and monitoring leading to the level of knowledge of condition of these to be considered to be adequate in comparison to the overall network. In fact, most participants were happy with their overall knowledge of these assets, with the lowest rating coming from B2 at 3 , which is the minimum acceptable rating identified in this study. For the IADT this means that these assets are of less importance at this early stage due to the limited additional gains in asset management efficiency that can be achieved here. As such, these are likely candidates for exclusion from the MVP, at least so far as direct assessment is concerned. It is possible that some additional assessment capability for these assets could come from the MVP, however this would likely be a consequence of the similarity of any installed componentry rather than due to specific targeting. As a later development of the IADT, the electromagnetic emissions around substations could be investigated, with the analysis of this being an additional input.

In addition to the above, B1 highlighted a specific problem with a particular type of isolator from South Africa. These are failing in service at an unacceptable rate and due to the lack of accurate data around the location of these, replacement before failure was proving problematic. A tool that could identify one of these potential failures before it becomes catastrophic could be a useful addition to the IADT. This is however a minor concern lacking the urgency of other aspects and as such may not be such a valuable feature for the MVP. It is worth noting here that if these faulty isolators could be identified incidentally by the MVP this would provide an added bonus for this particular business.

Another prevailing theme from the interviews at both EDBs was a desire to have more comprehensive condition data for their assets. Participants from B did have a high confidence in regard to their newer assets but had definite reservations about the integrity of data for assets older than 20 years (B2, interviews, 2016).

\subsection{Impact on Public Safety}

From this study, the businesses questioned expressed a strong desire to ensure the safety of the public around electrical distribution assets, with six participants explicitly stating this. There 
was a particular concern around the likelihood of wooden poles collapsing, not just during extreme weather events, but also during normal conditions. This public safety aspect was strongly discussed during the interviews at A due to the very high number of wooden poles on their network, some of which were up to 80 years old. This interest represents a good opportunity for the IADT as one of the value propositions identified from the research is enhanced public safety.

At B the focus of public safety was towards the overhead lines due to the aforementioned difficulty in assessing the condition of these with traditional methods, the risk to the public in the event of failure and the highly visible nature of these to the public. This focus indicates that this distributor was very conscientious of their public image, with two participants (B2 \& B4) clearly stating that they did not want to be featuring in the media with dangerous asset failures. This indicates that a feature to accurately monitor overhead line and fitting condition could be valuable within the MVP.

When analysing the needs of these businesses using the map of figure 3.12, it is not surprising that such a strong focus on public safety should be sensed from the participants. With the strongest need identified as the company's brand image, the avoidance of negative public reaction to business activities naturally includes a good public safety record.

\subsection{Business Model}

A number of business models were developed for the IADT during this study which were managed using the Business Model Canvas (BMC) of Strategyzer.com, with the MVP version shown in figure 3.11. As the project progressed, three main types of business model became apparent for the IADT as follows:

i. the direct engineering service from Electropar where data gathering and analysis is performed by Electropar and its partners

ii. the third party contractor where the IADT software is licensed from Electropar and the contractor performs the data gathering activities and analysis to sell to the EDB

iii. the in house model where the EDB employs a specialist team to perform the data gathering and analysis utilising the IADT software under license from Electropar.

For the engineering service model, cash flow would be dependent upon service requests from EDBs for specific sectors of their networks, e.g. a particular feeder. The condition data thus gathered would need to be contractually secured by the EDB in this case if they wish to own it 
which could form part of the charging structure for the IADT service. The service could be scheduled and carried out with appropriately trained personnel from Electropar and their partners which would likely require a significant expansion of the team. As this team would be a new area of operation for Electropar, new employment opportunities within the existing business could arise, opening the opportunity to create a new division. This new division would lead to the additional benefit of satisfying one of the conditions identified by Christensen (1997) for successfully introducing a disruptive technology, that is to operate autonomously from the parent company.

An alternative model is to provide the tools and training to a third party service provider for them to subcontract the analysis service to the EDBs. In this case the IADT would be licensed for a period of time which would give an ongoing cash flow for Electropar. Possible pitfalls here could be where the third party fails to use the product properly resulting in possible distrust of the product from the end customer, or where possible conflicts of interest exist, that is, the subcontractor appears to be using the toolset to generate other business. This has been known to happen with some of the traditional subcontractors used in this industry (D. Devonport, personal communication, 30 September, 2016), and has led to a distrust of these particular providers. This point therefore requires careful selection of the subcontractors engaged to undertake these tasks, and as such a chosen subcontractor should not have a vested interest in the results of any testing (A1, interviews, 2016), for example, a pole testing company should not also be in the business of replacing poles. In a similar manner to the first model, the ownership of the condition data would need to be contractually secured by the EDB if they wished to retain this information. After consultation with the main technology provider, Reliable Lines, this is their preferred model, and is the one which they currently use. They do however engage a specialised infrastructure testing team (which is focussed only on analysing pole integrity), then perform the data analysis themselves. This model ensures product integrity is maintained which would be very important during the early phase of product deployment. With the elimination of possible conflicts of interest, confidence could be built in the output of the IADT by the EDBs.

Within the EDBs however, there is a strong desire to perform as much analysis as possible in house, a result derived from the interviews with twelve participants indicating this preference. As such, the third option where the EDB employed a specialist team for this job should be considered as a possibility. This model would not necessarily result in a degradation of the performance required from the tool provided the internal team of the EDB understood fully the 
data integrity requirements of the tool, and were thus only focussed on analysing pole integrity. There is no reason why such a dedicated infrastructure testing team could not exist within an EDB, however, it would be important to ensure that this was controlled by a licensing agreement. The licensing agreement would need to limit the ability of an EDB to subcontract out this activity to a third party due to the historic potential for a conflict of interest to arise from within the traditional subcontractors used by EDBs, potentially undermining the results and therefore the integrity of the IADT. The cost of the assessment team in this case would go to the EDB but still give the revenue stream from the product to Electropar, similar to the third party model. In this model the asset condition data would clearly be owned by the EDB as they would have expended the effort to gather this.

In both licensed models, the IADT analysis could be conducted either through an onsite installation or via a cloud computing service. With the first of these, a suitable machine would need to be dedicated for this task and then kept in up to date with new developments to the IADT. With the cloud computing option, only the web interface would need to be updated, with any computing performance improvements being ensured by Electropar.

\subsubsection{Key Activities}

From the BMC for the MVP (shown in figure 3.11), the key activities to be performed are data collection, data analysis, and the destructive testing of poles after scanning. This third activity is necessary to verify the validity of the results from the IADT, and this will need to be done in conjunction with the pole owners, the initial customer EDB. It is noted that Busck Prestressed Concrete Ltd. in Whangarei have the required destructive pole testing facilities and as such could be contracted to perform this verification testing. Electropar have their own tensile destructive testing capability which could be used for analysing conductors. For the data gathering and analysis activities, it is recognised that the team processing this information will need to be dedicated to the task, not being influenced by other business motives.

\subsubsection{Value Propositions}

From the BMC, the main value propositions are highlighted in the centre. The obvious target added value to be gained is through improved efficiencies around infrastructure asset management via non-destructive testing in situ, however it should also be noted that both public safety, and the public image of the end user have been identified as potential value adds from the IADT. 
It has been stated during the interviews that on average for every 100 poles replaced on one of the networks studied, 40 were not yet requiring replacement as they had not deteriorated sufficiently to justify this (A6, interviews, 2016). With a pole replacement costed at $\$ 4500$ each, combined with the current rate of replacement of 1300 poles per year, the additional unnecessary cost in this case is $\$ 2.34$ million per year. If the MVP were to incorporate a feature which permitted accurate assessment of the condition of the wooden poles, a substantial saving could be made. The information from Reliable Lines indicates the cost to a distributor of testing a pole for structural integrity is from $\$ 50$ to $\$ 100$ per pole depending on accessibility. It would therefore cost approximately $\$ 97,500$ for the 1300 poles, making the accurate assessment of pole integrity well within the 1:5 cost - benefit ratio identified during the interviews (A2, interviews, 2016), with a potential saving here of $\$ 2.24$ million. This level of saving would be very valuable in helping the network to stay within the government defined target levels for supply stability within the permitted expenditure regime. Alternatively, this extra money could be reinvested into the network for the replacement of more poles. When the target pole replacement rate of 3000 poles per year is considered, the numbers are even more favourable with a possible saving of $\$ 5.18$ million per year being achievable. This could lead to just 5.9 years being required to potentially replace all of the defective wooden poles, down from the 30.8 years with the current rate and method. This makes such a feature an excellent option for inclusion in the MVP as the potential value is readily quantifiable.

Another value proposition here is in regard to the improved public image that an EDB might gain from using a smart tool such as the IADT. If the MVP of the tool can be shown to have significant public safety advantages, the EDB could leverage off of this in its own promotional activities. The analysis for marketing purposes (from the need diagram of figure 3.12) has indicated that the main reason that a business would invest in a new product or service is to improve their public image. This result is not uncommon across a variety of human centric businesses (ATEN503 Lecture, August 16, 2016). As the Pole Tester falls into this category of enhancing public safety, this is another excellent reason to include it in a possible MVP. Caution will however need to be exercised when marketing this particular application as there are many competing products on the market and it is likely that proof of performance will be required (A9, interviews, 2016). A9 also stated during the interviews that "poles had been done to death" and that the information gathered had not necessarily been put into use in the field. Due to these reservations, it is recommended to market the Pole Tester in conjunction with the 
Pole Designer application with load data coming from Point Geodata's LiDAR scanning to provide a more comprehensive solution.

\subsubsection{Channels}

There are two channels indicated for the IADT in its final form, the complete professional service and the licensing channel (Appendix C, figure C.2). These channels enable added flexibility which may be required to get the necessary buy in from the EDBs once the tool is ready for mass deployment.

The Professional service model allows the quality of the results to be entirely controlled by the Electropar team. This may be desirable as it removes a particular bias from the test results in regard to recommending premature pole replacement, however, from the perspective of the customer, this could be seen to introduce a bias towards replacement of certain electrical infrastructure components which are supplied by Electropar. This effect has been indicated as undesirable by the EDBs as they would like to retain their current ability to select replacement infrastructure components. A way around this issue would be to suggest only the components requiring replacement without reference to a particular product from Electropar. It would also be desirable for the Electropar team engaged in the infrastructure testing activities to be physically separated from Electropar's manufacturing and distribution operations. This latter point is eluded to by Christensen (1997) for successful disruptive businesses.

The alternative channel identified as a possibility would be to provide the software to the customer (the EDB or third party contractor) through a licensing arrangement. This is currently configured as an installed product but could also be provided through a software as a service (SAAS) arrangement. Although these are traditionally viewed as separate channels, for this product they are essentially the same in relation to the output of the IADT, and as such are considered together here. If the product were licensed to a third party it would make sense to engage with a business that was already dedicated to infrastructure analysis, with no interests in the supply of replacement components. The advantage of the licensing model is that it pushes the operational overheads onto the IADT user, either the EDB or the contractor. This may be desirable if Electropar wanted to insulate itself from possible increases in overhead costs, and avoid downtime within the IADT team when staff are not fully utilised. In the case where the customer is carrying these costs, they may have other projects or activities which they can move these staff to during periods of low data gathering or analysis due to operating under a different business model. The licensing model would however result in a continuous revenue 
stream for Electropar on an ongoing basis at the possible relinquishment of some control over the results of the IADT.

It should be noted here that the licensing model has been removed from the business model canvas for the MVP to allow a high level of control to be retained by Electropar at this early stage of the project, but it certainly should be considered as a possibility for a later, more developed version of the IADT. As such, this has been included in earlier iterations of the BMC which can be seen in Appendix A.

\subsection{Performance Measurement}

For the IADT to be viable, as with any other system using predictive analytics, it is necessary to have a clear performance baseline established. The challenge identified in this study is that often different distributors use different methods to calculate their performance measures (IEC, 2014). This inconsistency has been seen to be true even when the performance measures take the same names such as SAIDI and SAIFI, and is a recognised issue within the industry (IEC, 2014).

\subsubsection{Standards}

From the interviews it became apparent that the comprehensive operating standards developed by Powerco of Taranaki (A1, interviews, 2016) play a significant role in the operation of A along with 22 other EDBs within New Zealand which use these. Any tool that is developed for use within this market will need to take these standards into consideration as well as the new ISO55001 standard, to ensure wide reaching acceptance.

The implication of this issue for the proposed IADT is that the system would need to be calibrated to a standard of operation within any business into which it was deployed. For example, the performance measures of SAIDI and SAIFI in use by a particular EDB would need to be compared to the standard defined for these and adjusted appropriately. This calibration would then allow asset management efficiency gains derived from the IADT to be directly comparable to other calibrated EDBs. When properly implemented, the IADT should be insensitive to the prevalent inconsistency of performance measurement within the industry, and as such appropriate calibration would always be required to ensure meaningful results. 


\subsubsection{Product Verification}

When the IADT is being tested, a performance baseline will need to be established prior to implementation which would enable valid results to be derived as to its effectiveness as an asset management tool, particularly in its ability to reduce both SAIDI and SAIFI. During the study of Pattie and Silk (2016), Powerco has accumulated much data around the remaining strength of its wooden poles after their removal. If this type of data were to be gathered during the initial trial period of the IADT (in the event that the initial MVP includes the Pole Tester capability as indicated in this discussion), then this would be very helpful in validating the tool's effectiveness. At this stage of the project however, this remains the subject of conjecture as the product MVP is yet to be adopted by a distributor.

Although not a specific requirement for the IADT, if destructive testing of wooden poles or conductors could be carried out after testing and analysis, this would give a strong indication as to the validity of the results coming out of the IADT. It is therefore recommended that for the initial phase of the project, where the MVP is being trialled at an EDB, that destructive testing of both poles and conductors is contractually secured prior to tool implementation. It is also recommended that these wooden poles and conductors be selected from a fleet which has already been marked for replacement to limit the additional cost of this destructive testing. 


\section{Chapter 5: Recommendations - The Business Case}

The proposed Infrastructure Asset Diagnostic Tool (IADT) is a collection of software and hardware tools dedicated to the assessment in situ of electrical distribution hardware such as conductors, poles and insulators. Equipment included in this tool is LiDAR scanning capability, piezoelectric sensors for measuring pole decomposition, and electromagnetic scanning to determine the current state of overhead conductors. The tool as proposed draws upon both historic performance data and engineering test data for conductor assessment, as well as calculating values for remaining pole strength from the measurements taken during inspections, factoring in load and environmental conditions for the site. It can also assess vegetation encroachment around conductors, highlighting areas of concern. The data flow for the tool is shown in figure 5.1.

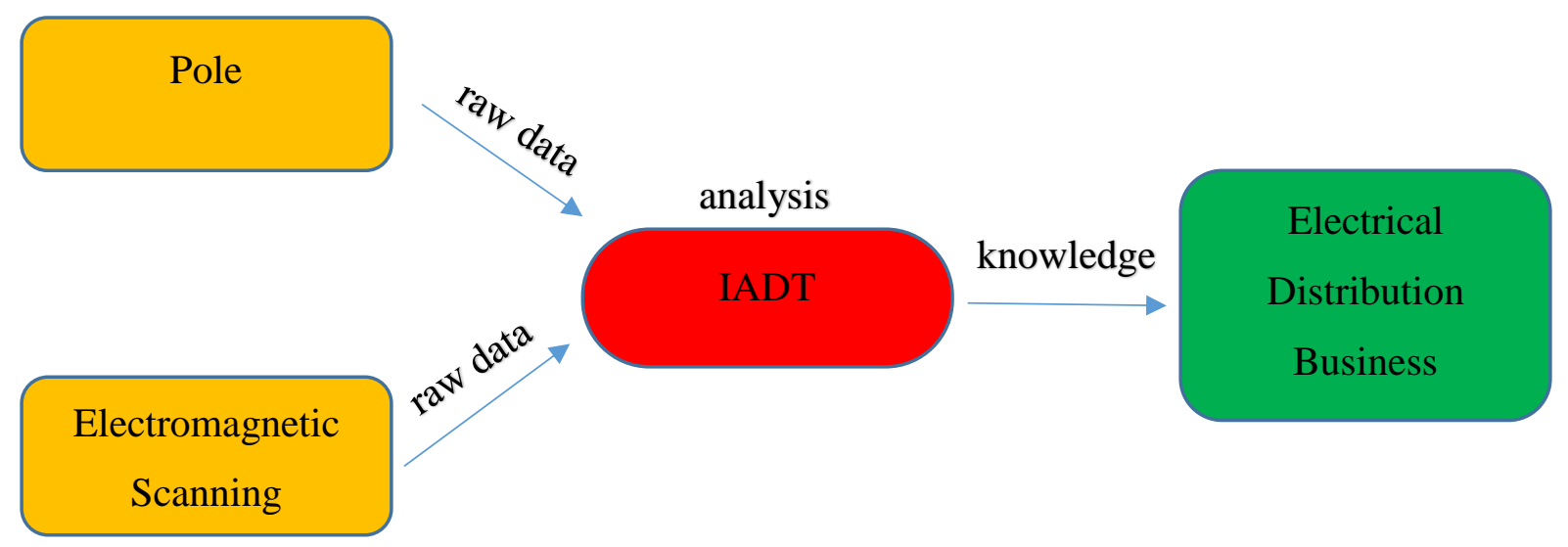

Figure 5.1. Overview of IADT data flow.

\subsection{Business Model Design}

\subsubsection{Goals and vision of project}

The main vision of this project is to enable a much smarter approach to infrastructure asset assessment and management in the electrical distribution industry. It is envisioned that a tool could be created which would deliver a comprehensive picture of the remaining condition of all hardware assets on a distribution network.

As a precursor to this encompassing product, it is desired to create a smaller, problem specific version of the above in order to test the viability of this vision. This test bed should be capable of delivering real benefits to an initial customer base in order to establish the brand within the target market. 


\subsubsection{Assessment of opportunities and constraints to development}

In order to implement the minimum viable product within the marketplace, partnerships will need to be established with both Reliable Lines, the key technology provider, and an Electricity Distribution Business (EDB). These will in turn provide the resource for developing the diagnostic tool and the initial test sample respectively. This test sample will be required to verify the integrity of the results of the tool. From a management perspective, this limitation to just two major partners should enable communication efficiencies which are envisaged to be necessary during the rollout of the tool. Additional resources required for this initial Minimum Viable Product (MVP) would be directly subcontracted by these two major partners.

\subsubsection{Testing Assumptions}

The key assumptions tested in this study were as follows:

- The observed buying behaviour of the electrical distribution businesses is being driven by underlying deficiencies within the infrastructure asset knowledge base.

- That this behaviour has been caused by a lack of sufficiently accurate tools or processes to allow proper monitoring of infrastructure assets.

- There are currently no suitable tools available in the market place to deliver on all of the needs of the EDBs within the asset maintenance and replacement space.

- If the prior assumption is proven incorrect, then the proposed IADT will likely be resegmenting a current market place, creating a market niche.

- The IADT will be developed in house by Electropar.

- Competition for the IADT will come from internal processes and spreadsheets currently used by EDBs for asset life forecasting and status monitoring, and from specialist tools which utilise condition assessment as primary drivers.

From the literature investigation, it was found that there are a number of tools available within the market place aimed at predicting asset failure or otherwise optimising the management of infrastructure assets. Of these, the most commercially prevalent were those which used some form of condition assessment to derive a remaining life for a given asset pool. The concept of condition indexing as found in Di Matteo (2015) has gained a substantial foothold within some parts of the industry, and has managed to find its way into the ISO 55000 series standards (Di Matteo, 2015). At the same time, although currently prevalent in the local industry, the use of survivor curves appears to be in decline, with many global EDBs preferring the greater accuracy afforded by the condition based predictive tools (Otal \& Bakulev, 2014). 
Condition based predictive analytics also forms the basis for the IADT, however the IADT differs from others in the market place through its higher precision measurement of asset condition. In regard to wooden pole assessment, there are other tools which performed superficially similar measurement tasks to the IADT, however on closer inspection, these fail to deliver consistently accurate results for all situations (Pattie \& Silk, 2016). The net result of this deficiency was that multiple tools would be required to conduct thorough analysis, with the additional limitation that all still required the subjective assessment of an experienced observer to deliver the safety levels required (Pattie \& Silk, 2016). The elimination of the subjective assessment is another area where the IADT will have a competitive advantage as it would enable staff with lower level qualifications to achieve consistently reliable results, meeting another point indicated from the interviews. In addition to the accurate measurement of asset condition, the IADT also delivers more value through its combined assessment with the surrounding assets. This combined analysis allows much greater confidence in remaining pole strengths, for example, allowing lower replacement thresholds to be safely used. As a technically more advanced solution to the problem of infrastructure asset condition assessment, the IADT will create its own market niche. This approach could yield a higher profitability in the initial phase of market delivery, especially as it will allow the EDBs to present a better public image.

For most of the duration of this study, it had been assumed that Electropar would be developing the IADT in house. After discussion with Electropar's partner, Reliable Lines, it is clear that Electropar are providing an interface to the industry, and a central point of contact for potential technology providers. Reliable Lines have produced the software and interfaces required thus far to deliver the base model of the IADT.

\subsubsection{Evidence based recommendations on most appropriate business model}

From the evidence found during this study, it is recommended that the business model represented on the BMC of figure 5.2 be adopted for the MVP of the IADT. This model uses the channel of a professional service to deliver the tool to the customer in the first instance, 


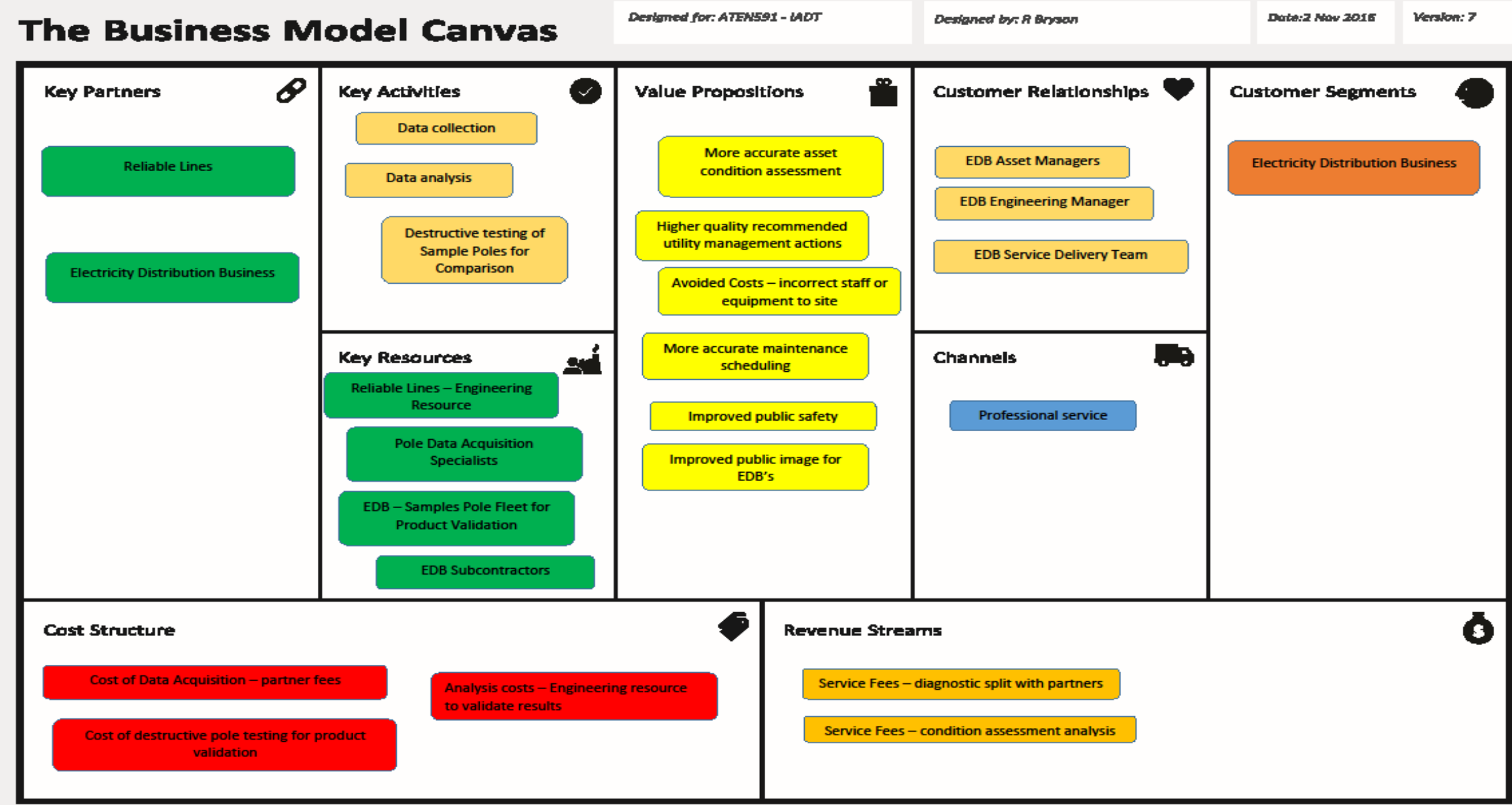

() (1) (1)

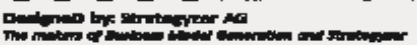

Figure 5.2. Business model canvas for MVP. 
allowing tight control to be maintained over the integrity of assessments. A high level of data integrity would be necessary for acceptance of this product by the industry due to the current fickle performance of competitor products (Pattie \& Silk, 2016). Although there was significant desire within the distribution businesses to conduct technical testing such as delivered by this tool in house, there was also an observed willingness to subcontract this type of activity where highly specialist knowledge or tools were required (A4, B2, interviews, 2016). Due to these combined factors, it is proposed that the after initial verification of the tool during MVP deployment, opportunities to license the tool to the customers for use in house should also be revisited.

Elsewhere on this canvas, this model has a component from the first pilot customer in the form of destructive testing of a sample of poles. This testing would not necessarily need to be conducted by the initial customer providing the pole fleet, however where a customer has the capability to conduct these tests, this may provide for some logistical efficiency to be gained. If the destructive testing is to be conducted by a third party, for example Busck of Whangarei, this cost is recommended to be met by Electropar. The removed poles may also have a depreciated remaining value in some cases which may need to be accounted for, although this is unlikely. Regardless of who conducts the destructive verification tests, a strong partnership between Electropar and the initial customer should be established prior to tool deployment to ensure securing of the test pole fleet.

The next area of interest is the value propositions achieved from the tool. In this early stage, the immediate benefit to be gained is through much more accurate pole condition assessments. This would immediately enable a reduction in pole replacement costs for a distributor looking to replace a large number of poles due to age. This situation applies to one of the businesses spoken to in regard to this tool, and as such they are a very good candidate for becoming the initial customer. In the slightly longer term, acceleration of dangerous pole replacements may be able to be leveraged by the customer to improve their public image. The increased speed of pole assessment with the replacement only of defective poles would also be of great benefit to public safety.

After consultation with the EDBs it became apparent that the main personnel to deal with during the pilot phase of tool deployment are the asset managers, the engineering manager and the service delivery team of the EDB. These personnel should be chosen 
as they are closest to the assets in question and should be able to provide the most valuable feedback on tool performance from the EDB perspective. The service delivery divisional lead would also need to approve any such deployment due to the significant cost exposure of the proposed tool. For the day to day performance assessments, the asset managers would provide the main interface into the business, and the engineering manager oversees these operations.

As the primary supplier of technology for the IADT, Reliable Lines also provide the engineering resource for the data analysis. They have indicated their preferred subcontractor for the data acquisition activities and as such should be engaged to oversee this operation for Electropar during the pilot phase. Using a subcontractor experienced in this activity would ensure that sufficient care is taken with these critical tasks to achieve the desired accuracy from the tool. The heightened accuracy thus gained should help to ensure satisfactory results when compared with the subsequent destructive testing.

Revenue for the pilot phase with the MVP will be derived from the fees for non-destructive diagnosis and condition assessment activities. As has been previously noted, the destructive testing of a sample fleet of poles will incur a cost on Electropar, either with a third party provider or as a rebate to the distribution business in the case where the EDB conduct this themselves. Other costs to be accounted for are the partner fees for professional services, listed here as data acquisition and engineering resource.

The BMC which has been developed is considered by the researcher to contain all of the elements necessary to ensure that the MVP can be successfully deployed and verified with the first customer. It should be noted that some of the value propositions listed may not be immediately achieved as they are consequences of effective tool use over time

\subsection{Market Validation and Development}

\subsubsection{Target market}

To investigate the opportunities available for the envisaged product, participants within the marketplace were interviewed from two discrete EDBs. Various staff at different levels within these businesses were interviewed using a standardised questionnaire touching on topics such as the importance of different asset classes, their knowledge of asset condition on their networks and other aspects of their business operations. This data was mostly qualitative in nature and as such required some manipulation and interpretation by the researcher to extract 
useful market knowledge. The combined asset importance and individual knowledge of asset condition data are presented graphically in figures 5.3, 5.4 and 5.5 respectively.

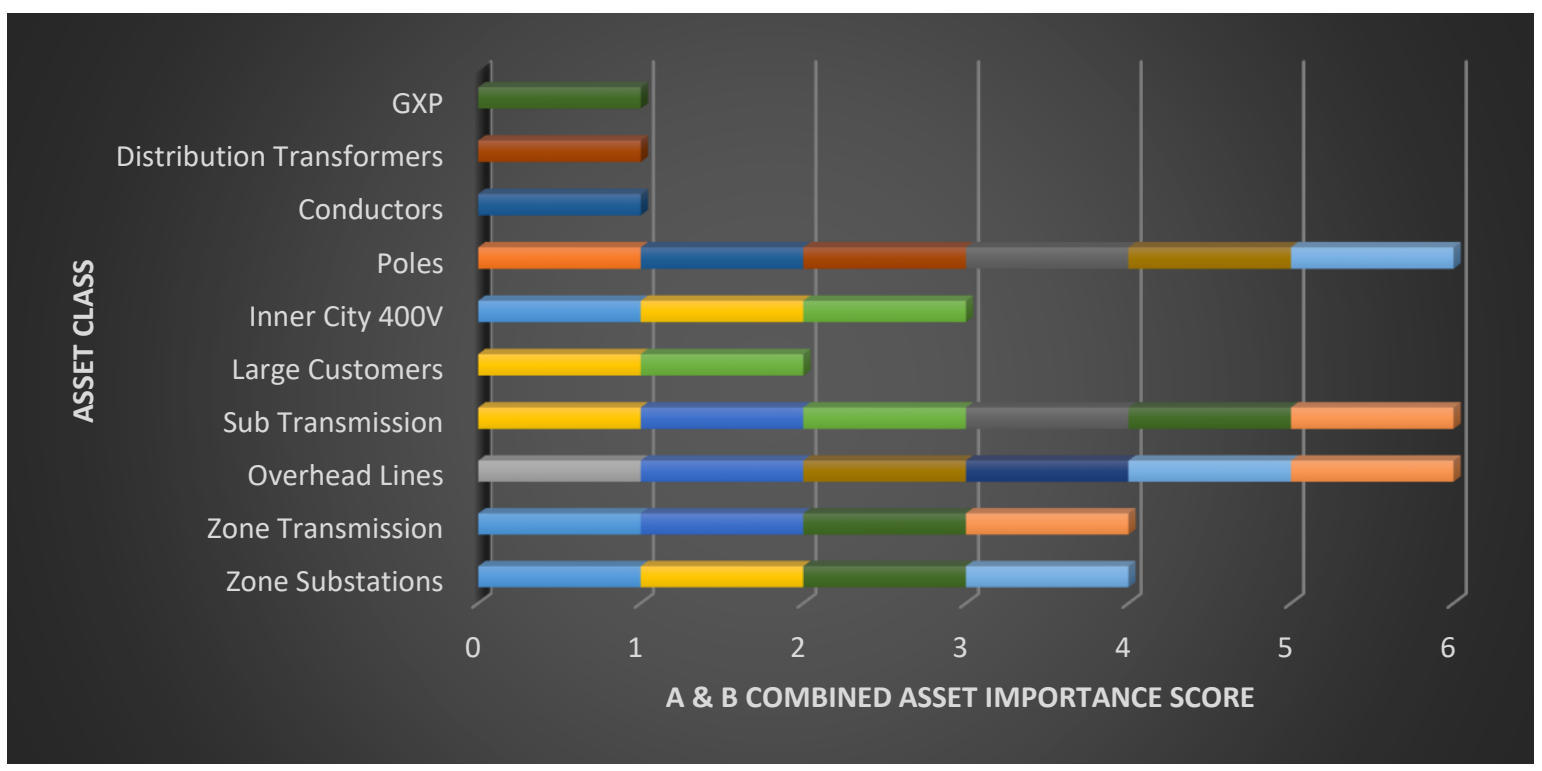

Figure 5.3. Combined asset class importance rating for EDBs A \& B, raw values.

The major findings to come from this study in regard to optimising asset management were as follows:

- The distributors felt they could do a better job of forecasting and were open to any genuine improvement. This was partly derived from the fact that they are prone to running out of available spend in a given year (as defined by the Commerce Commission) limiting their maintenance activities.

- There exists a strong concern in regard to the lack of knowledge held about the condition of certain asset classes, especially when those assets were exposed to public scrutiny e.g. overhead lines or power poles.

- There is a strong willingness to try any product that would make a genuine improvement over the status quo.

- They expressed a strong sense of wanting to serve the public good, especially in regard to securing public safety.

From these points it can be seen that the environment into which the IADT would be deployed is quite open to new ideas. This is very good for the IADT as it implies an openness to the testing that would be required to verify the analysis from the tool, and a willingness to try new approaches to how they do business now. The chosen path for the tool of targeting wooden pole integrity, then following it with overhead line analysis, is reinforced by the 


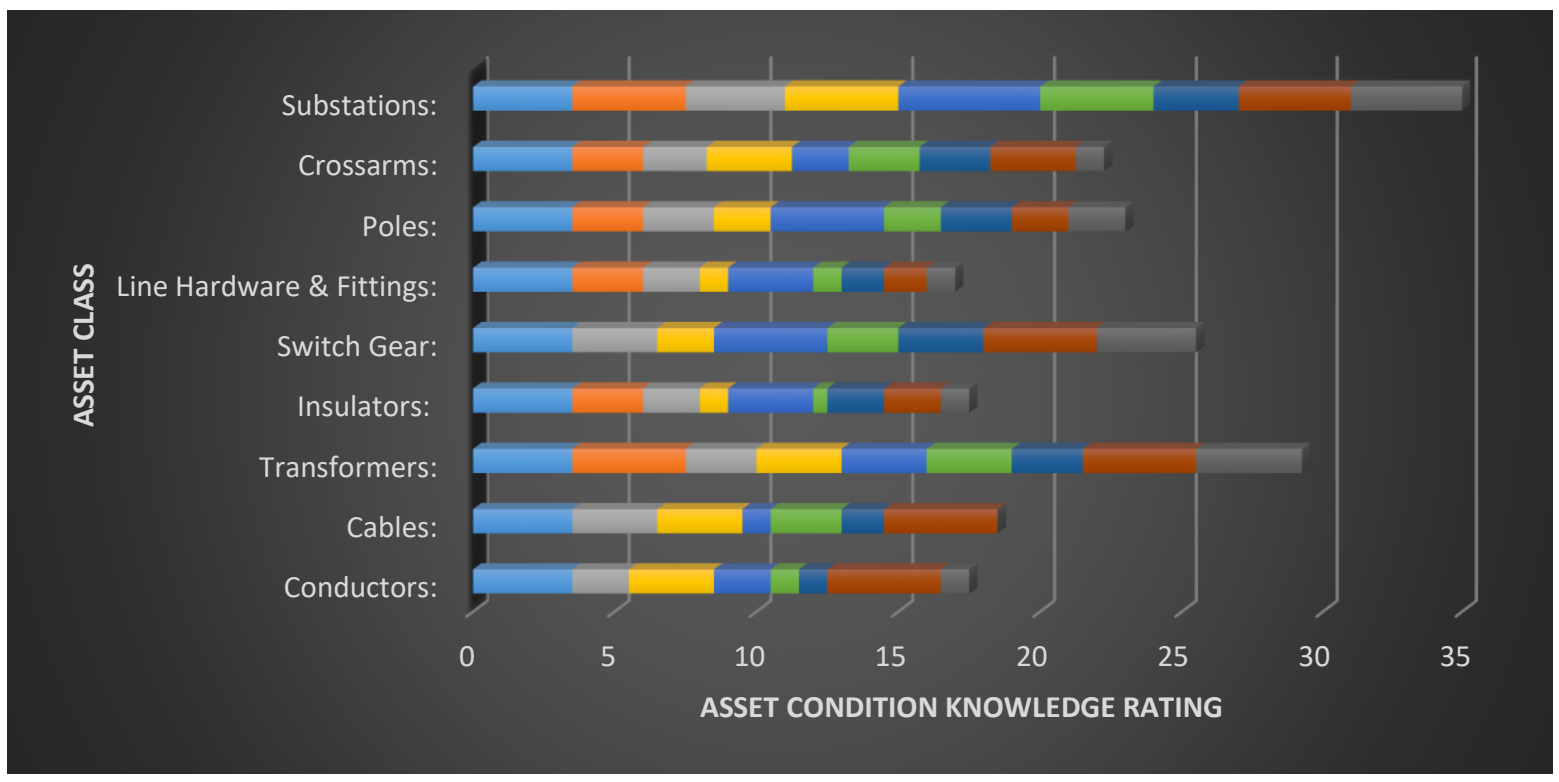

Figure 5.4. Knowledge of asset condition at A.

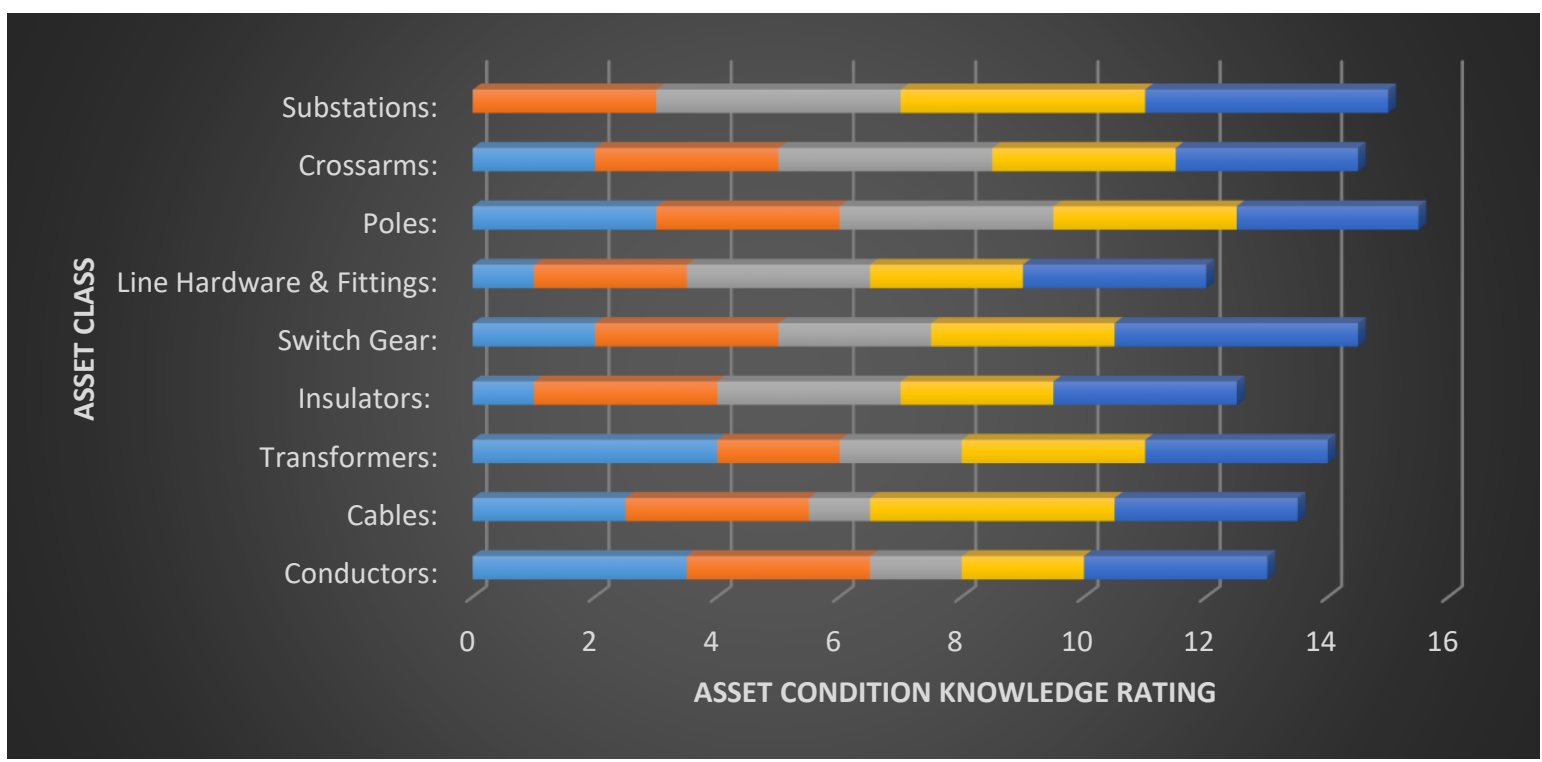

Figure 5.5. Knowledge of asset condition at B.

research which found these to be the asset classes of most concern when factoring in all aspects.

The diagnostic tool proposed in this study would enable a reduction in capital expenditure for any business which has a pressing need to replace its wooden poles. The current uncertainty surrounding the condition of these could be significantly reduced through use of this tool. At the moment businesses are replacing more poles than necessary due to the highly subjective nature of traditional testing methods. On average out of 100 poles failed and subsequently replaced with these tests, 40 have been shown to have sufficient strength remaining to justify continuing service (A6, interviews, 2016). These prematurely replaced poles could be accurately identified by the IADT and hence the premature replacement of these could be 
avoided. With the price of a pole replacement averaging around $\$ 4500$ per pole, an immediate saving of $\$ 2.34$ Million per year could be accessed. This money could then be reinvested into more pole replacements with the subsequent reduction in SAIDI and improvement in public safety.

\subsubsection{Current solutions}

Currently the problem is not being solved by all of the distributors, that is where the problem is overspending on the network to attempt to ensure the required targets for SAIDI and SAIFI are met. It has been stated during the interviews that power distributors are running out of money and suspending asset replacement programmes until the next financial year from which they can draw more funds, for example A9 stated “(A) don't have enough money”. This mode of operation unfortunately comes at the cost of public safety leading to the public being endangered by assets in an indeterminate condition scattered around the countryside. This situation is very undesirable for the companies, as was seen recently in the media in regard to Delta in Otago (“Story”, TV3, October 19, 2016).

Traditional test methods result in poor accuracy impacting negatively on the available fund pool, subsequently leading to the situation where over replacement of serviceable assets is wasting money that could be better spent on securing public safety. Unfortunately for the distributors, these are often the assets with some of the poorest monitoring technology, that is the overhead conductors and the poles holding them up. It has been stated during the interviews that it was almost impossible to test conductor condition as the technology to do so was not available, leading to these being replaced only if faults were noticed during other nearby maintenance or after failure. This problem has subsequently led to a strong desire to seek out better, more accurate ways of testing these assets which are subject to high public scrutiny.

Some companies are achieving their replacement programs within the prescribed budgets (B4, interviews, 2016), but would welcome more accurate tools as these would enable them to provide even higher levels of service. It was also stated during the interviews that delivering a consistently high level of service is a strong marketing tool for bringing businesses into a particular region. A desire to be able to never be offline has also been expressed during the interviews, although this was stated to be an ideal situation (A6, interviews, 2016). 


\subsubsection{Barriers to changing existing behaviours}

The main barrier to overcome with the IADT is convincing the end users that it is in fact sufficiently accurate, and then convincing the higher level management who are not used to such levels of accuracy. The high accuracy of this tool has the potential to require significant restructuring of the distribution businesses around how they test and replace poles for example. In one case quoted by Reliable Lines, the feeder tested was deemed completely safe strength wise, however the owner in this case elected to replace the weakest poles to keep their team employed. This approach should only be a short term measure until such time as the business can be restructured to account for the significant improvement in accuracy delivered by this tool.

With successful implementation of the IADT, it is highly likely that the skill distribution within an EDB would change, at least for the inspection teams. In this situation, incumbent employees may fear for their jobs and as such may resist changes to the business model, which may hinder the successful deployment of the tool. Due to this possibility, it is recommended that the internal staff used in infrastructure asset maintenance ultimately be trained in the use of the new tool, and during the initial trial phase, these staff should be used to aid in the assessment of the tool's accuracy where possible. This approach will help to gain buy in from the most at risk staff which will be valuable later on as they will help to use the tool in the most effective manner possible, ultimately becoming product champions. This staff buy in will be especially true where they can see both the business benefits (delivery of power to customers) and safety benefits for themselves and the public. The tool in itself is unlikely to lead to a reduction of employees within a business, but rather to a more effective use of the incumbent employee's time, which aligns with the researcher's previous experience of deploying smart tools into new environments.

There are however likely to be some people that simply don't accept the new tool. These people are likely to provide significant resistance and may ultimately need to be removed from the business. Such a change could be achieved effectively with a restructure redefining the skill sets required for certain tasks within the business. If a change of more than $20 \%$ can be allotted to any given role, the role can be legally made redundant. Although this is not an ideal path, it does at least provide an avenue forward if internal resistance to the use of smart tools such as the IADT is too severe. 


\subsubsection{Implementation pathway}

Everybody spoken to about the IADT during the interview process indicated that if such a tool existed, it would be extremely helpful for managing their infrastructure asset maintenance and replacement programmes. Key difficulties identified from the study were the lack of accurate knowledge of the condition of wooden poles, overhead conductors and the associated fitting hardware. Some concerns were also raised around the incorrect specification or design of poles occurring during replacement leading to subsequent failure in the short term. If the proposed tool could address some of these issues early on, its value to the distribution business would be easier to sell.

The EDBs already have a number of tools in place for dealing with infrastructure asset management and replacement, for example spreadsheets which forecast remaining life, and as such a new tool would need a significant point of difference. The IADT delivers on this point of difference by offering a comprehensive analysis of a distribution feeder, including remaining pole strength and current physical load, conductor sag, and in the complete package, conductor electromagnetic radiation leakage, all from simple drive by, fly by or stationary measurements.

Due to the comprehensive view of the condition of a distribution line presented by the IADT, this is believed to check many of the boxes required by the industry. The ability to deliver an integrated analysis was determined from the interviews as being of significant value for the maintenance of infrastructure assets as this would enable more efficient use of resources from less input.

The product identified in this study as the MVP consists of technology to accurately measure the remaining strength in the wooden poles, replacement pole design functionality, and provides an indication of where conductors have fallen below the minimum permissible clearance above ground level. As an added bonus, this tool also provides information in regard to where vegetation needs to be cut back.

Due to the advanced state of development of this tool, it is recommended that it be made immediately available to the distributors on request. The tool needs to be positioned with a payback period of no more than five years for the end user. It was indicated within the interviews that a period of three to five years would likely be acceptable, or alternatively a cost to benefit ratio of 1:5 in the case of a service (A2, interviews, 2016). 
It is therefore recommended that the IADT be delivered as a professional service to the distribution businesses, at least in the early stages of its life. The likely early adopters (Blank, 2007; Blank \& Dorf, 2012) are facing immediate needs for the accuracy of wooden pole analysis offered by this tool and have indicated a willingness to pay with a cost to benefit ratio of 1:5. With some of the pressing needs in the market, it may be viable in some cases to deliver just the pole testing capability, however this as a standalone product does not offer the same level of accuracy as the more complete tool which adds pole load. For this reason, it is recommended that this only be done for extremely unsafe pole installations where immediate assessment is required as was seen in the very public case at Delta in Otago ("Story", TV3, October 19, 2016).

\subsection{Product Validation and Development}

\subsubsection{Does the product work as intended?}

Some initial components for inclusion within the IADT have already been contracted by Electropar, specifically those provided by Reliable Lines and Point Geodata. The software integrating these elements has also been developed and used in field trials. This current version of the IADT is performing very closely to the desired accuracy in testing thus far. At the time of writing, this consists of the ability to assess remaining pole strength as a percentage of original, the loads that a given pole is subjected to and the clearance of conductors from the ground and from trees. A key advantage achieved so far by the IADT is factoring in of loads on installed poles. This load assessment allows the pole replacement threshold to be reduced from $40 \%$ to $25 \%$ residual strength without the threat of premature failure (Reliable Lines, personal communication, September 30,2016), hence maintaining public safety. The claimed accuracy of the IADT has been called into question by some trial users and as such verification of this accuracy will be required.

\subsubsection{Process for development, testing and the regulatory environment}

To ensure confidence in the IADT for the customers, a fleet of poles will need to be secured in order to verify its accuracy in this environment. These poles would then be destructively tested with the results compared to those from the IADT. This requirement can be achieved when working in partnership with an EDB supplying this pole fleet. Reliable Lines and Electropar are confident that the IADT will pass this accuracy verification procedure.

The process to be followed for verifying the integrity of the IADT is: 
- Scan the target pole fleet, including both the Pole Tester application and the LiDAR scanning of overhead conductors.

- Calculate and measure the remaining pole strengths and conductor clearances respectively using the IADT.

- Remove the sample pole fleet for destructive testing and transport these securely to the test site, ensuring that no transit damage occurs.

- Compare the results of the destructive tests with those derived from the IADT.

Regulation and standards defining when and how a pole should be replaced are not strictly enforced within the industry at this stage, with businesses taking it upon themselves to define the limits and processes. Powerco for example, have developed their own standards defining how a pole should be tested with current methods, and the other information that should be gathered about its condition during inspection. Powerco's standards have also been adopted by 22 other EDBs within New Zealand, therefore these standards would need to be revisited to incorporate the added accuracy available from the IADT. Once the accuracy of the IADT is verified through the destructive testing of a sample pole fleet, the process to amend the standard to accommodate this should be much simpler.

\subsubsection{Can the IP be protected?}

The IP for the IADT is owned by Electropar, with contractual arrangements between them and the primary technology providers that drive the tool. As such Victoria University has contracted out of any claim to the IP of this study.

It has been assumed for the purpose of this report that Electropar have undertaken the necessary steps to ensure that their IP around the IADT is protected. For the researcher's part, the report can be embargoed for up to two years if required.

\subsubsection{Essential features identified}

The two main features required to be delivered by the IADT as determined from the interviews are as follows:

- Overhead conductor strength analysis

- Accurate wooden pole strength analysis

Ideally, for the MVP, these features could be reduced to analysis of the overhead conductors in situ as this represented the most widely recognised pain point. The addition of wooden pole 
analysis would then form part of the second iteration of the IADT. However, due to the advanced nature of the pole assessment tools from Reliable Lines, these two features will be prioritised in reverse for the MVP in this recommendation. As each of these feature featured strongly in the interviews as pain points, reversing them should not cause significant issues for the uptake of the IADT. The two reason for selecting wooden pole analysis as the initial feature of the MVP are:

- The advanced state of development of this feature.

- A specific request from a target initial EDB.

It should be noted here that the initial version of the IADT, that is the MVP, includes the ability to factor in load information when measuring remaining pole strength. This feature enables much more confidence in the safety of poles left installed for longer periods. As a part of this feature, conductor clearances also become available along with vegetation encroachment. These combined outputs give the MVP significant value by combining two or three former operations and extracting more useful data from these than has been historically available. Consequently, the EDBs will be able to extend the lives of many poles, reducing expenditure, and hence freeing up this cash for other areas. It will also save them the cost of revisiting the feeders to separately analyse conductor sag and vegetation clearance bringing an additional operational efficiency.

If the IADT were being developed strictly following the processes recommended by Blank (2007), Adams (2010) and Ries (2011), the development of the product should not necessarily have been as advanced in a particular direction as it is without accurate market need knowledge. This has led to the potentially most valuable feature, the conductor analysis, becoming part of the second iteration of the IADT. Based upon this study, the conductor analysis tools should have taken precedence over the wooden pole analysis tools due to the greater overall impact potential, and the lack of suitable tools within the market place. However, the advanced state of development of the technology provider, Reliable Lines' suite of tools is primarily due to key staff there having extensive experience within the electrical distribution industry. This experience has given them the confidence to take a leap of faith in the development of the product. When combined with the extensive knowledge brought by Electropar it is understandable that product market confidence is high in this case and, in the opinion of the researcher, the current incarnation of the IADT from Electropar should be taken to the market. It conforms to the basic requirements for a possible MVP and as such will be able to add 
significant value to an EDB. The main obstacle likely to be encountered is defining exactly how it is better than the current competitors within the market. As such, a strong marketing approach will be required to achieve customer buy in as "poles have been done to death" (A9, interviews, 2016). The initial customer deployment should also be used to verify the accuracy of the tool, becoming a valuable marketing tool when approaching subsequent EDBs.

\subsection{Resource Requirements and Returns}

\subsubsection{Skills required in team}

The main skills required for the continuing development of the IADT are:

- Sales skills to convince distribution businesses to use the tool.

- Computational analysis skills for programming the algorithms which drive the tool.

- Negotiation skills to secure additional measurement technology for expanding the functionality of the tool.

- Technical skill and dedication when using the pole testing and network scanning equipment.

As Electropar is to be the supplier of the IADT, the sales skills should come from this business. Also from Electropar should come the negotiating skills for new technology acquisition.

Reliable Lines have thus far provided the technical analysis and programming skills for IADT development. They have already integrated the different measurement technologies into an accurate tool which is ready for deployment, and it is recommended that this successful arrangement should continue.

During the initial stages of tool implementation, it is recommended to continue with the current teams which perform the pole measurement and overhead line scanning duties. As time progresses, these activities could be subcontracted out to other suppliers, or could be done by the EDBs themselves with appropriate training. An advantage to be had from training EDB staff in the use of the tool is empowerment. This is very important when introducing a technology with the capability to disestablish many previous roles. Additionally, a number of participants have stated a desire to keep analytical capability in house for a variety of reasons, with A1 stating "it would enable them to find 'holes' in their standards".

It is also recommended at this early stage that ownership over the hardware for pole testing be retained by Electropar, and this equipment be held by their designated testing subcontractor. 
This is to ensure the integrity of the data collected which needs to be consistent if successful accuracy verification is to be achieved. The data gathered will also need to be retained by Electropar for further analysis. Although there is a strong desire from the EDBs to own their data, this could be limited to the resulting analysis which provides them with useful knowledge rather than direct access to the raw data, however this is likely to require an explicit contract.

Once the IADT has been established in service, the measuring hardware for it could be leased to the EDBs to allow them to use their own data capturing teams. In this case a decision will need to be made as to whether to license the analysis software, or to provide this analysis as a cloud based service.

\subsubsection{Development and manufacturing process and required equipment}

The IADT is primarily a software tool. As with most consumer and enterprise software products, it is likely that a future development team will be needed to ensure that the software remains compatible with updated hardware platforms as this becomes available. For example, The Pole Tester application is currently running on an Android platform. As this platform is updated to use the new hardware features being continually added by manufacturers, it is conceivable that at some stage the current incarnation of this IADT component will not be able to run on the future available hardware. This potential issue is a common condition of any software product regardless of the chosen consumer or enterprise platform.

Waterfall development where products are developed linearly and released in a completed state is not appropriate for the IADT as it requires a more dynamic and adaptable environment to maximise capability within the shortest possible time frame. A variation on the Agile environment where the product is broken into individual components, with progress on each closely monitored, may be able to work for development of the IADT. This approach will need to be adapted where significant interface code blocks are being developed to allow more time for code delivery. In these cases, instead of small code blocks being demanded as daily targets, larger functioning code blocks should be demanded with appropriately realistic delivery time frames. A weekly progress report is likely to be more than adequate here, and this may even be extended out to a month for a significant piece of work. These suggestions are to fit in with the engineer's perspective of wanting to get the job done, and of being trusted to do so. This is in contrast to the software development industry where developers have not necessarily had the same level of structured, formal training that is always a requirement for professional engineers. 
The next suggested expansion for the IADT is to add the overhead conductor scanning capability which would target the other major concern to come out of the interviews with the EDBs, that being the current difficulty in assessing the condition or likelihood of failure of the conductors with current techniques. To achieve this goal, an appropriate technology provider will need to be contracted, such as Exacter Corporation, or the technology will need to be developed to provide the required scanning and assessment technology. To effectively interface this data into the IADT, the output of this electromagnetic radiation scanning tool would need to be brought into a format compatible with the current IADT databases. Once this condition information is available in an appropriate format, value will be able to be added to it through combining it with the information already available within the IADT. The main benefit to be achieved from the addition of the conductor scanning, allowing imminent failures to be detected, will be the enhanced safety delivered to the public and the reduction in SAIDI minutes for the EDBs.

It has also been mentioned during the interviews that type identification for both poles and conductors would be really valuable, with A9 stating "we don't know our type issues" and from A6 “... it was light, medium or heavy, ... we don't know if it's copper, aluminium or steel", amongst similar comments. This indicates that a tool to determine conductor or pole material composition from a distance could add significant value for EDBs

Further enhancements which require further investigation could be to interface transformer condition data which would lead to an even more comprehensive tool. Additionally, information currently held around the condition of substations could be added as a reference source for the IADT. These data sources may add value to the analysis through enhancing the load information on which assessments are made, however this has not been suggested as anything other than a very high level idea. As such more investigation into the impact of such data on condition assessments further out in the network would be required.

Ultimately, the output from the IADT should be able to be imported into a corporate enterprise resource planning (ERP) system which would likely require custom interfaces to be built for which ever package a particular distributor was using. However, once the core interface has been built, it may be possible to have the IADT as a plugin for the ERP system. It is likely that such interfacing will be able to be justified for larger, widely spread ERP systems, however in the case where a distributor was using a bespoke system, this interface value would need to be 
properly assessed. It is possible that the standalone output from the tool may in these cases be sufficient.

\subsubsection{Funding and financial analysis}

This project is being funded privately by PLP Electropar New Zealand with additional funding secured from Callaghan Innovation for the development of this high added value tool. As such, the possibility for exporting the tool to generate revenue for New Zealand from a new high added value stream has also been investigated.

The financial viability of the MVP version of the IADT has been determined from data collected during the interviews used in combination with data from publically available corporate publications. The data includes the cost of pole assessment with the IADT, the current process, the average replacement cost for a pole and the current rate of pole replacement. In addition to the current rate of replacement, the target rate of replacement was also given. These data were added to financial information from the annual report for the appropriate company. Where specific data were not available, reasonable assessments of costs have been made following logical processes. As such, where the data is calculated, the accuracy of this is dependent upon whether or not the assumptions made by the researcher in these cases are reasonable. Calculated data includes the high cost pole assessment rate and the available cash pool for assessment and replacement activities. Other aspects considered was the potential to reduce SAIDI minutes, the potential impact on public and staff safety, and other approaches which had already been explored by the distributors. For the following analysis, a distributor with a particular need in the area of wooden pole assessment has been chosen, with the data for it laid out in Table 5.1. This distributor has the additional requirement of inspecting every pole on a 5 yearly basis.

These data were entered into a spreadsheet (Figure 5.6) where calculations for replacement costs, percentage of operating expenditure (OPEX), potential savings from assessment and additional pole replacement capacity due to potential savings per year were made. The total cost per year for pole assessment activities was assumed to be constant with the rate of pole assessment being the varying factor, and assuming a fixed amount of funding for these activities. This resulted in an average rate of pole assessment being available within the data. The calculations embedded within the spreadsheet can be found in Appendix D. 
Table 5.1.

Provided Data around Wooden Pole Replacement and Assessment.

\begin{tabular}{|l|l|}
\hline Poles needing testing & 40,000 \\
\hline Current replacement error rate & $40 \%$ \\
\hline Replacement cost per pole & $\$ 4,500$ \\
\hline Current replacement rate, poles/year & 1,300 \\
\hline Target replacement rate, poles/year & 3,000 \\
\hline Current OPEX & $\$ 29,268,000$ \\
\hline Pole assessment cost low & $\$ 50$ \\
\hline Pole assessment cost high & $\$ 100$ \\
\hline Pole assessment rate @ low cost, poles/day & 30 \\
\hline Days available per year for assessments & 249 \\
\hline
\end{tabular}

To determine the magnitude of potential savings, the initial calculation made was for the cost of pole replacement using the current methodology, and what percentage of the current operating expenditure this represented. These values were found to be $\$ 5.85$ million and $20 \%$ respectively, indicating that this operation is of high significance within this business and hence is a good candidate to seek improvements in efficiency. The current replacement error rate of $40 \%$, that is where poles are being replaced that still have significant service life remaining, indicates a potential saving with accurate remaining strength assessment of $\$ 2.34$ million per year. This potential saving could represent 437 additional poles per year which could be replaced when factoring in the cost of assessment at $\$ 373,500$ per year, leading to a subsequent improvement to public safety and to a reduction of SAIDI minutes.

The EDB of this example has a requirement to assess its poles every five years so the impact of this on the above additional poles needs to be considered. At the current pole assessment capacity quoted for the Pole Tester embedded within the MVP, the time to assess all 40,000

of the wooden poles would be 7.1 years. This length of time exceeds the 5 yearly limit per pole imposed by this EDB's own standard, and as such an increase in assessment capacity of 143\% would be required to meet this target. As the amount of money available for this total 


\begin{tabular}{|c|c|c|c|c|c|c|}
\hline No. Wooden Poles on Network & 40,000 & & Pole Replacement Cost & $\$ 4,500$ & Current OPEX & $\$ 29,268,000$ \\
\hline Current replacement error rate & $40 \%$ & & Assessment Cost Low & $\$ 50$ & Calculated OPEX at Target level & $\$ 36,918,000$ \\
\hline \multirow[t]{2}{*}{ Days available for assessment pa } & 249 & & Assessment Cost High & $\$ 100$ & & \\
\hline & No. Poles Replaced (pa) & Cost of Replacements & $\%$ OPEX & $\begin{array}{l}\text { Potential Savings from Accurate } \\
\text { Assessment }\end{array}$ & $\begin{array}{l}\text { Extra pole replacement from } \\
\text { available funds }\end{array}$ & \\
\hline Current & 1,300 & $\$ 5,850,000$ & $20.0 \%$ & $\$ 2,340,000$ & 437 & 401 \\
\hline Target & 3,000 & $\$ 13,500,000$ & $36.6 \%$ & $\$ 5,400,000$ & 1,117 & 1,081 \\
\hline \multirow[t]{3}{*}{ Pole assessment per day } & 30 & & & & & \\
\hline & 15 & & & & & \\
\hline & Pole assessments pa & Cost pa & & & Increased assessment rate cost & \\
\hline Easy Access (e.g. roadside) & 7,470 & $\$ 373,500$ & & & $\$ 533,333.33$ & \\
\hline \multirow[t]{3}{*}{ Difficult (e.g. over hilly farmland) } & 3,735 & $\$ 373,500$ & & $\begin{array}{l}\text { Increase in testing capacity } \\
\text { required }\end{array}$ & & \\
\hline & & Time to assess (years) & 7.1 & $143 \%$ & & \\
\hline & & & poles pa & 1 st 7 years & Thereafter extra pa & $\begin{array}{l}\text { including } 5 \text { yearly } \\
\text { assessment cycle }\end{array}$ \\
\hline Time to replace all poles current rate & 30.8 & with assessment pa & 1,737 & 12,402 & 520 & 1,701 \\
\hline \multirow[t]{2}{*}{ target rate } & 13.3 & & 4,117 & 29,394 & 1,200 & 4,081 \\
\hline & & with pole test halt & & after 7 years & after 7 years & \\
\hline Time to replace faulty poles current & 13.8 & 13.4 & 1,820 & 11,598 & 6.4 & \\
\hline target & 5.8 & & 4,200 & $-5,394$ & -1.3 & \\
\hline \multicolumn{7}{|l|}{ Including 5 yearly assessment cycle } \\
\hline Time to replace faulty poles current & 14.1 & & & & & \\
\hline target & 5.9 & & & & & \\
\hline
\end{tabular}

\footnotetext{
Figure 5.6. Value of wooden pole assessments
} 
operation is assumed to be fixed in this analysis, this increase to $\$ 533,333$ per year for assessment results in a decrease in additional poles possible to 401, giving a total possible under this regime of 1,701 per year. This reduction leads to a total 14.1 years to replace all poles currently suspected of having insufficient strength for continuing service at the current replacement rate. Although this is a considerable improvement over 30.8 years, it is still a long time to be exposed to the inherent safety risks associated with these aging poles.

It has been stated during the interviews that the target rate of pole replacement is 3,000 poles per year (A6, interviews, 2016). As such this figure forms the basis for the next analysis and it has been assumed that the increase in OPEX associated with this would be proportional. Using the present replacement methodology, the cost per year for the target case would be $\$ 13.5$ million, representing $36.6 \%$ of the proportionally adjusted OPEX, and a requirement of 13.3 years to replace all poles. In this case, the potential savings using the error rate of $40 \%$ would be $\$ 5.4$ million leading to an additional number of poles replaced per year of 1,081, again factoring for the 5 yearly inspection cycle. This saving leads to a total of 4,081 poles per year being replaced, resulting in total wooden pole network condition knowledge integrity being achieved after 5.9 years. This is substantially better than the 30.8 years to achieve this goal with the current methodology and rate, and as such is a strong indication of value for the MVP. Table 5.2 summarises this data.

Table 5.2.

Key Results from Analysis.

\begin{tabular}{|l|c|c|c|c|}
\cline { 2 - 5 } \multicolumn{1}{c|}{} & $\begin{array}{c}\text { Current rate of } \\
\text { replacement }\end{array}$ & $\begin{array}{c}\text { Total achievable } \\
\text { at current rate } \\
\text { using IADT }\end{array}$ & $\begin{array}{c}\text { Target Rate of } \\
\text { pole } \\
\text { replacement }\end{array}$ & $\begin{array}{c}\text { Total achievable } \\
\text { at target rate } \\
\text { using IADT }\end{array}$ \\
\hline $\begin{array}{l}\text { Poles } \\
\text { replaced per } \\
\text { year }\end{array}$ & 1,300 & 1,701 & 3,000 & 4,081 \\
\hline $\begin{array}{l}\text { Years to } \\
\text { complete }\end{array}$ & 30.8 & 14.1 & 13.3 & 5.9 \\
\hline
\end{tabular}

It is clear from this analysis that in both cases a significant improvement to public safety can be achieved through accurate pole condition assessment. In the first case, total data integrity is achieved after 14.1 years, which is longer than the 13.3 years that the second case would require with present methods. An argument could be built here that investment in more pole 
replacement may be acceptable to the customer. This approach would however leave the customer in a similar situation to where they are today of limited pole condition knowledge, albeit with no poles over 13.3 years old. This method is undesirable as it would not use the available money in the best manner possible, with possible neglect to other areas of the business. When looking at the potential gains achievable with accurate assessment in the second case, with total condition knowledge integrity being achievable in just 5.9 years, these gains would give the EDB a strong position for marketing themselves to their customers. The inherent improvement in public safety associated with accurate condition knowledge through the removal of truly defective poles would be a strong selling point for this EDB. The associated reduction in SAIDI minutes from the improved network integrity may also aid this EDB in attracting businesses from other regions onto its network when looking to build new factories for example.

\subsubsection{Timeline for all activities}

The value of using the proposed tool for both improved public safety and reduced SAIDI minutes is likely to be considered significant by the EDBs based upon the research conducted in this study. Due to this combined value, coupled with the pressing need within a number of EDBs around New Zealand for pole assessments and replacements, it is recommended to enter into negotiations to implement the IADT with a trial EDB as soon as possible.

Ideally, the sample of 100 poles that are due for replacement should be identified by the first quarter of 2017. It is recognised that at the time of writing, New Zealand is approaching summer and as such certain locations have significant holiday traffic, and subsequent additional electrical load. This situation should be considered when selecting the test sample as the impact on the public is recommended to be minimised.

At a replacement rate of approximately 5 poles per day, the test sample could theoretically be gathered in one month. Therefore, using a contingency of two months, verification of the MVP should be possible by the end of the first quarter of 2017. This timing would indicate that the verified MVP could be available for deployment by the second quarter of 2017 at the trial EDB. In the unlikely event that the tool verification fails, the tool may need to be revised. It should be noted here that this verification process is to reassure potential customers of the accuracy of the tool, which has already been proven to deliver in smaller tests thus far. 
By the end of the second quarter of 2017, a good idea of the rate of progress through pole assessments should be able to be determined. As such, this figure could be used to reassess the forecasts of this study if necessary. At this stage the tool should be ready for marketing to the wider electrical distribution community. It would be worth preparing a presentation for the EEA Conference in 2017, using the results from the verification process to sell the tool to the community. The Asset Management Forum within the EEA would also be a good opportunity to market the tool if verified. Both of these events occur mid-year and as such having solid results from the initial deployment would be a valuable marketing tool. 


\section{Chapter 6: Conclusions}

The research in this report has been able to verify an immediate need within the electrical distribution industry for a smarter means of infrastructure asset assessment. It has been shown that this need is especially true in New Zealand where these businesses operate as regulated monopolies, with budget controls set by the government regulator, the Commerce Commission. The key areas of concern from the analysis were for wooden poles and for overhead lines, with a particular focus on sub-transmission elements. The immediate financial need within one particular business was in the area of accurate pole assessment and as such this feature is proposed as the Minimum Viable Product (MVP) for the initial incarnation of the Infrastructure Asset Diagnostic Tool (IADT) for the market.

To achieve the desired accuracy and hence marketability from the MVP, it has been determined that it should include all three currently available components. These are the Pole Tester and Pole Designer applications from Reliable Lines, integrated with the LiDAR assessment capability from Point Geodata. Although the Pole Tester application appeared as an initial possible MVP for this study, it would be difficult to sell in the face of the current competition with no marketable point of difference. By including the two other applications in the IADT, the product capability becomes market leading, and importantly becomes capable of delivering the accuracy required to achieve the cost reductions necessary within the marketplace.

With all three applications integrated together, the residual pole strength replacement threshold can be set as low as $25 \%$ of initial strength. The added confidence brought in by including the pole load data derived through use of the LiDAR scanner and Pole Designer enables the lower threshold in contrast to the $40 \%$ threshold that would normally be used for the Pole Tester alone. At a $25 \%$ threshold it was seen that a cost - benefit ratio of 1:5 could be achieved, the target figure indicated from the interviews.

For the EDB used in the example analysis, it was found that potential savings of up to $\$ 5.4$ million per year could be achieved with the MVP form of the IADT when meeting their target pole replacement rate. This saving could then be translated into additional pole replacements which would allow this distributor to reduce the time required to replace its wooden pole fleet from 31 years to just 6 years. This reduction in replacement time would enable a subsequent reduction in SAIDI minutes and result in a substantial improvement to public and staff safety from the reduction in unplanned catastrophic pole failures. Benefits of this could include attracting businesses from other regions into this EDB's region when establishing new 
operations, and an improved public image which could be leveraged for marketing of the EDB. In this price sensitive industry, looking good to the consumers and avoiding conflict with the Commerce Commission can help alleviate pressure on the business, allowing the business to focus on more important issues. It is worth noting that if an EDB delivers fewer SAIDI minutes than their specified requirement, the Commerce Commission will pay a credit of up to $\$ 250,000$.

When using the tool, an EDB would build a very good condition knowledge base for its difficult to assess assets such as wooden poles and conductors. Having very good knowledge of the condition of these assets would enable better scheduling of the maintenance and replacement of these. In the example for the MVP it was seen that a significant gain in this knowledge base for wooden poles could be achieved, with the additional benefit of accelerating the replacement program.

It is recommended that in this early phase, the control over the use of the IADT be retained by Electropar and their carefully selected subcontractors, delivering the results to the EDBs as a professional service. It is desirable however for the initial EDB selected for deployment of the tool to agree to supply a series of poles due for replacement which could then be destructively tested. After this destructive testing is completed, it is expected that accuracy of the tool will be verified, and the potential benefits will become clear to the EDB.

The IADT should be developed into a stable version which could be used in the marketplace. The MVP identified above would be the best option for an initial product due to its superior accuracy over the competitor products, and would enable the IADT to establish itself firmly within the New Zealand Industry. Once established, the ability to assess conductor condition would be a valuable addition to the IADT and as such this is recommended as the next natural development step for the product. This combination of features would then allow the tool to deliver analysis of all of the assets identified during this study as being of most concern to the EDBs.

In the future additional features could be added for the assessment of assets identified as being of lesser importance or concern in this study. It is worth noting here that some of the analysis capability required for some of these assets may become incidentally available due to the nature of the installed equipment, for example electromagnetic fields around substations. This capability should be accurately assessed prior to further development to ensure value is being added by any proposed improvements. 
In regard to the potential to export this tool, the researcher notes that where a distribution network displays similar issues using similar base components, the MVP could also offer a viable analysis solution. If componentry was substantially different however, or if the issues being experienced were quite dissimilar, the cost reductions offered by the MVP may be insufficient for effective deployment resulting in poor uptake of the product. It is therefore suggested that prior to entering a new market outside of New Zealand, an investigation of the specific issues present within that market should be conducted. This proposed investigation could be done in a similar manner to that conducted in this study. It is worth noting that much of the background information used in this study has come from North America and as such it should be clear that potentially similar issues may exist in those markets, both in the United States and in Canada. Anywhere that distributors use wooden poles with overhead conductors could also offer potential markets for the IADT in this early form.

A possible further area for investigation is the integrity of concrete poles. It has been noted from some late feedback that the typical indicator used to identify structurally compromised poles, spalling, does not necessarily indicate imminent failure. Instead, degradation by corrosion of the reinforcing steel, or pretensioning cables in prestressed poles, through chloride ingress has been identified as a concern. Technology to assess the level of this degradation would be a potentially valuable addition to the IADT as the bulk of poles in New Zealand are now concrete. Incorporation of such technology into the IADT presents an additional avenue of further product development. 


\section{Appendix A - Example Interview Questionnaire}

1 What do you understand Asset Management to mean in who is responsible for it in your organisation?

2 Who in your organisation is responsible for collecting Asset Condition information/data from the field?

3 Who collects that data from the field?

$4 \quad$ Who owns that data? Asset owner or contractor?

$5 \quad$ Where does the data reside and how does it get there?

6 Describe the data you currently gather?

7 Is there a template for capturing the data - paper or system driven?

8 Do you feel that you are sufficiently well informed as to the condition of your infrastructure assets?

9 How accurate would you say your data is for the following asset classes: Rate per asset accuracy as: 1) not recorded, 2) recorded but unsure of accuracy 3) recorded \& accurate (as best known), 4) highly confident in terms of all data relating to the asset, 5) data resides in the appropriate repository and is $100 \%$ accurate for all attributes

Conductor: age, condition, sag, remaining life

Cables:

Transformers: location, kVA/MVA, remaining life, last test, number of closes

Insulators:

Switch Gear:

Line Hardware \& Fittings:

Poles:

Crossarms:

Substations: 
10 When a site visit is performed to a specific asset e.g. pole what data is collected and is any other data collected for other associated assets at site.

11 What is the frequency of data collection?

12 Who makes the decisions on accuracy of data?

13 How much of your current work load is being generated by failed components rather than scheduled maintenance and do you feel this is an issue for the company?

14 Is your business is looking to increase its analytical capability and If so, how do you think this should be performed? Do you think this should be done in house, subcontracted to a third party or a combination of both?

15 Are you currently doing any kind of forecasting in regard to asset failure, and would you be interested in a tool that could forecast potential failures more accurately for specific parts of your network?

16 Which parts of the network do you consider the most critical in this regard? IE - where would you focus?

17 Are currently experiencing increasing network interruptions due to parts of your network approaching the end of its useful life. If you were able to be provided information more accurately identifying the most critical of the assets to your business, what monetary/time value would you place on this?

18 Have you identified your inherited assets (from mergers/prior organisations). How far through this process are you and are you comfortable where you are currently?

19 Do you think that you are spending money on avoidable maintenance costs, where for example the incorrect personal (e.g. not the right skill set) or equipment (tools) have been sent to site due to incorrect asset information or poor planning? What might that value be? [ $\$ \$ \$ \$$ or hours]

20 Is this cost a major concern to the business or is it at an acceptable level, in other words, are other issues more important?

21 When considering an acceptable level, does this include the cost of insurance against such failures, is there any insurance cost advantage that could be gained if the risk of asset failure could be more accurately predicted? 
22 What might motivate you to seek to reduce this cost or even eliminate it altogether?

The tool I am investigating is primarily concerned with optimising the replacement and maintenance of infrastructure assets. To achieve this an accurate and comprehensive asset condition database will be required. As such...........

23 What 'step change' benefit do you think such a tool could bring to your business?

24 What level of cost reduction do you feel would need to be achieved for this to be a viable product?

25 What is your priority at the moment in regard to achieving acceptable asset reliability?

26 A requirement of the asset diagnostic tool will be to have very accurate asset condition data. What hurdles can you see to the successful implementation of such a tool?

27 If a tool could predict the failure of a particular asset accurately $95 \%$ of the time, would you utilise it and how valuable would it be?

28 Would you still consider it valuable if it was only accurate $75 \%$ of the time?

29 In an ideal world what would expect to see in a perfect tool for AM?

30 Thinking about today, what areas or data could be improved to aid your role in AM? What are the weaknesses in what you have now?

31 Do you think that the current maintenance process takes account of your customer's business needs? E.g. that your program does not conflict with their busy operating times. Is your regime customer focussed?

32 Is there anything you would like to add that you feel would be of benefit to my research?

33 Would you be available to answer further questions at a later date if they arise? 


\section{Appendix B: Interviewee Information}

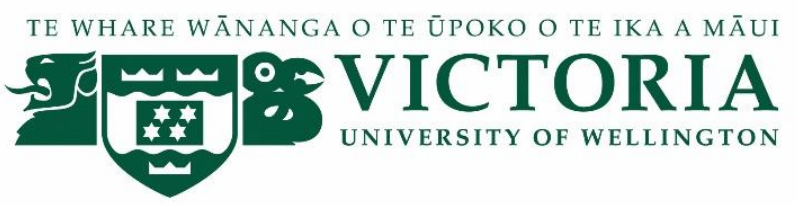

\section{Infrastructure Asset Diagnostic Tool}

\section{CONSENT TO INTERVIEW}

This consent form will be held for 3 years.

Researcher: $\quad$ Richard Bryson, Faculty of Science, Victoria University of Wellington

- I have read the Information Sheet and the project has been explained to me. My questions have been answered to my satisfaction. I understand that I can ask further questions at any time.

- I agree to take part in an audio recorded interview.

I understand that:

- I may withdraw from this study up to four weeks after the interview, and any information that I have provided will be returned to me or destroyed.

- The information I have provided will be destroyed 3 years after the research is finished.

- $\quad$ Any information I provide will be kept confidential to the researcher and the supervisor. I understand that the results will be used for a Masters report and a summary of the results may be used in academic reports and/or presented at conferences.

- My name will not be used in reports, nor will any information that would identify me. 
- I consent to information or opinions which I have given being attributed to me in any reports on this research:

Yes $\square \quad$ No

- I would like a copy of the transcript of my interview:

Yes $\square \quad$ No

- I would like a summary of my interview:

Yes $\square \quad$ No $\square$

- $\quad$ I would like to receive a copy of the final report and have added my email Yes $\square$ No address below.

Signature of participant:

Name of participant:

Date:

Contact details: 


\section{Master of Innovation and Commercialisation}

\section{INFORMATION SHEET FOR PARTICIPANTS}

Thank you for your interest in this project. Please read this information before deciding whether or not to take part. If you decide to participate, thank you. If you decide not to take part, thank you for considering my request.

\section{Who am I?}

My name is Richard Bryson and I am a Masters student in the Master of Innovation and Commercialisation at Victoria University of Wellington. This research is working towards developing a major report on my innovation and commercialisation project, being conducted in conjunction with PLP Electropar.

\section{What is the aim of the project?}

This project relates to assessing the development and commercialisation of an Infrastructure Asset Diagnostic Tool. This programme has been approved by the Victoria University of Wellington Human Ethics Committee, application 22989.

\section{How can you help?}

If you agree to take part I will interview you in a suitable place, such as at your office. I will ask you questions about infrastructure asset management within your organisation. The questions may concern technical issues of how information about asset management is collected and acted upon, or the value to your organisation of asset management practices and information related to asset management. The interview should take no more than 50 minutes. I may record the interview and write it up later. You can stop the interview at any time, without 
giving a reason. You can withdraw from the study up to four weeks after the interview. If you withdraw, the information you provided will be destroyed or returned to you.

\section{What will happen to the information you give?}

This research is confidential. I will not name you in any reports, and I will not include any information that would identify you. Only my supervisors and I will read the notes or any transcript of the interview. Any interview transcripts, summaries and any recordings will be kept securely and destroyed 3 years after the research ends.

\section{What will the project produce?}

The information from my research will be used in my Masters report, a copy of which will be provided to PLP Electropar. I may also use the results of my research for conference presentations, and academic reports.

\section{If you accept this invitation, what are your rights as a research participant?}

You do not have to accept this invitation if you don't want to. If you do decide to participate, you have the right to:

- $\quad$ choose not to answer any question;

- $\quad$ ask for the recorder to be turned off at any time during the interview;

- $\quad$ withdraw from the study up until four weeks after your interview;

- $\quad$ ask any questions about the study at any time;

- $\quad$ receive a copy of your interview recording (if it is recorded);

- $\quad$ read over and comment on a written summary of your interview;

- $\quad$ agree on another name for me to use rather than your real name;

- be able to read any reports of this research by emailing the researcher to request a copy. 


\section{If you have any questions or problems, who can you contact?}

If you have any questions, either now or in the future, please feel free to contact either:

\section{Student:}

Name: Richard Bryson

University

address:brysonrich@myvuw.ac.nz

\section{Supervisor:}

Name: Dr Nick Long

email Role: A/Prof

School: Robinson Research Institute

Phone: 044630079

Nick.Long@vuw.ac.nz

\section{Human Ethics Committee information}

If you have any concerns about the ethical conduct of the research you may contact the Victoria University HEC Convener: Associate Professor Susan Corbett. Email susan.corbett@vuw.ac.nz or telephone +64-4-463 5480. 


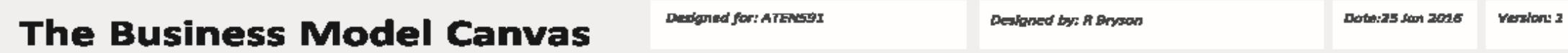

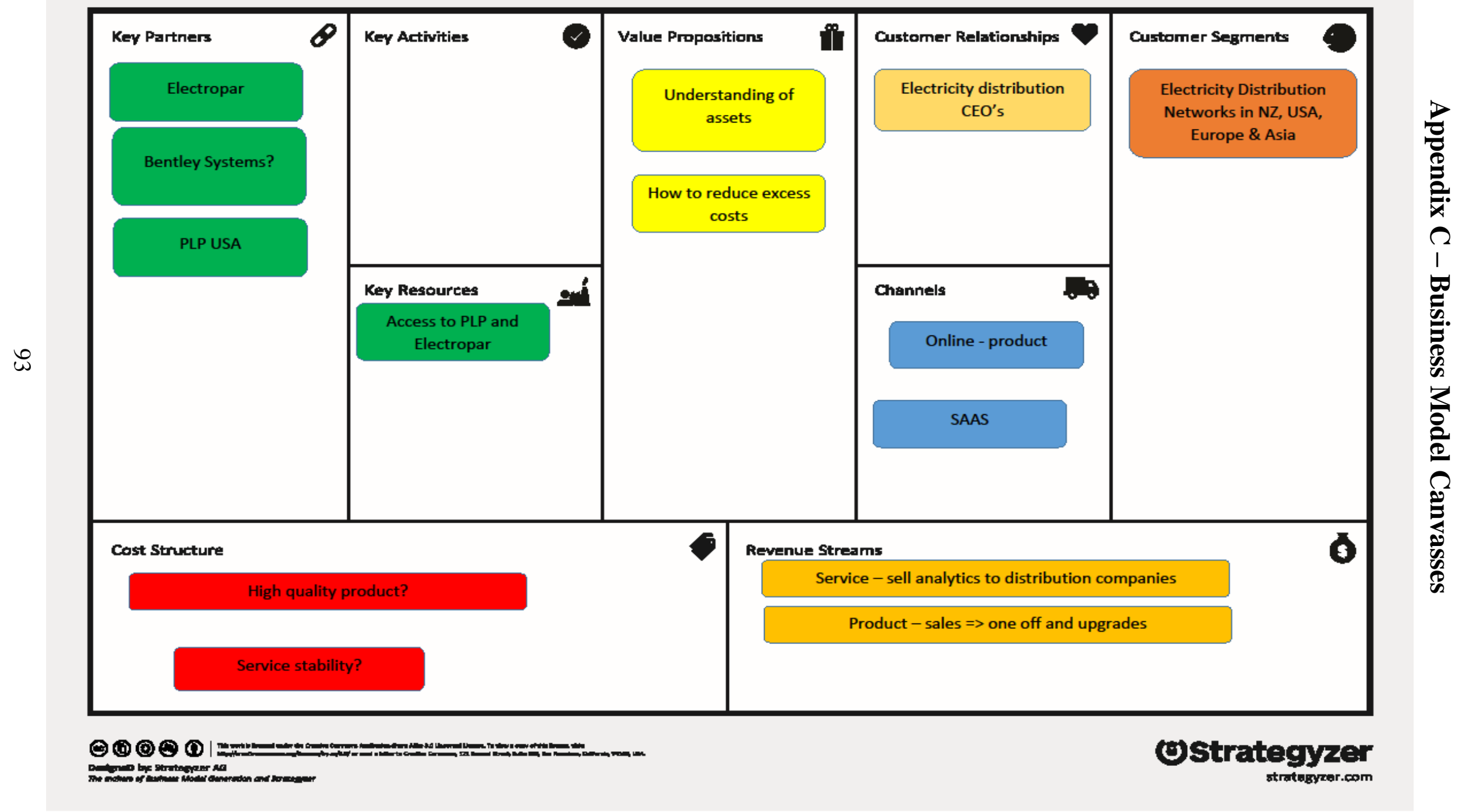

Figure C.1. BMC version 1, original ideas. 
The Business Model Canvas

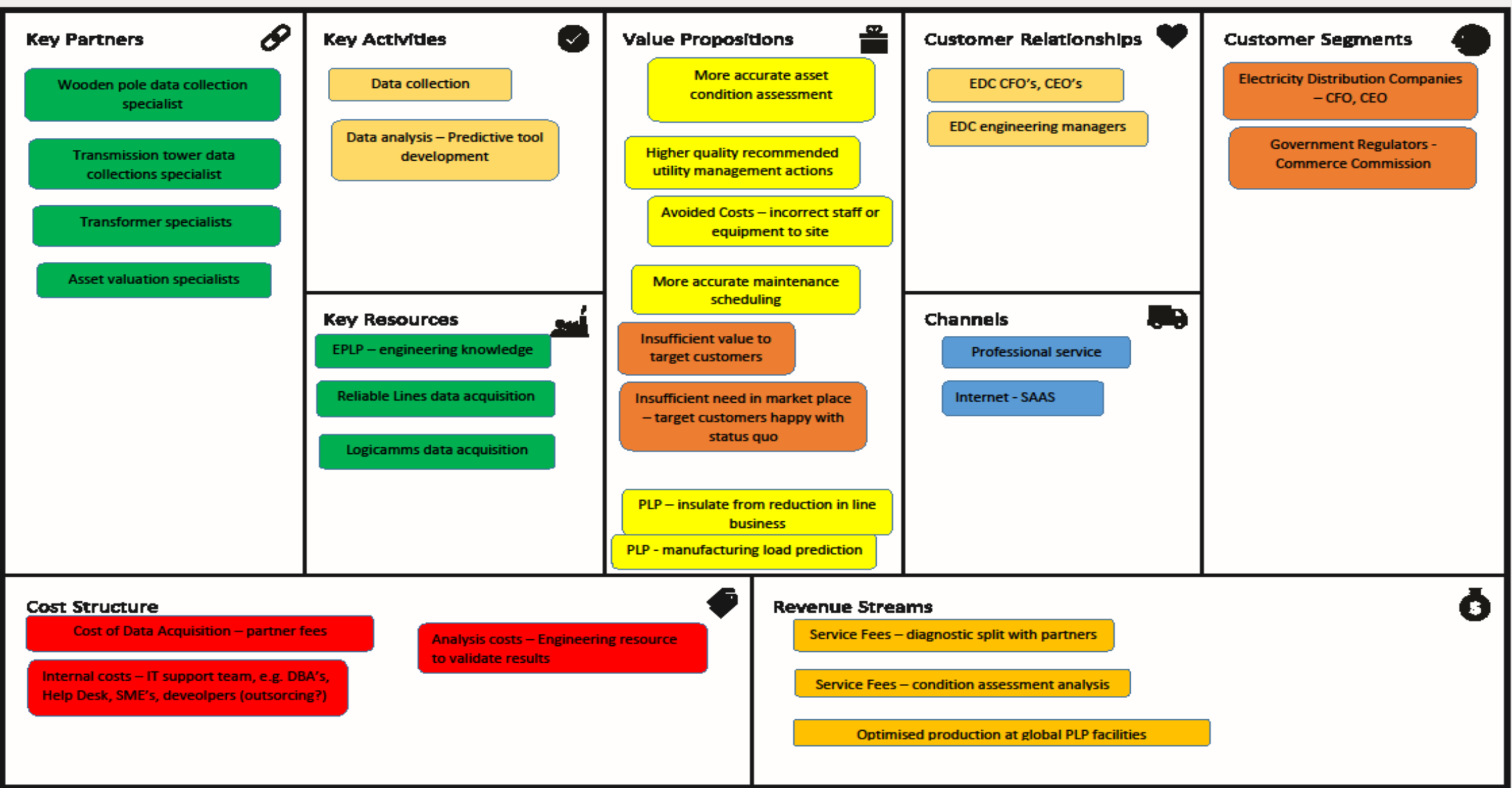

(우이 $\rightarrow \infty$ 
The Business Model Canvas

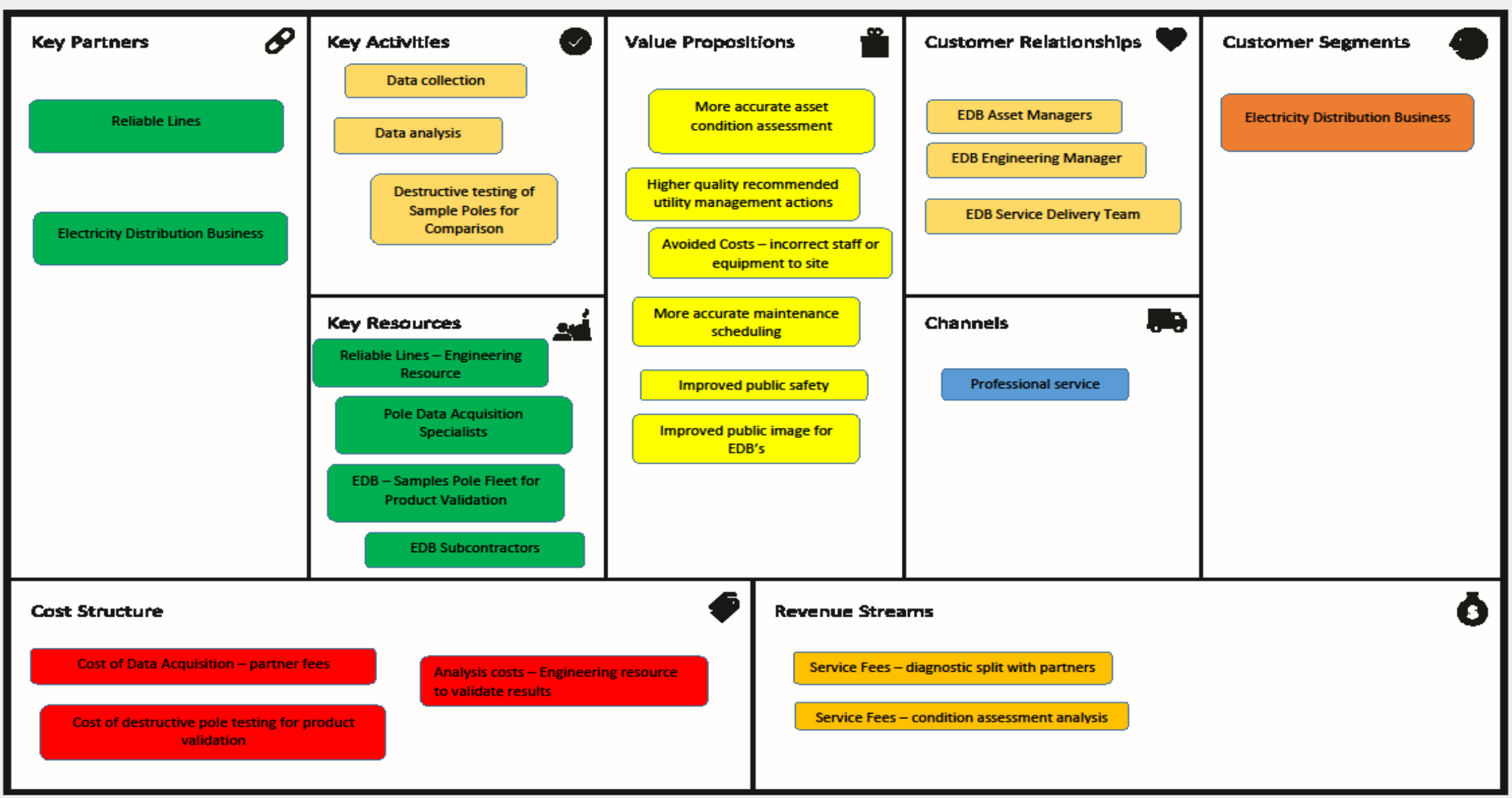




\section{Appendix D: Calculations}

The following formulae and data were used in the spreadsheet of figure D.1 to make the calculations of this study. The pool of funds available has been assumed to be constant for each case investigated, with the current rate and target rate of pole replacement being proportional.

Table D.1

Provided Data around Pole Replacement and Assessment

\begin{tabular}{|l|l|}
\hline Poles needing testing & 40,000 \\
\hline Current replacement error rate & $40 \%$ \\
\hline Replacement cost each & $\$ 4,500$ \\
\hline Current replacement rate per year & 1,300 \\
\hline Target replacement rate per year & 3,000 \\
\hline Current OPEX & $\$ 29,268,000$ \\
\hline Pole assessment cost low & $\$ 50$ \\
\hline Pole assessment cost high & $\$ 100$ \\
\hline Pole assessment rate low cost & 30 poles/day \\
\hline Days available per year for assessments & 249 \\
\hline
\end{tabular}

\section{Formulae:}

\section{Current situation:}

Current pole replacement cost:

poles replaced per year $\mathrm{x}$ cost per pole $=$ current rate replacement cost

$1,300 \times \$ 4,500=\$ 5,850,000$

Percentage of OpEx:

current rate replacement cost $/ \mathrm{OpEx}=$ Current OpEx percentage

$\$ 5,850,000 / \$ 29,268,000=20 \%$

To calculate potential saving with $40 \%$ pole replacement error rate:

Rate replacement cost $\mathrm{x}$ error rate $=$ possible saving available

$\$ 5,850,000 \times 40 \%=\$ 2,340,000$ 
Saving as additional pole replacement capacity:

(Saving amount - cost of pole assessment) / cost of replacement $=$ additional pole capacity

$(\$ 2,340,000-\$ 373,500) / \$ 4,500=437$

Time to replace wooden poles:

Daily rate:

poles replaced / normal work days available $=$ poles replaced daily

$1,300 / 249=5.2$

Total pole fleet:

number of poles $/$ poles replaced $=$ time to replace

40,000 poles / 1,737 annual rate $=30.8$ years

Similar calculations are performed for the target replacement rate of 3,000 per year. For this a proportional OpEx is assumed to be available:

current OpEx $+($ target rate $\mathrm{x}$ cost of replacement $)-($ current rate $\mathrm{x}$ cost of replacement $)=$ target OpEx

$\$ 29,268,000+(3,000 * \$ 4,500)-(1,300 \times \$ 4,500)=\$ 36,918,000$

Inserting the target values in place of the current values above yielded the following:

Target cost per year $=\$ 13,500,000$

Target OpEx Percentage $=36.6 \%$

Possible saving per year $=\$ 5,400,000$

additional poles capacity $=1,117$

poles replaced daily $=12$

years to replace fleet $=13.3$

\section{Using the IADT for accurate pole condition assessment:}

Poles requiring replacement:

total number $\mathrm{x}$ error rate $=$ number of poles to replace 
$40,000 \times(1-40 \%)=24,000$ poles

annual rate + additional capacity $=$ IADT pole replacement rate

$1,300+437=1,737$

poles requiring replacement $/$ replacement rate $=$ years to replace

$24,000 / 1,737=13.8$ years

Similarly, for the target rate we get 4,117 poles $\& 5.8$ years to replace all defective poles.

The company of the example requires 5 year inspections for the poles:

Pole inspection rate:

cost per pole $\mathrm{x}$ poles per year $=$ current assessment cost per year

poles per day $*$ normal working days per year $=$ poles per years

$30 \times 249=7,470$

$\$ 50 \times 7,470=\$ 373,500$

This value remains constant as the variation in assessment cost is assumed to be inversely proportional to the rate of assessment.

average inspection rate $=($ high rate + low rate $) / 2$

number of poles in fleet $/$ average inspection rate $=$ time to complete inspections

$40,000 /((7,470+3,735) / 2)=7.1$ years

Therefore, the required inspection capacity increase to meet company requirement is:

current time to complete inspections / company requirement = percentage adjustment

$7.1 / 5=143 \%$

This implies the inspection cost per year must increase to $143 \%$ of the current level which reduces the funds available for replacements:

current assessment cost $\mathrm{x}$ percentage adjustment $=$ new assessment cost per year

$\$ 373,500 \times 143 \%=\$ 533,333$ 
Recalculating for the new saving level, and hence the number of poles per year which can be replaced we get:

(original saving - new assessment cost) $/$ pole replacement cost $=$ additional poles available $\$ 2,340,000-\$ 533,333) / \$ 4,500=401$

This leads to a total of 1701 poles per year replaced requiring 14.1 years to replace all defective poles. Similarly, the new values at the target rate are 4,081 poles per year and 5.9 years respectively. 


\section{References}

Adams, R. (2010), If you build it will they come: Three steps to test and validate any market opportunity. John Wiley \& Sons.

Blank, S (2007), The Four Steps to the Epiphany: Successful strategies for products that win, Steven G. Blank.

Blank S. \& Dorf, B. (2012), The Startup Owner's Manual: The step-by-step guide for building a great company. K\&S Ranch, Inc.

Brown, R.E. (2004), Reliability and Distribution Asset Management, Electric Energy T\&D Magazine Vol 8, No.6, retrieved from http://www.electricenergyonline.com/show_article.php?mag=\&article=179, January 27, 2016.

Christensen, C.M. (1997), The Innovator's Dilemma: When new technologies cause great firms to fail. Harvard Business School Press.

Di Matteo, S. (2015), Big Data, Predictive Analytics and Asset Health Indexing, Industry Update Manufacturing Magazine and Directory, Issue 85.

Electricity Authority, (2016), What does the Electricity Authority do? retrieved from http://www.ea.govt.nz/consumers/what-does-the-electricity-authority-do/, October 6, 2016.

Electropar PLP (2016), Electropar - Preformed Line Products, retrieved from http://www.electropar.co.nz/overview/, October 20, 2016.

Energy NZ (2013), A Huge Scheme and a Long Build, retrieved from http://energynzmag.co.nz/hydro/a-huge-scheme-and-a-long-build/, October 6, 2016.

Gross, P, Boulanger, A. Arias, M. Waltz, D. Long P. M. Lawson, C. Anderson, R. \& Koenig, M. Mastrocinque, M. Fairechio, F. Johnson, J. A. Lee, S. Doherty, F. Kressner, A., (2006), Predicting Electricity Distribution Feeder Failures Using Machine Learning Susceptibility Analysis, retrieved from http://static.googleusercontent.com/media/research.google.com/en//pubs/archive/12490.pdf, June 6, 2016.

IAM (n.d.), What is ISO 55000?| The IAM, retrieved from theiam.org, January 27, 2016. 
IEC, 2014, Strategic asset management of power networks, retrieved from http://www.iec.ch/whitepaper/pdf/iecWP-assetmanagement-LR-en.pdf, June 6, 2016.

IER, 2014, Electricity Distribution, retrieved from http://instituteforenergyresearch.org/electricity-distribution/, October 6, 2016

Letourneau, R. Jr. (2015), Failure: When \& Where? retrieved from http://tdworld.com/gridopt-smart-grid/failure-when-and-where, June 2, 2016.

Marlborough Lines, (2016), Asset Management Plan, retrieved from http://www.marlboroughlines.co.nz/Documents/20160323_AMP-2016-issue-I-v0-4.aspx MBIE, (2015), Chronology of New Zealand Electricity Reform, retrieved from http://www.mbie.govt.nz/info-services/sectors-industries/energy/electricitymarket/electricity-industry/chronology-of-new-zealand-electricity-reform/chronology-of-nzelectricity-reform.pdf, October 6, 2016.

MBIE, (2016), Electricity Distribution, retrieved from http://www.mbie.govt.nz/infoservices/sectors-industries/energy/electricity-market/electricity-industry/electricitydistribution, October 6, 2016.

Newton, C, (2002), Asset Management Software for Utilities, retrieved from http://tdworld.com/smart-grid/asset-management-software-utilities, October 6, 2016. Otal, R. \& Bakulev, A. (2014). Risk-based asset management optimization. T D Conference and Exposition, 2014 IEEE PES. Chicago, Il, USA. doi:10.1109/TDC.2014.686341

Otal, R. \& Hjartarson, T. (2010) Transmission \& Distribution World, Sustainment Actions Take a New Direction retrieved from http://tdworld.com/smart-grid/sustainment-actions-takenew-direction, 17 August, 2016.

Pattie K. \& Silk, J. (2016), The Art of Wooden Pole Testing, received from author June 30, 2016.

Point Geodata (2016a), Mobile 3D Laser Scanning, retrieved from http://pointgeodata.com, May 25, 2016.

Point Geodata (2016b), Services, retrieved from http://pointgeodata.com, May 25, 2016. Powerco, (2015), retrieved from http://www.powerco.co.nz/Publications/Disclosures/Electricity/, February 8, 2016. 
Powerco, (2016), Powerco Annual Report 2016, retrieved from http://www.powerco.co.nz/uploaded_files/Publications-and-Disclosures/New/Annual-andInterim-reports/2016-AR-web-version.pdf, 21 November 2016.

Powernet, (2014), A short history of electricity supply management in New Zealand, retrieved from http://www.powernet.co.nz/uploads/2014/01/history1.pdf, October 6, 2016. Ries, E, (2011), The Lean Startup: How today's entrepreneurs use continuous innovation to create radically successful businesses, Crown Business.

Strategyzer.com, (n.d.), template retrieved from

http://businessmodelgenertion.com/downloads/business_model_canvas_poster.pdf, February 8, 2016.

Te Ara, (2010), Hydro and the Environment, retrieved from http://www.teara.govt.nz/en/hydroelectricity/page-4, October 6, 2016.

Transpower, (2017a), Frequently Asked Questions, retrieved from https://www.transpower.co.nz/about-us/frequently-asked-questions, February 8, 2017. Transpower, (2017b), Power System Live Data, retrieved from https://www.transpower.co.nz/power-system-live-data, February 8, 2017. 